\title{
\%) OECD
}

\section{Climate Change Expert Group Paper No.2020(4)}

\section{Addressing the COVID-19 and climate crises:}

Potential economic recovery pathways and their implications for climate change mitigation, NDCs and broader socio-economic goals

Simon Buckle (OECD), Jane Ellis (OECD), Aimée Aguilar Jaber (OECD), Marcia Rocha (OECD), Brilé Anderson (OECD), and Petter Bjersér (External consultant) 


\title{
OECD/IEA CLIMATE CHANGE EXPERT GROUP PAPERS
}

This series is designed to make available to a wider readership selected papers on climate change issues that have been prepared for the OECD/IEA Climate Change Expert Group (CCXG). The CCXG (formerly called the Annex I Expert Group) is a group of government delegates from OECD and other industrialised countries. The aim of the group is to promote dialogue and enhance understanding on technical issues in the international climate change negotiations. CCXG papers are developed in consultation with experts from a wide range of developed and developing countries, including those participating in the regular Global Forum on the Environment organised by the CCXG. The full papers are generally available only in English.

The opinions expressed in these papers are the sole responsibility of the author(s) and do not necessarily reflect the views of the OECD, the IEA or their member countries, or the endorsement of any approach described herein.

Comments on the series are welcome, and should be sent to:

OECD Environment Directorate, 46 Quai Alphonse le Gallo, 92100 Boulogne-Billancourt, France, or by email to env.contact@oecd.org

OECD/IEA Climate Change Expert Group Papers are published on www.oecd.org/environment/cc/ccxg.htm

This document and any map included herein are without prejudice to the status of or sovereignty over any territory, to the delimitation of international frontiers and boundaries and to the name of any territory, city or area.

The statistical data for Israel are supplied by and under the responsibility of the relevant Israeli authorities. The use of such data by the OECD is without prejudice to the status of the Golan Heights, East Jerusalem and Israeli settlements in the West Bank under the terms of international law.

This document has been produced with the financial assistance of the European Union.

The views expressed herein can in no way be taken to reflect the official opinion of the European Union.

(c) Copyright OECD/IEA (2020)

You can copy, download or print OECD content for your own use, and you can include excerpts from OECD publications, databases and multimedia products in your own documents, presentations, blogs, websites and teaching materials, provided that suitable acknowledgement of OECD as source and copyright owner is given.

All requests for commercial use and translation rights should be submitted to rights@oecd.org Applications for permission to reproduce or translate all or part of this material should be addressed to:

\author{
Head of Publications Service \\ OECD, 2 rue André-Pascal, 75775 Paris Cedex 16, France \\ or
}

IEA, 31-35 rue de la Fédération, 75739 Paris Cedex 15, France 


\section{Acknowledgements}

The authors would like to thank a range of OECD, IEA and ITF colleagues for their comments on this paper, in particular Rodolfo Lacy, Anthony Cox, Laszlo Varro, Nathalie Girouard, Timothy Goodson, Kumi Kitamori, Blandine Barreau, Hélène Blake, Enrico Botta, Malithi Fernando, Chiara Falduto, Marine Gorner, Nicolina Lamhauge, Myriam Linster, Luca Lo Re, Luis Martínez, Mechthild Worsdorfer, Sara Moarif, Daniel Nachtigall, Joshua Paternina Blanco, Stephen Perkins, Andrew Prag, Cecilia Tam, Jacob Teter, Daniel Wetzel, Ekta Meena Bitra, Elizabeth Connelly. The authors would also like to thank delegates to the CCXG Global Forum of 15-16 September 2020 for their comments and suggestions, as well as delegates from the UK and Turkey for their written comments.

The Secretariat would like to thank Australia (Department of Foreign Affairs and Trade), the European Commission, Finland (Ministry of the Environment), Germany (Federal Ministry for the Environment, Nature Conservation and Nuclear Safety), Italy (Ministry for the Environment, Land and Sea), Japan (Ministry of the Environment), the Netherlands (Ministry of Economic Affairs and Climate Policy), New Zealand (Ministry for the Environment), Norway (Ministry of Climate and Environment), Sweden (Swedish Environmental Protection Agency), Switzerland (Federal Office for the Environment) and the United Kingdom (Department for Business, Energy \& Industrial Strategy) for their direct funding of the CCXG in 2020, and the OECD and IEA for their in-kind support.

\section{Questions and comments should be sent to:}

Simon Buckle (OECD)

Email: simon.buckle@oecd.org

Jane Ellis (OECD)

Email: jane.ellis@oecd.org

Aimée Aguilar Jaber (OECD)

Email : Aimee.aguilarjaber@oecd.org

OECD Environment Directorate

46 Quai Alphonse le Gallo

92100 Boulogne-Billancourt

France

All OECD and IEA information papers for the Climate Change Expert Group on the UNFCCC can be downloaded from: www.oecd.org/environment/cc/ccxg.htm 


\section{Abstract}

This paper provides decision-makers with a framework for prioritising different economic, social and environmental goals and analysing the options available to achieve them. To this end, it develops three stylised COVID-19 recovery pathways ("Rebound", "Decoupling" and "Wider well-being") that differ in the extent to which they encompass greenhouse gas (GHG) emission reductions and the integration of mitigation and wider well-being outcomes or, broadly equivalently, SDGs. A number of real-world examples of COVID-19 recovery measures in the surface transport and residential sectors were identified, and the paper maps these measures onto these three stylised pathways. The paper finds a wide divergence in the environmental and social impacts of COVID-19 recovery measures developed to date, with several countries putting in place measures that correspond to all three pathways. The nature and pace of economic recovery in different countries and in aggregate will have important implications for existing, updated and new Nationally Determined Contributions (NDCs) under the Paris Agreement, and the paper also highlights the possible impact of the COVID-19 recovery measures being put in place on NDCsincluding on the ambition of both current and future NDCs. The paper concludes that it will be important for governments to improve their understanding of the impact of their recovery measures across multiple policy dimensions (economic, social, environmental) as well as across different time periods (short and long-term) and spatial scales.

JEL Classification: A13, D62, D63, E61, H54, Q01, Q52, Q54

Keywords: Climate change, inequality, wider well-being, transport, residential, net-zero economy, beyond growth, sustainable recovery, SDGs, NDCs 


\section{Résumé}

Le cadre décrit dans le présent document permet aux décideurs d'analyser les options envisageables pour atteindre divers objectifs environnementaux, sociaux et économiques par ordre de priorité, et d'analyser les options envisageables pour les atteindre. À cette fin, il prévoit trois trajectoires stylisées de redressement post-COVID-19 ( rebond ", " découplage » et " bien-être collectif »), qui se distinguent par le degré auquel sont prises en compte la réduction des émissions de gaz à effet de serre (GES) et l'intégration de l'atténuation et des aspects plus généraux du bien-être, qui recoupent globalement les ODD. Un certain nombre de mesures de relance adoptées ou planifiées dans les transports de surface et le secteur résidentiel ont été prises en exemple et mises en regard des trois trajectoires stylisées. II en ressort que les incidences environnementales et sociales des mesures de relance élaborées à ce jour face au COVID-19 divergent nettement, plusieurs pays ayant mis en place des dispositions qui correspondant aux trois trajectoires à la fois. La nature et le rythme de la reprise économique dans les différents pays et dans l'ensemble auront des répercussions notables sur les contributions déterminées au niveau national (CDN) existantes, actualisées et nouvelles, dans le cadre de l'Accord de Paris, et l'impact possible des mesures de relance actuellement appliquées face au COVID-19 sur les CDN est mis en évidence, y compris l'impact sur l'ambition des CDN actuelles et futures. II en découle, en conclusion, qu'il importe que les pouvoirs publics connaissent mieux les incidences de leurs mesures de relance dans les différentes dimensions de leur action (économique, sociale et environnementale), ainsi qu'à différents moments (court et long termes) et à différentes échelles spatiales.

Classification JEL : A13, D62, D63, E61, H54, Q01, Q52, Q54

Mots-clés : Changement climatique, inégalité, bien-être collectif, transport, résidentiel, une économie neutre en carbone, au-delà de la croissance, reprise durable, ODD, CDN 


\section{Table of contents}

Acknowledgements 3

Abstract $\quad 4$

Résumé $\quad 5$

List of Acronyms $\quad 8$

Executive Summary $\quad 10$

1 Introduction $\quad 15$

2 Three stylised COVID recovery pathways 17

Three stylised recovery pathways out of the COVID-19 crisis: Rebound, Decoupling and Wider Well-Being

Trade-offs between GDP growth and wider well-being outcomes across the three recovery pathways

3 Overview of recovery measures in surface transport according to the three pathways

Using the recovery to accelerate the decarbonisation of surface transport $\quad 27$

Mapping of selected recovery measures in surface transport $\quad 29$

4 Overview of recovery measures in the residential sector according to the three pathways

Using the recovery to accelerate climate action in the residential sector $\quad 45$

Mapping of selected recovery measures in the residential sector 46

5 Links between COVID-19 recovery and NDCs 54

COVID-19 containment and recovery measures can impact the ambition of current NDCs 54

The pandemic may affect resources available to governments for the purposes of implementing and achieving their NDCs 56

COVID-19 responses can help or hinder the domestic policy alignment and coherence needed in order to efficiently achieve NDC targets 
6 Conclusions 65

$\begin{array}{ll}\text { References } & 70\end{array}$

Tables

Table 1. Scenarios mirroring the three different pathways and energy and carbon reduction potential 40 Table 2. Scenarios for energy usage in buildings mirroring the three different pathways

\section{Figures}

Figure 1. Stylised recovery pathways from the COVID-19 crisis

Figure 2. Different illustrative GHG emission pathways to limit warming to $1.5^{\circ} \mathrm{C}$ by 2100

Figure 3. Stylised recovery pathways from the COVID-19 crisis

Figure 4. The OECD well-being framework includes multiple indicators in a dashboard

Figure 5. Conceptual trade-offs between GDP and wider well-being across the three stylised pathways

Figure 6. Mapping of surface transport recovery measures according to the three pathways

Figure 7. Mapping of residential sector recovery measures according to the three pathways

Figure 8. Variations in GDP projections for 2021 for selected countries

Figure 9. Variation in $\mathrm{CO}_{2}$ emissions levels projected for selected countries and time periods, as estimated over 2006-2010

\section{Boxes}

Box 1. Background on decoupling in relation to Green Growth 21

Box 2. The "Beyond GDP" rationale 24

Box 3. Case studies of selected Wider Well-being pathway compatible measures

Box 4. Lowering energy demand from the residential sector $\quad 51$

Box 5. Case studies of measures compatible with Wider well-being 53

Box 6. Increased uncertainty of developing BAU scenarios during an economic downturn 60 


\section{List of Acronyms}

2DS IEA 2 degree scenario

6DS IEA 6 degree scenario

AFOLU Agriculture, Forestry and Other Land-Use

BAU Business-as-usual

BECCS Bio-energy with carbon capture

BEV Battery Electric Vehicle

CCXG Climate Change Expert Group

CDR Carbon Dioxide Removal

$\mathrm{CH}_{4}$ Methane

$\mathrm{CO}_{2}$ Carbon dioxide

EV Electric vehicles

FCEV Fuel cell electric vehicle

GDP Gross Domestic Product

GHG Greenhouse gas

ICE Internal Combustion Engine

IEA International Energy Agency

IPCC Intergovernmental Panel on Climate Change

Maas Mobility as a service

$\mathrm{N}_{2} \mathrm{O}$ Nitrous oxide

NDC Nationally Determined Contribution 
NZE 2050 IEA Net Zero Emissions by 2050 case

OECD Organisation for Economic Co-Operation and Development

PV Photovoltaic

SDG Sustainable Development Goal

SDS IEA Sustainable Development Scenario

TOD Transit-oriented development

UNFCCC United Nations Framework Convention on Climate Change

VAT Value Added Tax 


\section{Executive Summary}

The emergence and rapid spread of COVID-19 from the end of 2019 and through 2020 has dramatically impacted lives, societies and economies across the world. Governments are responding to the crisis by developing an array of policies and recovery measures that cover several sectors and policy types. In addition to their economic impact, these will have potentially large environmental and social impacts in the short and long term. Indeed, some individual recovery measures may risk reversing some of the hard-won progress in the pre-crisis period on e.g. greenhouse gas (GHG) emission trends and clean air. Misalignment between recovery measures and long-term environmental and social goals can in turn lead to longer-term economic costs - both in terms of stranded assets, and increased costs associated with climate or other environmental impacts. The nature, focus and design of COVID-19 recovery packages will therefore affect the ability of individual countries simultaneously to meet a range of domestic economic, social and environmental goals, as well as their collective ability to achieve the aims of the Paris Agreement, the envisaged post-2020 framework for biodiversity and the 2030 Sustainable Development Goals (SDGs).

Even before the COVID-19 pandemic, it was clear that current Nationally Determined Contributions (NDCs) under the UNFCCC, even if fully implemented, would not put the world on a credible pathway to a wellbelow $2^{\circ} \mathrm{C}$ goal. Achieving this goal will require sustained annual global reductions in carbon dioxide $\left(\mathrm{CO}_{2}\right)$ emissions; for a $1.5^{\circ} \mathrm{C}$ goal these would need to be of a similar order to those seen in 2020 up to 2030, though significantly lower for a $2^{\circ} \mathrm{C}$ goal (perhaps around $2-4 \%$ reductions per year). ${ }^{1}$ Yet many of the recovery measures and associated expenditures announced to date provide support for fossil fuels, much of which is unconditional. Any further delay or lock-in of fossil-intensive infrastructure is likely make a wellbelow $2^{\circ} \mathrm{C}$ - let alone a more stringent - target more costly and difficult to achieve. The pressures on public finances because of the COVID-19 crisis suggest that, to the extent possible, it would be helpful if recovery measures aimed to address a range of goals - economic, social and environmental simultaneously rather than sequentially or in isolation.

This paper provides decision-makers with a framework for prioritising different economic, social and environmental goals and analysing the options available to achieve them. To this end, it develops three stylised recovery pathways that differ in the extent to which they encompass (i) greenhouse gas (GHG) emission reductions ${ }^{2}$ and (ii) the integration of mitigation and wider well-being outcomes or, broadly equivalently, SDGs. There is no "one size fits all" solution. The nature and scope of individual recovery pathways will always be context dependent and vary across countries, reflecting national priorities and circumstances. The balance each country might wish to achieve between economic, social and environmental goals may also vary considerably both across and within different countries or groupings of

\footnotetext{
${ }^{1}$ See, for example, UNEP's Emissions Gap Report 2019.

2 The analysis of measures is narrower, focusing on fossil-fuel related carbon dioxide $\left(\mathrm{CO}_{2}\right)$ emissions but, in principle, the framework can be applied to all GHGs and other climate forcers, like black carbon though these emissions of non$\mathrm{CO}_{2}$ forcers do not reach zero globally in 2050 , even in pathways limiting warming to $1.5^{\circ} \mathrm{C}$ (IPCC, $\left.2018_{[14]}\right)$.
} 
countries (e.g. income groupings). However, the focus of this paper is to establish the framework and classify existing recovery packages in two sectors, leaving country-specific analysis for further work.

Nevertheless, this document does provide a number of real-world examples of recovery measures announced by an array of countries. The analysis shows how the many individual recovery measures that have been proposed in these two sectors (surface transport ${ }^{3}$ and residential) can be mapped onto three stylised recovery pathways ${ }^{4}$, noting that a country's recovery pathway may encompass measures that are consistent with all three stylised pathways. Indeed, while the entirety of a country's recovery package may not fit into a single pathway, individual measures for different sectors may still be broadly consistent with the narrative of a given pathway. The document also discusses the implications of the COVID-19 crisis and the uncertainty around the nature and pace of eventual recovery pathways for the level of ambition of current and future NDCs, as well as for the process of updating NDCs. Figure 1 summarises key features and a detailed description of the three stylised pathways, "Rebound", "Decoupling" and "Wider well-being", follows immediately below. Of these, only Decoupling and Wider well-being focus on the early climate mitigation action needed to credibly limit global temperature increases to well-below $2^{\circ} \mathrm{C}$.

Rebound would prioritise a rapid re-establishment of economic growth and macroeconomic stability. It would not prioritise carbon dioxide $\left(\mathrm{CO}_{2}\right)$ emissions reductions nor progress on wider social or environmental objectives. Measures consistent with Rebound would provide incentives or support measures for specific economic sectors or activities purely in relation to their contribution to re-establishing growth and macro-economic stability, with no social or environmental conditions attached. Examples in the transport sector include reducing fuel excise tax rates and introducing other fossil fuel subsidies; support for vehicle purchase (e.g. VAT reductions) with little or no environmental conditionality; measures that incentivise car ownership and use by (temporarily or permanently) waiving or reducing charges that reflect the social costs of car use (e.g. congestion or driving charges). Examples in the residential sector include: incentivising the purchase of dwellings outside urban cores; and fast-tracking building permits without sustainable planning considerations. Rebound measures would aim to safeguard companies, restore and create new jobs and increase incomes, investment and trade, but could also exacerbate the lock-in of fossil and energy-intensive infrastructure, lead to an increase in air pollution and further entrench inequalities.

Like Rebound, Decoupling is also assumed to be focused on the conventional metric of economic success, i.e. GDP growth. Decoupling, however, represents a significant step towards placing climate change mitigation at the heart of the recovery strategy. Decoupling would restore economic growth and macroeconomic stability and aim for an absolute decoupling of $\mathrm{CO}_{2}$ emissions, i.e. emissions would be flat or falling with positive GDP growth. It would incentivise (incremental) improvements in energy efficiency and a rapid scaling up of low-carbon energy. Low-carbon electricity would enable the decarbonisation of end-use sectors such as transport so a typical transport measure might be to incentivise electric vehicles, while maintaining a focus on low-occupancy private vehicle use (e.g. implementing "cash-for-replacing" scrapping schemes that condition eligibility to cleaner or electric vehicles). Thus, there would be limited or no focus on using the recovery to move away from car dependency, with any pre-crisis efforts in this respect being only maintained rather than increased. Decoupling measures that do decrease car dependency tend to be either: (i) temporary (e.g. temporary infrastructure for active and public transport); or (ii) of limited scope, e.g. incentives for teleworking without a direct link to increasing public transport capacity and improving planning. In the residential sector, it would focus on individual dwellings and

3 For the purposes of this document, "surface transport" includes all road transport modes: walking, cycling, micromobility, and rail (including metro, light rail, and commuter as well as long-distance rail). Marine transport is excluded.

\footnotetext{
${ }^{4}$ Note that as many OECD countries were hit relatively early by the COVID-19 pandemic, these countries have had more time to develop their recovery measures than many non-OECD countries, which explains the prominence in this draft of examples from OECD countries.
} 
measures to incentivise incremental improvements in energy efficiency or reduced emissions, e.g. roof insulation or installation of rooftop solar, instead of holistic improvements to the dwelling to significantly reduce energy demand. Decoupling measures might not use best available technologies and design for retrofits and new builds due to inadequate assessment and failure to apply full-cost accounting e.g., in relation to the potential health implications of poor quality buildings into project appraisals. Decoupling may or may not be consistent with a well-below $2^{\circ} \mathrm{C}$ or more stringent target depending on the specific rate for $\mathrm{CO}_{2}$ emission reductions achieved. If $\mathrm{CO}_{2}$ reduction rates are too low, achieving such targets might require the large-scale deployment of Carbon Dioxide Removal (CDR) technologies to remove $\mathrm{CO}_{2}$ from the atmosphere later in the century. A limited range of wider social and environmental benefits would be inherent in Decoupling, e.g. reductions in air pollution.

\section{Figure 1. Stylised recovery pathways from the COVID-19 crisis}

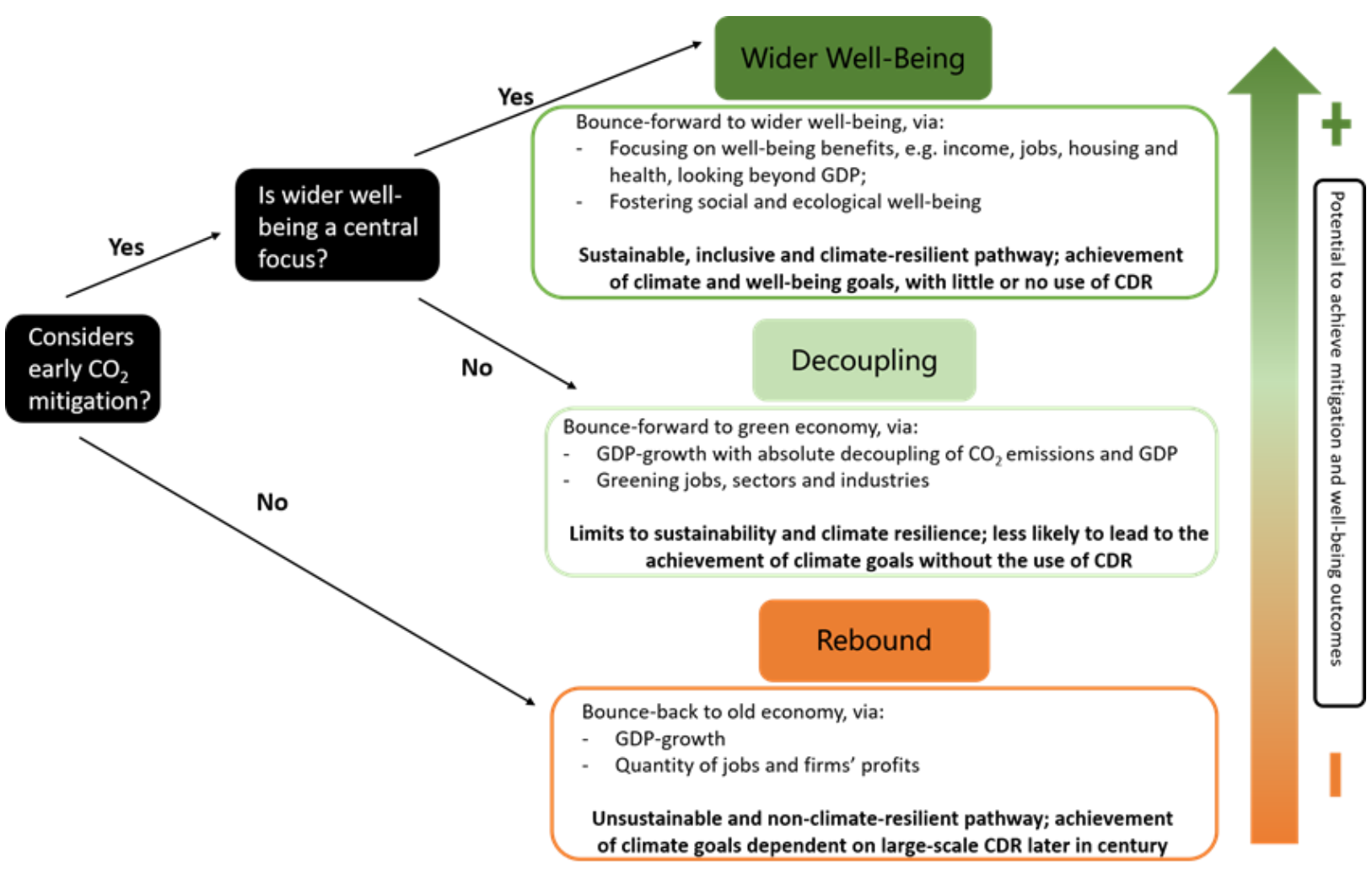

Note: $\mathrm{CDR}$ stands for Carbon Dioxide Removal. $\mathrm{By} \mathrm{CO}_{2}$ emissions, this discussion document refers to fossil-fuel related $\mathrm{CO}_{2}$ emissions, as measures assessed in this document relate to those tackling those emissions specifically. This discussion document acknowledges that $\mathrm{CO}_{2}$ emissions from non-fossil fuel related sectors (e.g. from the land use sector) as well as other greenhouse gas emissions from fossil-fuel combustion (e.g. $\mathrm{CH}_{4}$ from fugitive emissions) and in other sectors (e.g. $\mathrm{N}_{2} \mathrm{O}$ and $\mathrm{CH}_{4}$ from agriculture) are important and need also to be tackled by specific measures during the recovery and beyond.

Wider well-being would integrate economic recovery, $\mathrm{CO}_{2}$ emission reductions and well-being outcomes. This pathway would prioritise improvements in current well-being (e.g. income, jobs, health etc.) rather than focusing simply on aggregate GDP growth ${ }^{5}$ and would take into account the resources needed to maintain well-being over time (e.g. human, physical, natural and social capital). The synergies and tradeoffs between these diverse goals are complex and context dependent, so Wider well-being would encompass approaches that help decision makers to identify, quantify and exploit economically efficient

\footnotetext{
${ }^{5}$ Indeed, positive well-being outcomes may not always correlate with GDP.
} 
synergies and to manage trade-offs between them. It would monetise a fuller range of social and environmental costs and benefits, and address some of the limitations to the effectiveness of carbon pricing. In the transport sector, it would focus not only on accelerating the move towards cleaner vehicle technologies and fuels but also on moving away from car dependency through improvements to accessibility, a significant shift to shared, active and micro-mobility modes, and the strengthening of public transport and inter-urban rail. In the residential sector, it would aim to enlarge mitigation potential at all spatial scales (dwelling, neighbourhood, city and wider hinterland). Measures might include integrated planning of new developments and infrastructure; holistic retrofits that lower energy demand; and green spaces in neighbourhoods to regulate microclimates and provide safe spaces for inhabitants. Sections 3 and 4 provide a range of real-world examples for these two sectors.

The nature and pace of economic recovery in different countries and in aggregate will have important implications for existing, updated and new NDCs under the Paris Agreement. For example, the mitigation ambition of current NDCs can be affected by the form of the NDC, the depth and length of the economic downturn as well as the pace of the recovery in activities and emissions. Thus, any mitigation target that was framed in a static, fixed way in 2015 may now be significantly less ambitious than expected, because of the fall in activities and emissions caused by response measures to the pandemic. Given the uncertainties around the timing of economic recovery and emissions pathways, countries may face challenges during this period in formulating updated or new NDCs that accurately represent the strength of intended mitigation action and that are robust to this uncertainty. This could have significant implications for the level of ambition of NDCs, particularly for targets based on a "deviation from BAU" emissions trajectory, which was the most common type of first NDC for developing countries. A strong national commitment to ensure that COVID recovery measures take climate and/or well-being considerations into account, could facilitate the development of national and sub-national recovery measures that are aligned with a broad set of national and international objectives.

According to the OECD's Economic Outlook from December 2020, global economic recovery is anticipated to gain momentum in 2021, while this recovery is likely to be uneven across countries. If recovery measures do not radically change the emissions intensity of economic activity from previous trends, emissions are also likely to rebound towards a pre-crisis Business as Usual (BAU) trajectory. In this case, the implications of the crisis for the ambition and achievement of 2030 climate mitigation targets of any type may be quite limited. For NDCs running to 2025, the implications may be larger - particularly for multi-year NDC targets, which may now be more easily achieved than anticipated. This may offer opportunities for some countries to over-achieve their initial target, or to revise it. Targets formulated in terms of the emissions intensity of GDP may be less affected, depending on the precise sectors affected by the crisis in each country and the extent to which the fall in emissions is correlated with the fall in GDP. The type of recovery pursued is, however, likely to result in significant changes to the GDP and emissions pathways envisaged pre-crisis, with consequences for 2030 targets. Rebound would likely make existing mitigation targets more challenging to achieve, and may limit future mitigation options and ambition. Decoupling and Wider wellbeing on the other hand may offer new opportunities for simultaneously achieving recovery and emission reductions, and may allow countries to adopt more stretching mitigation targets or deliver already ambitious targets under more difficult economic and social circumstances than originally envisaged. Wider well-being further increases the chances of achieving stringent targets (near- and longer-term), while also delivering improved well-being, which can help make the case for mitigation action.

Recovery pathways that encompass more climate mitigation (Decoupling and Wider well-being) are likely to be more capital-intensive in aggregate in the short and mid-term than Rebound but are capable of yielding significant savings (e.g. in fuel costs). Wider well-being may, however, lead to reductions in aggregate capital demand, e.g. by reducing the need for new electricity generation capacity or overall vehicle numbers relative to other scenarios. It also has the potential to deliver both longer-term climate benefits and important near-term improvements in well-being (e.g. health, environmental health and reduced inequalities) that tend to have high social returns. These features may be attractive in a post-crisis 
situation where inequalities within and between generations have been amplified and where there have been sharp increases in public debt due to economic support measures. Further work is needed, however, to address the macro-economic implications of these stylised scenarios and to quantify their broader socioeconomic implications.

There are also important practical dimensions of implementing or updating an existing NDC or creating a new NDC that are affected by the initial and ongoing pandemic containment measures. For example, data collection may be delayed or hampered, making it difficult to assess the performance of current mitigation measures and whether they need to be adjusted to meet current or updated NDC targets. Such delays can compound the uncertainty of BAU projections as well as the existing difficulties in assessing the economic and wider benefits of mitigation actions. Evidence suggests that such challenges have increased in many developing countries, particularly where responses to the pandemic have led to a diversion of human resources, as well as to a cut in direct climate spending. Conversely, in other, often sub-national contexts, the crisis seems to have motivated efforts to collect data and develop innovative solutions, which may simultaneously address current challenges and allow for improved practices in the future e.g. in the transport sector. Taking into account initiatives at different jurisdictional levels will help ensure recovery pathways and updated or new NDCs are coherent.

In rolling out COVID-19 recovery measures, it will be important to understand the impact of policy choices across multiple dimensions (economic, social, and environmental) and time periods (short and long-term). Countries' recovery plans may not always sit neatly in one or other pathway, even within a single sector, and several countries appear to be developing recovery measures that are misaligned with their broader stated policy aims in the medium-term (e.g. NDCs and SDGs). To the extent that this is the case, countries' actions to recover from the COVID-19 pandemic may also run counter to their own longer-term goals (e.g. long-term low-emission development and the increasing number of net-zero commitments). Such misaligned actions, if sufficiently widespread, could jeopardise meeting goals at the international level (e.g. the Paris Agreement goals on limiting the rise in average temperature to well-below $2^{\circ} \mathrm{C}$, and on ensuring consistency of financial flows with climate objectives). Taking a well-being approach to mitigation would help quantify and make more visible the synergies and trade-offs between different goals. This could in turn encourage greater co-ordination and policy coherence, which is key to delivering on the multiple challenges that governments are currently facing. 


\section{Introduction}

The social and economic responses to the COVID-19 pandemic have widespread ramifications for people and economies across the globe. Apart from the tragic health consequences, the stringent restrictions on social and economic activity put in place by many authorities to contain the pandemic have led to an extremely sharp recession globally and increased unemployment (on the scale of hundreds of millions of jobs, see (ILO, 2020[1])), travel and services most affected.

Governments had, by August 2020, put in place short-term recovery measures estimated to cost at least US\$11.8tn or $8.7 \%$ of global GDP (World Bank, 2020[2]) (Vivid Economics, 2020[3])). Such measures are to provide immediate support to the most vulnerable categories of population, workers and firms and, as conditions allow, to drive near-term economic recovery. These measures also have implications for the achievement of broader national and international goals in the short and long-term. These include countries' current Nationally Determined Contributions (NDCs) to the Paris Agreement on climate change (which usually run to 2030), any revisions or updates to these NDCs (which are to be communicated nine months prior to COP26) and the Sustainable Development Goals (SDGs). Many governments have also indicated their aim to reach net zero greenhouse gas (GHG) emissions by mid-century.

The responses to the pandemic have led to dramatic short-term changes in specific activities, sectors and employment levels. $\mathrm{CO}_{2}$ emission levels fell sharply initially (Le Quéré et al., 2020[4]) and are projected to be around $8 \%\left(2.8 \mathrm{Gt} \mathrm{CO}_{2}\right)$ lower in 2020 relative to 2019 levels, taking emissions back to levels last seen around 2010 (IEA, 2020[5]). This short-term reduction in $\mathrm{CO}_{2}$ emissions will, however, not have a significant impact on future climate risks unless it is coupled with robust mitigation measures from governments as part of their recovery and subsequently. Indeed, a rapid and sustained reduction in global GHG emissions is needed if the world is to meet the goals of the Paris Agreement.

The COVID-19 recovery packages being developed are extensive. For example, the economic stimulus in Canada (approximately USD 240bn or $14.3 \%$ of GDP in 2019, (Government of Canada, 2020[6])) and the Philippines (USD12.6bn or 12.4\% of GDP in 2019) (Government of the Philippines, $2020[7]$ ), is supporting industry, infrastructure investment, as well as local communities in both countries. The development of such wide-reaching COVID-19 recovery packages offers governments the possibility to rekindle economic activity in different ways - as described in sections 2, 3 and 4. For example, COVID-19 recovery measures could encourage a rapid re-establishment of economic growth and macroeconomic stability. This will clearly be more difficult in the sectors that are most severely affected by containment measures, such as travel, tourism and related services. Recovery will also be more difficult for countries that are highly dependent on incomes from tourism, such as small island states, or on remittances. Alternatively, rather than pursuing a "bounce back", governments could consider that going forward, recovery measures could be designed in such a manner as to enable absolute decoupling of $\mathrm{CO}_{2}$ emissions ${ }^{6}$ and GDP-growth (i.e., to pursue economic growth while keeping flat or reducing emissions). A third recovery pathway could be

\footnotetext{
${ }^{6}$ The focus of this paper is on fossil-fuel related $\mathrm{CO}_{2}$ emissions and measures to tackle those emissions in two specific sectors. $\mathrm{CO}_{2}$ emissions from non-fossil fuel related sectors (e.g. from the land use sector) as well as other greenhouse gas emissions from fossil-fuel combustion (e.g. $\mathrm{CH}_{4}$ from fugitive emissions) and in other sectors (e.g. $\mathrm{N}_{2} \mathrm{O}$ and $\mathrm{CH}_{4}$ from agriculture) are of course also important and need also to be tackled by specific measures during the recovery and beyond.
} 
where governments pursue an economic recovery that focuses on integrating mitigation action and broader well-being goals, such as health, income and jobs, with strong decarbonisation action, which would help countries achieve their NDC targets. Indeed, previous related analyses have focused on how to realise possible synergies and manage trade-offs between climate change mitigation and wider well-being (OECD, 2019[8]), as well as experience with aligning policies over multiple different areas (e.g. in the biodiversity, climate and food nexus, (OECD, 2020[9]).

This paper provides a framework (in section 2) for categorising and assessing recovery measures, building on previous analysis (OECD, 2019[8]) and selected measures implemented or announced to date as part of the COVID-19 recovery in a number of sectors and countries. Sections 3 and 4 explore recovery measures related to the surface ${ }^{7}$ transport and residential sectors respectively, and map how these measures align to the three stylised recovery pathways developed in this document. Section 5 discusses the implications of COVID-19 recovery packages for the implementation and achievement of current NDCs, as well as for the ambition of updated and new NDCs. Conclusions are presented in section 6.

\footnotetext{
${ }^{7}$ For the purposes of this document, "surface transport" includes road transport, walking, cycling, and public transport (including overground and underground metro). Marine transport is excluded.
} 


\section{Three stylised COVID recovery pathways}

At the onset of the COVID-19 crisis, governments' priorities focused on containment and health measures to help contain the spread of the COVID-19 virus and save lives. These restrictive measures led, and continue to lead in many countries, to a sharp economic slowdown caused by a reduction in consumption, income and jobs with significant repercussions for firms in several sectors. In many countries, special schemes, to address the economic consequences for incomes, employment and companies, led to higher public spending and indebtedness in virtually all countries touched by the virus. In many countries, attention is now turning to designing recovery packages. These packages will have varying costs, and potentially significant impacts on a country's economic prospects, many of which will be long-lasting (OECD, 2020[10]). These recovery packages can also have significant effects on environmental and social goals at a national and international level. Such a prospect emphasises the need for renewed and well-targeted structural policy reforms in all economies, aiming at a sustainable recovery which could in turn pave the way to fairer and safer economies in the future (OECD, 2020[10]).

This section presents a framework to assess the recovery measures that countries are putting in place as part of their packages, to recover from the effects of the responses to the COVID-19 crisis. It examines in particular the ability of these measures to create a sustainable, climate-resilient future. This is important because the Paris Agreement sets the long-term temperature goal of "holding the increase in the global average temperature to well below $2^{\circ} \mathrm{C}$ above pre-industrial levels and pursuing efforts to limit the temperature increase to $1.5^{\circ} \mathrm{C}$ above pre-industrial levels" (Paris Agreement, $\left.2015_{[11]}\right)$. These efforts remain urgent in order to limit the risks of "severe, pervasive and potentially irreversible impacts" from global warming and for advancing progress on sustainable development and poverty eradication (IPCC, 2014[12]).

Choices made in the next decade, and notably the design of the recovery, will be critical for the international community's collective ability to achieve its international climate mitigation goal and avoid the most dangerous impacts of climate change. ${ }^{8}$ The latest research shows that there are different ways to achieve the globally-agreed climate goals of the Paris Agreement, considering different socio-economic future trajectories, efficiency measures, societal and technological developments (Riahi et al., 2017[13]; IPCC, 2018[14]; Gambhir et al., 2019[15]). Figure 2 extracted from the IPCC Special Report on $1.5^{\circ} \mathrm{C}$ shows potentially different illustrative futures to achieve the goal of limiting warming to $1.5^{\circ} \mathrm{C}$ by 2100 . What is clear is that trade-offs exist. For example, scenarios with higher levels of future energy demand show lower levels of $\mathrm{CO}_{2}$ emissions reductions to 2030 (moving towards the right hand side of Figure 2) and rely to a much greater extent on the use of Carbon Dioxide Removal (CDR) technologies later in the century (in this case assumed to be bioenergy with carbon and capture storage). In addition, $1.5^{\circ} \mathrm{C}$ pathways relying on low-energy demand, low material consumption, and low GHG-intensive food consumption (in line with the "P1" scenario in Figure 1) also show the most synergies (positive interactions) and the lowest number of broad trade-offs (negative interactions) with other environmental goals and the SDGs (IPCC, 2018[14]).

\footnotetext{
${ }^{8}$ For example, the IEA has recently highlighted key investments that would be needed for a Sustainable Recovery (IEA, 2020[229])
} 
How the recovery is designed in countries, and worldwide, will therefore determine the type of transition the world will go through in the next decades and the risks associated with it.

\section{Figure 2. Different illustrative $\mathrm{GHG}$ emission pathways to limit warming to $1.5^{\circ} \mathrm{C}$ by 2100}
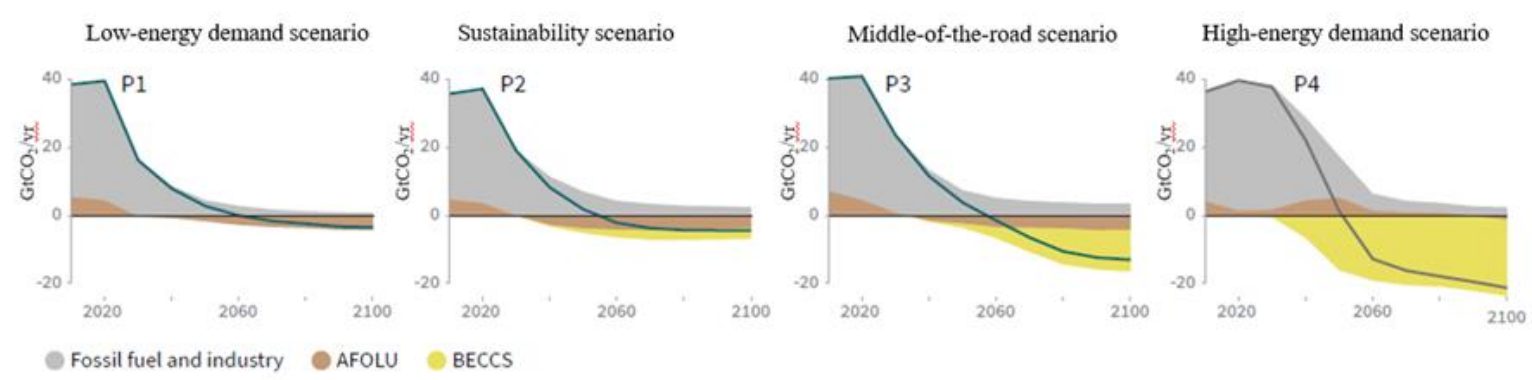

Note: AFOLU and BECCS stand for Agriculture, Forestry and Other Land-Use and Bio-energy with carbon capture and storage respectively. P1 is a scenario with low energy demand (LED) (Grubler et al., 2018[16] $)$ and reflects recent literature with a stronger focus on demand-side measures; P2 is a sustainability oriented scenario (based on SSP1) developed with the AIM model (Fujimori et al., 2017 ${ }_{\text {[17] }}$ ); P3 is a middle-ofthe-road scenario (based on SSP2) developed with the MESSAGEGLOBIOM model (Fricko et al., 2017[18]) and P4 is a fossil-fuel intensive and high energy demand scenario (based on SSP5) developed with the REMIND-MAgPIE model (Kriegler et al., 2017[19]). In short, the three SSPS referred to here include scenarios following a sustainability path (SSP1), a middle-of-the-road development pattern (SSP2), further and a fossilfuel based economic development (SSP5). A description of the different SSP scenario narratives can be found in (O'Neill et al., 2017 [20]).

Source: IPCC Special report on $1.5^{\circ} \mathrm{C}$ (IPCC, 2018[14]).

\section{Three stylised recovery pathways out of the COVID-19 crisis: Rebound, Decoupling and Wider Well-Being}

This paper develops three stylised recovery pathways to help better understand the extent to which different types of individual measures may contribute to economic recovery, emissions reductions in line with internationally agreed climate goals and broader societal goals. The three stylised pathways are the Rebound, Decoupling and Wider Well-Being pathways. They have been conceptualised as narratives based on a number of considerations around the ability and likelihood to meet international global climate goals and the relationship between and relative priorities across economic growth, climate mitigation and wider well-being outcomes. Figure 3 summarises some of the key features of these pathways and the remainder of the section explores in detail how these different pathways can lead to different futures, where they overlap and where they differ at the macro level.

The narrative behind the three stylised pathways serves as a basis for sections 3 and 4 , which analyse how different types of recovery measures currently considered and implemented in the surface transport and the residential sectors relate to these different pathways. Needless to say, recovery packages will need to go beyond the sectors here analysed and integrate actions across the whole economy. The sectoral analysis can illustrate how a given measure could impact the speed and scale of emission reductions in a given sector as well as the implications for other well-being goals. It is important to note that the implementation of an individual measure in isolation would not necessarily address all the key features of a pathway. Rather, it is the implementation of a coherent combination of measures, which would put the whole of a country's recovery strategy within one of the pathways. In this sense, while the entirety of a country's recovery package may not fit into a single pathway, individual measures for different sectors (and potentially even within sectors) may still be consistent with the narrative of a given pathway. 
Figure 3. Stylised recovery pathways from the COVID-19 crisis

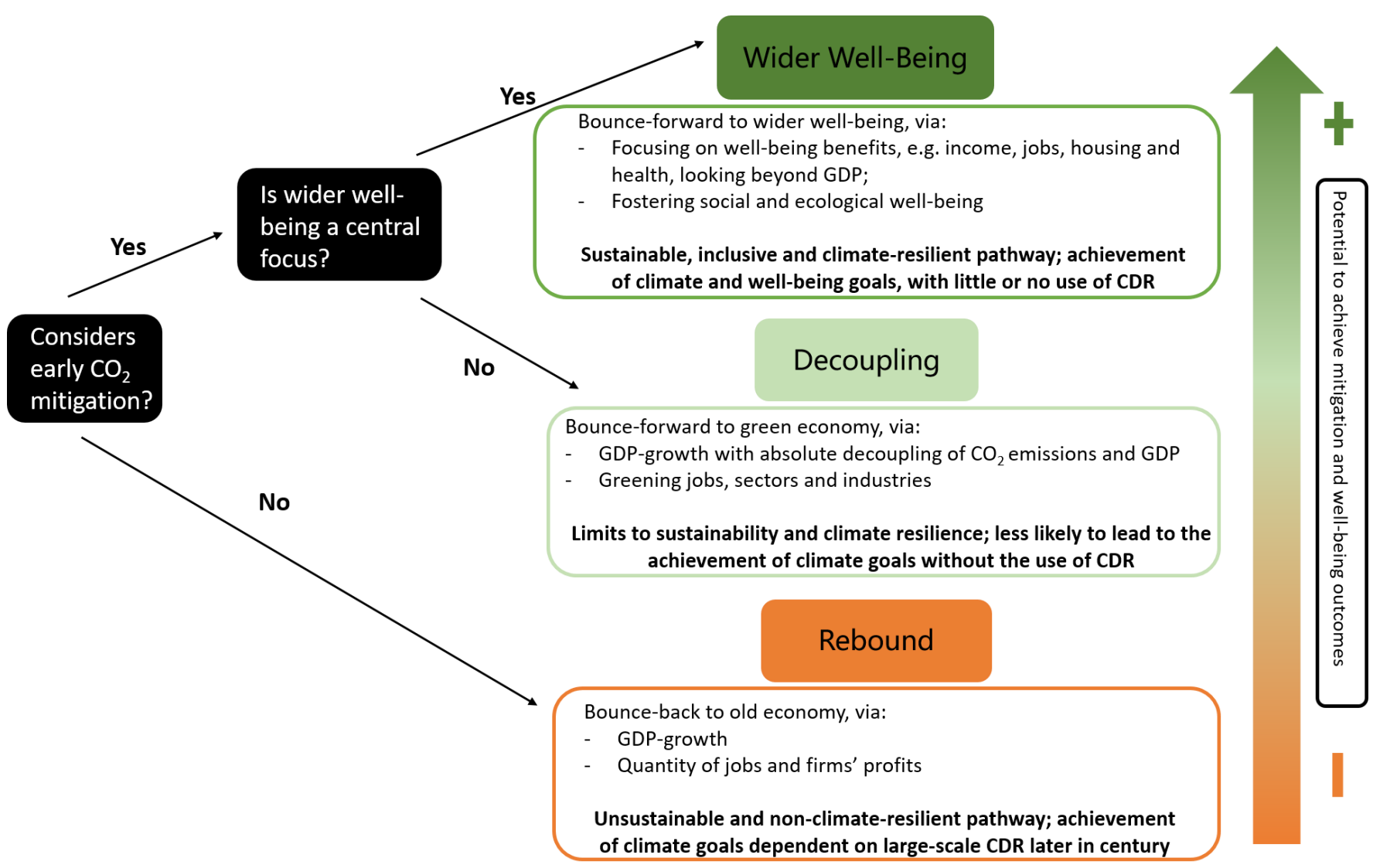

Note: CDR stands for Carbon Dioxide Removal. By $\mathrm{CO}_{2}$ emissions, this discussion document refers to fossil-fuel related $\mathrm{CO}_{2}$ emissions, as measures assessed in this document relate to those tackling those emissions specifically. This discussion document acknowledges that $\mathrm{CO}_{2}$ emissions from non-fossil fuel related sectors (e.g. from the land use sector) as well as other greenhouse gas emissions from fossil-fuel combustion (e.g. $\mathrm{CH}_{4}$ from fugitive emissions) and in other sectors (e.g. $\mathrm{N}_{2} \mathrm{O}$ and $\mathrm{CH}_{4}$ from agriculture) are important greenhouse gas emissions and need also to be tackled by specific measures during the recovery and beyond.

Source: Authors.

\section{Rebound pathway}

Following important negative economic impacts of the COVID-19 pandemic, recovery measures in line with Rebound focus on re-igniting economic activity and on achieving a recovery of economic output, i.e. GDP, as soon as possible. Rebound is characterised by a "bounce-back" rationale, meaning that measures in line with this pathway aim at bringing countries back to similar economic conditions where they were before the crisis, in the shortest amount of time possible. While preventing fiscal instability in the near-term and getting employment levels comparable to pre-pandemic levels is needed in virtually all post-COVID19 contexts, there are different ways this can be achieved ${ }^{9}$. Measures in line with Rebound include unconditional rescue packages for important industries, maintenance or increase of incentives for fossil fuel production, use or technologies that can lead to the lock-in fossil fuel infrastructure. Such measures do not prioritise transformative change to achieve zero net $\mathrm{CO}_{2}$ emissions in the second half of the century - necessary to stop climate risks increasing - and are therefore unlikely to lead to better sustainability, climate resilience and the achievement of wider well-being goals. Rebound could also lead to a roll-back

\footnotetext{
${ }^{9}$ Sections 3 and 4 explore these issues in detail in the context of the transport and the residential sectors.
} 
of previous actions to decouple carbon emissions and environmental outcomes and economic growth, and risks perpetuating environmental (e.g. air pollution and health), social (e.g. exclusion), economic (e.g. support to uneconomic sectors) and other pre-pandemic challenges, instead of stimulating wider and deeper change. Key features of a Rebound pathway include that associated measures are that:

- It is rooted in a conventional economic growth framework: Focus on recovering GDP growth and macroeconomic stability in the short-run, with no direct assessment of whether measures would contribute to a more resilient future or reduce inequalities in society;

- It has no explicit focus on improving environmental trends, in terms of e.g. GHG emissions, energy or materials: the improvement of environmental productivity consists of decoupling the growth in e.g. carbon emissions and growth in economic output; no focus on reducing environmental pollution or increasing environmental quality;

- It has little focus on synergies across measures implemented in different sectors/areas.

\section{Decoupling pathway}

The COVID-19 crisis, despite its severe socioeconomic impacts, may act as a catalyst for governments to re-think their actions and rebalance their investments with a view to de-risking activities in the mid- and long-term through e.g. increased climate resilience. This discussion document defines as in line with Decoupling those measures aiming at the absolute decoupling of economic output, in terms of GDP and $\mathrm{CO}_{2}$ emissions ${ }^{10}$, through increasing energy efficiency, low-carbon energy, investment and innovation support related to these aims as well as market-based mechanisms. Climate-related externalities would be priced and inefficient fossil-fuel subsidies phased out.

Like Rebound, Decoupling is also assumed to be focused on the conventional metric of economic success, i.e. GDP growth. Decoupling, however, represents a significant step towards placing climate change mitigation at the heart of the recovery strategy. This means that recovery measures in line with Decoupling integrate climate and economic goals, which may contribute to more sustainable and climate resilient futures. Importantly, such measures would likely prevent a roll-back of effective climate and environmental policy.

\footnotetext{
${ }^{10} \mathrm{By} \mathrm{CO}_{2}$ emissions, this discussion document refers to fossil-fuel related $\mathrm{CO}_{2}$ emissions, as measures assessed in this document relate to those tackling those emissions specifically. This discussion document acknowledges that $\mathrm{CO}_{2}$ emissions from non-fossil fuel related sectors (e.g. from the land use sector) as well as other greenhouse gas emissions from fossil-fuel combustion (e.g. $\mathrm{CH}_{4}$ from fugitive emissions) and in other sectors (e.g. $\mathrm{N}_{2} \mathrm{O}$ and $\mathrm{CH}_{4}$ from agriculture) are important greenhouse gas emissions and need also to be tackled by specific measures during the recovery and beyond.
} 


\section{Box 1. Background on decoupling in relation to Green Growth}

In general terms, decoupling occurs when the growth rate of an environmental pressure is less than that of its economic driving force over a given period (OECD, 2002[21]). Decoupling can be relative or absolute. In a climate context, relative decoupling occurs when $\mathrm{CO}_{2}$ emissions and GDP are both growing, but $\mathrm{CO}_{2}$ emissions are growing at a smaller pace. Absolute decoupling occurs when $\mathrm{CO}_{2}$ emissions are stable or decreasing while GDP is increasing. A recent review of a large body of literature on the issue of decoupling shows that the large majority of the papers analysed ${ }^{11}$ on decoupling are either inserted in green growth frameworks or follow a green growth perspective (Haberl et al., 2020[22]). Considering that the terms "decoupling" and "green growth" are often linked, this discussion document also looks into the different green growth frameworks, which in several respects go beyond the Decoupling pathway described here. Decoupling should not therefore be equated with green growth, despite the shared focus on GDP growth.

There is not a single green growth model or framework; rather, there are different schools of thoughts defining what constitutes green growth with different organisations promoting green growth in slightly different ways. For example, the OECD Green Growth Strategy aims to help governments foster economic growth and development, while ensuring that natural assets continue to provide the resources and environmental services vital to human wellbeing (OECD, $\left.2011_{[23]}\right)$. The measurement framework that underpins this uses a dashboard to measure green growth focusing on four areas: Environmental and resource productivity, Economic and environmental assets; Environmental quality of life, and Economic opportunities and policy responses (OECD, 2011[23]). In the context of the OECD Green Growth Framework, indicators for measuring progress on issues such as welfare and well-being benefits, inclusiveness, synergies and policy alignment across sectors have been enhanced over the past decade and are designed to be used in conjunction with the broader set of OECD indicators, including those for well-being. The World Bank explores the implications of green growth on human, natural and physical capitals with a special focus on how to make it inclusive (World Bank, 2012[24]). UNEP approaches a green growth framework by defining a green economy as "one that results in improved human well-being and social equity, while significantly reducing environmental risks and ecological scarcities", promoting enhanced resource and energy efficiency and recognising that decoupling the creation of economic value from natural resource use and environmental impacts is urgent (UNEP, 2011 $1_{[25])} .^{12}$

Most, if not all, of the green growth frameworks rely broadly on a common set of standard measures centred around (but not limited to) increasing efficiency, promoting renewable and low-carbon energy, introducing technological solutions and market-based mechanisms (Haberl et al., 2020[22]). Effectively addressing climate change requires an absolute decoupling of the growth in GDP and $\mathrm{CO}_{2}$ emissions. The central aim of the Decoupling pathway, as defined in this paper, is therefore to achieve such a decoupling, without a specific focus on broader social, economic and environmental goals. To the extent that Decoupling delivers broader well-being benefits, these would arise through GDP growth (e.g. jobs and income) or as a by-product of this central focus on reducing $\mathrm{CO}_{2}$ emissions (e.g. improved air quality and health from lower fossil-fuel combustion). The Wider well-being pathway would also need to deliver absolute decoupling, but it would seek to do so in a way that integrates climate and broader socio-economic concerns. 
A potential drawback of a strategy narrowly focused on decoupling is that the decoupling concept itself has no automatic link to the environment's capacity to sustain, absorb, or resist pressures of various kinds (OECD, 2006 [26]; Stoknes and Rockström, 2018[27]). ${ }^{13}$ In a growing economy, while an absolute decoupling of $\mathrm{CO}_{2}$ emissions and GDP would ensure that $\mathrm{CO}_{2}$ emissions decrease over time, the level of this reduction is not measured against or explicitly constrained by the pace of emissions reductions needed to achieve global climate goals. Indeed, in recent years, while $\mathrm{CO}_{2}$ emissions have decoupled from GDP, in most countries this decoupling has only been in relative and not absolute terms and not sufficient to drive emissions down in the scale and rate necessary to achieve international climate goals (OECD, 2017[28]). Key features of Decoupling include that:

- It is rooted in a conventional economic growth framework: Focus on recovering GDP growth, macroeconomic stability and market-based approaches, including carbon pricing, which may also lead to improvements in other aspects of environmental quality (e.g. air pollution).

- It avoids rolling-back of already implemented actions that are in line with decoupling $\mathrm{CO}_{2}$ emissions and economic growth;

- It may not highlight some potentially important well-being gains and losses, inequalities and risks for society as a whole from decarbonisation, since the relevant indicators may not be adequate to measure, monitor and drive progress on these other dimensions;

- It considers, although only to a limited extent, synergies across measures implemented in different sectors/areas (e.g. low-carbon electricity to decarbonise road transport via electric vehicles (EVs)).

\section{Wider well-being pathway}

Wider well-being aims at a recovery from the COVID-19 crisis that simultaneously achieves both climate change mitigation and wider well-being outcomes. It does so by taking a "beyond GDP" perspective and by defining societal goals in terms of well-being outcomes and systematically reflecting these in decisionmaking across the economy (Box 2). The OECD well-being framework applied to climate change mitigation (OECD, 2019 $\left.{ }_{[8]}\right)$ argues for approaching mitigation and well-being simultaneously in order to reduce barriers and potentially increase the political and societal buy-in and support for ambitious, early action to reduce GHG emissions. The rationale is that climate mitigation policies would be able to attract broader political and social support if they explicitly identify and incorporate potential synergies and manage potential trade-offs between climate and well-being objectives. An explicit consideration (e.g. through costbenefit or multi-criteria assessment) of all the costs and benefits across sets of policy choices would be at the core of this exercise in any given situation, and would be key to ensure policy prioritisation in an integrated and efficient way.

\footnotetext{
${ }^{11}$ Haberl et al. (2020) performed a systematic review on the issue of decoupling, identifying and screening more than 11500 scientific papers, analyzing full texts of 835 empirical studies on the relationship between economic growth (GDP), resource use (materials and energy) and greenhouse gas emissions.

12 Under the Green Growth Knowledge Platform, the OECD, World Bank and UNEP followed up on their original work with joint papers "Moving towards a Common Approach on Green Growth Indicators" (Kim et al., 2013[216]) and "Measuring Inclusive Green Growth at the Country Level (2016)" (Narloch, Kozluk and Lloyd, 2016[217])

13 The OECD's Green Growth framework does, however explicitly focus on ensuring that natural assets continue to provide the resources and environmental services on which human well-being relies.
} 
Wider well-being would require decision-makers to take account of all environmental, social and economic costs and benefits. Like Decoupling, it would need to employ carbon pricing (and in this case an array of other externalities), support low-carbon energy, as well as foster investment and innovation. However, it addresses limitations on the effectiveness of carbon pricing to achieve the (socially) optimal allocation of resources and guarantee minimum environmental standards (e.g. due to political acceptability or constraints on responses to price signals). It does so through complementary non-price measures that alter the supply and demand of key services, opening up a wider range of options for simultaneously achieving well-being and mitigation goals. In this sense, Wider well-being would encourage more systemic change across society and the economy, going beyond improving the energy efficiency and reducing the carbon intensity of existing modes of consumption and production, notably service delivery. Wider wellbeing would have equity concerns at its core (e.g. focusing on joint affordability of housing and transport) as well as seeking to anticipate and address the potential trade-offs (e.g. negative distributional impacts) of carbon (and other externality) pricing to increase public acceptability. This pathway could even contribute to increasing the elasticity of response to carbon pricing, e.g. by relaxing the constraints on behavioural changes through targeted infrastructure public transport investments.

In comparison to Rebound and Decoupling, Wider well-being could provide the basis for faster emissions reduction rates in line with the internationally-agreed temperature goal in the Paris Agreement. For example, measures in line with Wider well-being would aim at reducing the growth in energy and materials demand, while improving distributional and well-being outcomes. A Wider well-being approach would therefore align towards the low-energy demand and sustainability scenarios ( $\mathrm{P} 1$ and $\mathrm{P} 2$, respectively) in Figure 2. Recent research (IPCC, 2018[14]) shows that rapid growth in demand for energy and materials reduces the chances of achieving stringent mitigation targets such as the ones in the Paris Agreement. This means that recovery measures in line with Wider well-being can address the need for a rapid transition in line with internationally-agreed climate and other goals, such as the SDGs, as its core challenge. 


\section{Box 2. The "Beyond GDP" rationale}

While economic growth in terms of GDP may be correlated with welfare in some respects, this relationship may also be inexistent or negative in others (Weitzman, 1976[29]; Stiglitz, Fitoussi and Durand, 2018[30]; OECD, 2019 $\left.{ }_{[8]}\right)$. Indeed, recent OECD analysis shows that the dominant patterns of growth in OECD countries over recent decades have generated considerable harms including e.g. rising inequalities (OECD, 2020[31]). In addition, current patterns of economic growth are often not correlated with the achievement of well-being outcomes in OECD countries and may undermine their capacity to maintain current standards of living (OECD, 2020[31]).

Using GDP as the main measure of progress can be problematic, as it disregards important distributional patterns of the economic growth. Some of the key problems with using GDP as a measure of welfare include (Bergh, 2009 $\left.{ }_{[32]}\right)$ :

- GDP is a flow and not a stock measure, so it does not directly capture the change of the different types of capital or "wealth" (environmental, economic and social) over time. GDP does not therefore directly provide information about the sustainability of the economic activity or the possibility of achieving well-being over time (Boarini and D'Ercole, 2013[33]) (Fleurbaey, 2009[34]);

- GDP does not provide any information on the distribution of wealth across society, which is at the heart of a number of dimensions of welfare and individual and societal well-being, including social inclusion, access to services, quality of jobs, parity of opportunity and economic security;

- GDP includes activities that can actually negatively affect well-being. Examples include higher transportation costs due to congestion, the costs of remediating environmental destruction (e.g. the cleaning of coastal areas after an oil spill) and increased consumption stemming from reduced ecosystem services (e.g. bottled water or masks due to undrinkable water and unbreathable air) (Fleurbaey, 2009[34]; OECD, 2011 [35]);

- GDP excludes non-market activities potentially contributing to well-being, such as - often gendered - services produced by households (e.g. childcare).

In this sense, any approach focused merely on GDP growth will not capture the multitude of goals that governments have signed up to, such as the Sustainable Development Goals (SDGs). Using GDP as a central metric to evaluate recovery stimulus measure will therefore mask important gains and losses in actual societal well-being and prosperity.

Source: Authors, based on (OECD, 2019[8]

Recognising that increases in GDP may or may not be correlated with increases in well-being, the OECD well-being framework applied to climate change mitigation does not aim at GDP growth as an aggregate measure of progress (Box 2), but seeks improvements in key economic measures such as income, jobs and economic and human capital (see Figure 4). In addition, policies in line with Wider well-being explicitly focus on distributional aspects of well-being rather than only focusing on the aggregate indicators. Success would be measured in terms of the simultaneous achievement of well-being and mitigation outcomes; this framework shifts therefore the focus of policies from outputs (e.g. GDP, mobility) to outcomes (e.g. incomes, job quality, accessibility). Quantifying the level and changes in well-being is, however, challenging as there is no simple way of representing well-being in a single number in the way GDP describes economic output. This is due to the high granularity and diversity of potential well-being aspects (see Figure 4), and the difficulty in quantifying them in comparable terms. The OECD's well-being 
framework is multi-dimensional and uses a set of indicators, or a dashboard to evaluate well-being (OECD, $\left.2013_{[36]}\right)$. It is this multi-dimensional set of indicators that the framework developed in OECD (2019) would seek to use to drive simultaneous progress on mitigation and well-being objectives.

\section{Figure 4. The OECD well-being framework includes multiple indicators in a dashboard}

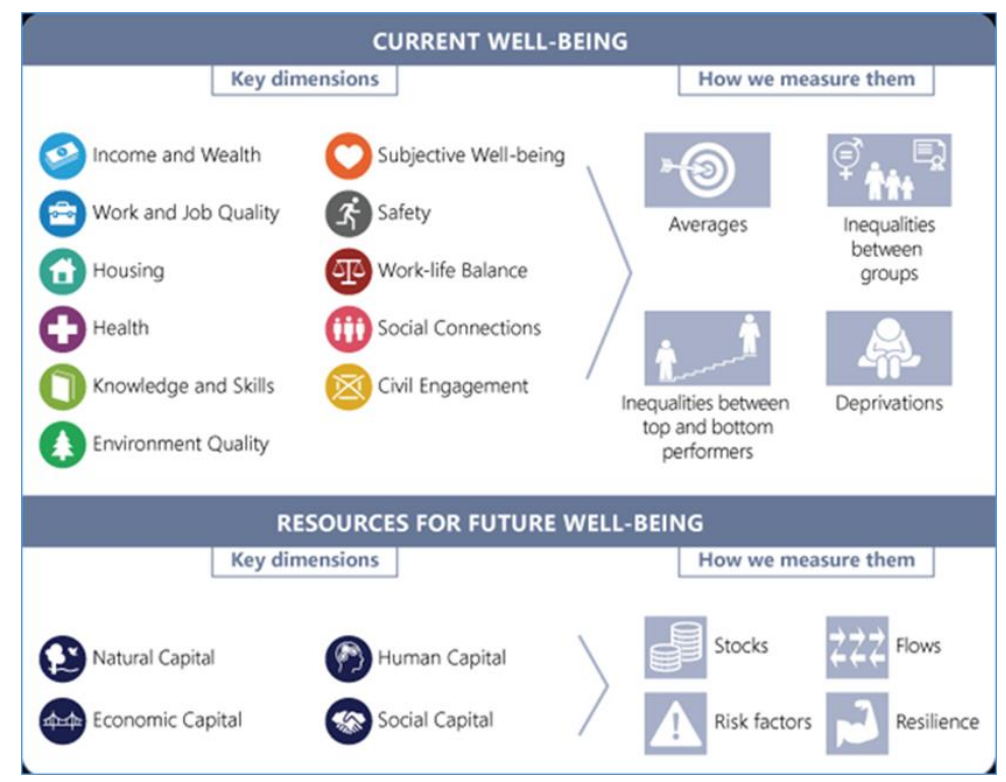

Source: "In the OECD Well-being Framework, current well-being is comprised of 11 dimensions. These dimensions relate to material conditions that shape people's economic options (Income and Wealth, Housing, Work and Job Quality) and quality-of-life factors that encompass how well people are (and how well they feel they are), what they know and can do, and how healthy and safe their places of living are (Health, Knowledge and Skills, Environmental Quality, Subjective Well-being, Safety). Quality of life also encompasses how connected and engaged people are, and how and with whom they spend their time (Work-Life Balance, Social Connections, Civic Engagement)." (OECD, 2020[37])

Wider well-being seeks to align short- and long-term policies. This means that policies and measures in line with Wider well-being aim to reduce GHG emissions in the short term and facilitate deep emissions reductions in the longer term. Previous CCXG analysis (Falduto and Rocha, 2020[38]) has highlighted that aligning short- and mid-term policy priorities with long-term mitigation strategies (such as the long-term low-greenhouse gas emissions development strategies (LT-LEDS)) can facilitate more ambitious NDCs and can also reduce the risk that policies in different areas within a given country are misaligned. Key features of a Wider well-being pathway are that:

- Success in the Wider well-being pathway is measured against both climate and well-being outcomes, including key economic quantities such as income, jobs and capital, other dimensions such as health, and in doing so, it looks at both aggregate and distributional measures. It does not target economic (GDP) growth as such;

- It integrates climate mitigation and well-being goals by quantifying (supplementing with qualitative measures where needed) and economically exploiting synergies and managing trade-offs, potentially reducing barriers to ambitious climate mitigation policy;

- It explicitly aims to deliver globally-agreed climate and other goals in a context-sensitive way. 


\section{Trade-offs between GDP growth and wider well-being outcomes across the three recovery pathways}

While it is beyond the scope of this paper to provide a quantitative assessment of how different policies may impact GDP growth or well-being indicators, this section provides in Figure 5 an illustration of the potential trade-offs between GDP growth and the achievement of wider-well-being benefits across the Rebound, Decoupling and Wider well-being pathways. In summary, these trade-offs are:

- Rebound, while leading to GDP growth (Figure 5, panel A), does not prioritise early climate mitigation or other environmental aspects, nor does it explicitly or coherently aim at well-being improvements. Recovery measures in line with this pathway are likely to lead to increased $\mathrm{CO}_{2}$ emissions over the coming decades, and may lead to the deterioration of well-being indicators (e.g. because GDP growth delivers its benefits unequally, Figure 5, panel B). Moreover, in ensuring GDP growth (Figure 5, Panel A), and considering that not all economic output components resulting in GDP correlate with well-being outcomes (Weitzman, 1976[29]; Van den Bergh, 2011 [39]; Stiglitz, Fitoussi and Durand, 2018[30]; Haberl et al., 2020[22]), measures in line with Rebound may not guarantee the achievement of well-being benefits.

- Decoupling, by ensuring absolute decoupling between economic activity and $\mathrm{CO}_{2}$ emissions, guarantees that $\mathrm{CO}_{2}$ emissions will decrease over time with growing economic activity. This decoupling however does not ensure $\mathrm{CO}_{2}$ emission reduction rates at the scale and pace needed to achieve internationally agreed climate goals. In ensuring GDP growth (Figure 5, Panel A), through measures that would aim at greening sectors of the economy, measures in line with Decoupling aim at the achievement of some well-being benefits, but not in a systematic manner. Such an approach could lead therefore to the deterioration of some well-being indicators (Figure 5, Panel B), while still resulting in GDP growth (Figure 5, Panel A).

- By not targeting GDP growth as such, Wider well-being may yield positive, negative or neutral impacts on GDP, while still having a positive impact on key economic components of well-being such as income and jobs (Figure 5, Panel A). By focusing on exploiting the synergies and managing the trade-offs between early climate mitigation policy and well-being outcomes, Wider-well-being may lead to more rapid $\mathrm{CO}_{2}$ reductions than seen historically (Figure 5, Panel $A$ and $B)$.

Figure 5. Conceptual trade-offs between GDP and wider well-being across the three stylised pathways
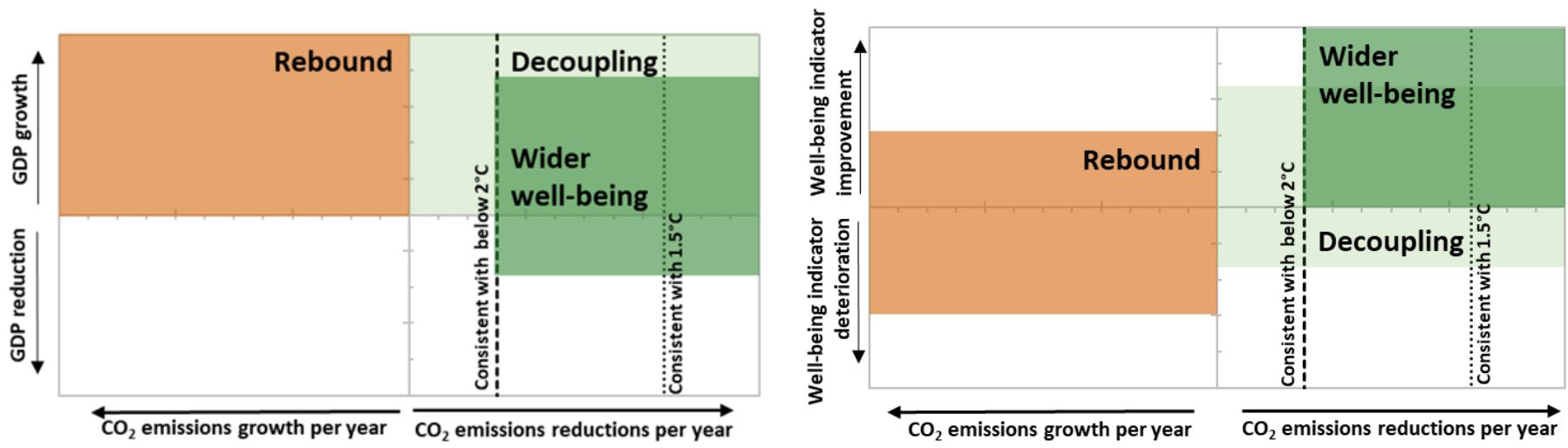

Note: The Decoupling pathway, as conceptualised in this discussions document, encompasses measures that envisage the absolute decoupling between $\mathrm{GDP}$ and $\mathrm{CO}_{2}$ emissions.

Source: Authors. 


\section{Overview of recovery measures in surface transport according to the three pathways}

The three stylised recovery pathways introduced in section 2, namely Rebound, Decoupling and Wider well-being, can inform analysis and assessment of specific sectoral recovery measures. This section maps recovery measures for the surface transport sector into the three stylised recovery pathways. This sector was selected as it is a major source of direct and indirect GHG emissions and relates intimately to a range of well-being outcomes, as highlighted below.

Transport is essential to connect people and places and to move goods. It therefore adds huge social and economic value to societies. Surface transport is important to job creation. For example, car manufacturing accounts for around 14 million jobs globally (ILO, 2020[40]) and already in 2013 public transport accounted for 13 million (UITP, 2013[41]). However, energy related $\mathrm{CO}_{2}$ emissions from the transport sector have grown faster than those from any other sector in the last 50 years (OECD, 2019 $\left.{ }_{[8]}\right)$. Indeed, direct $\mathrm{CO}_{2}$ emissions from the transport sector increased by $75 \%$ between 1990 and 2017 to an estimated 8 gigatonnes $\left(\mathrm{Gt} \mathrm{CO}_{2}\right.$ ), and represent $24 \%$ of global energy-related $\mathrm{CO}_{2}$ emissions (emissions (IEA, $\left.\left.2020_{[42]}\right)\right)$. In 2015, around half of transport emissions came from surface passenger transport, with urbanpassenger transport making up 32\% of total sectoral emissions. Surface (road and rail) freight made $28 \%$ of sectoral emissions in the same year (ITF, 2019[43]).

The transport sector has historically been considered a difficult sector to decarbonise (IPCC, 2014[44]) (Gota et al., 2019[45]). The International Transport Forum (ITF) has estimated that in a scenario where the negative economic impact from the COVID-19 crisis is long-lasting, ${ }^{14}$ even if countries maintain in place policies implemented and announced before the crisis, global emissions from the transport sector would only be $2 \%$ lower than those in 2015 by 2030 , and would increase by $8 \%$ by 2050 (ITF, 2021 [46]). A similar scenario modelled by the IEA, which includes existing policy frameworks and announced policy intentions (STEPS), estimates that emissions could be $5 \%$ higher by 2030 than those in 2019 (IEA, 2020). Beyond $\mathrm{CO}_{2}$ emissions, mobility systems have large impacts on well-being through air pollution, road crashes and noise, and may entrench social inequalities where segments of the population have limited or no access to economic (e.g. jobs), social (e.g., health, education) and environmental (e.g., green space areas) opportunities (OECD, 2019[8]).

\section{Using the recovery to accelerate the decarbonisation of surface transport}

The policy landscape in the transport sector has changed significantly following the COVID-19 crisis, because of the social distancing measures put in place by governments to stem the pandemic and the economic fall-out caused by lock-down measures. In April 2020, daily global activity in passenger surface-

\footnotetext{
${ }^{14}$ Assuming economic impacts linger in the form of a five-year GDP and trade projection "step back" (ITF, 2021 [46])
} 
transport was reduced by $50 \%$ on average in comparison to average activity in 2019 (Le Quéré et al., $2020_{[47]}$. The extent and rate of recovery of transport activity levels after confinement is uncertain. It will depend on local circumstances and behaviours, as well as policies and actions implemented and the transport mode in question. Nonetheless, some general factors of relevance for the sector can be identified. Confinement resulted in oil-price volatility and to some extent these were reflected in lower fuel prices, which could tend to boost demand for travel and transport fuels as countries lift confinement measures. In addition, the use and provision of public transport has fallen and may not quickly return because of perceived risks of contagion. Increased demand for transport as economies begin to return to normal may therefore lead to higher levels of car use than pre-COVID (ITF-OECD, 2020[48] $)$. Any drop in public transport use also puts further pressure on already-constrained public transport budgets through the loss of fare box revenues, jeopardising the long-term financial health of many public transport systems and the jobs that depend on them. For instance, the expected loss of revenue from fares by the end of 2020 in European public transport systems is EUR 40 billion (UITP, 2020[49])].

At the same time, the COVID-19 situation has interesting lessons and opens new possibilities for the transport sector. For instance, many cities have rapidly re-allocated road space to active transport modes (walking and cycling) and powered micro-mobility, such as e-scooters and e-bikes. Temporary protected lanes provide a safe environment for such alternatives to public transport alongside car use, helping manage capacity and providing conditions for social distancing. ${ }^{15}$ The result has been a large increase in the volume of cycling (BBC, 2020[50]). This demonstrates that these "sustainable" modes can effectively contribute to increasing the resilience of transport systems (Schwedhelm, 2020[51]) (Julien Bert, 2020[52]). Several cities have decided to make many of these temporary facilities permanent. More generally, the reductions in car traffic and the need for social distancing have prompted governments to reassess the current allocation of road space between different modes of transport (e.g. space for car travel and parking versus space for walking and cycling), as well as between transport and alternative uses (e.g. space for car parking vs. space for commercial activity).

Travel by active and micro-mobility modes has continued to be crucial for some cities as they prepare plans for adapting public transport services for social distancing (Bloomberg City Lab, 2020[53]). The continued and increased role of public transport will be crucial in many cities to avoid exacerbated private car use, but increasing the role of active and micro-mobility is key to ease crowding and address safety (see case studies in Box 3). Nonetheless, while individual bicycle and micro-mobility use have increased, shared services using these modes have in many cities been temporarily closed down or demand for these services has also been reduced (Julien Bert, 2020[52]). Shared e-scooter services, which in contrast to many bike and e-bikes shared schemes in different cities are not supported by public funds, have been hit the hardest (Hawkins, 2020[54]).

Reduction in traffic (and in other polluting activities such as industry) due to the COVID-19 crisis led to a sharp drop in pollutants including and particulates such as $\mathrm{NOx}, \mathrm{NO}_{2}$ and PM2.5 and PM10 during lockdown (Vincendon, 2020[55]) (University of Melbourne, 2020[56]) (Mahato, Pal and Ghosh, 2020[57]). For instance, $\mathrm{NO}_{2}$ levels in China during January and February 2020 were between 10-30\% lower than those experienced over the same period in 2019 (Earth Observatory, 2020[58]). In Paris NOx concentration were as low as $25 \%$ of pre-confinement levels for central Paris and $30 \%$ down in peripheral areas (Vincendon, 2020[55]), while in Delhi PM2.5 and PM10 concentrations fell up to 50\% reduction (Mahato, Pal and Ghosh,

\footnotetext{
${ }^{15}$ Micro-mobility is a term used for light-weight modes of transport. According to the Society of Automotive Engineers, micro-mobility has to be low speed. Most are 20 miles $(32 \mathrm{~km})$ per hour but could reach a maximum of 30 miles -48 $\mathrm{km}$ - per hour). They also need to be of small size (maximum of 500 pounds- $226 \mathrm{~kg}$, but most are less than 100 pounds $-45 \mathrm{~kg}$ ). Thus in principle, the term includes regular bicycles. Among micro mobility vehicles, powered ones, such as e-scooters or e-bikes are in general associated with the term. These be fully motorised or use some human power as source of energy.
} 
$\left.2020_{[57]}\right)$. Any shift away from private, car-based mobility systems could contribute to making this improvement permanent, rather than having air quality deteriorate rapidly towards pre-confinement levels, as is already the case in many places (Vincendon, 2020[55]) (EEB, 2020[59]). Although not all local air pollutant emissions are attributable to transport, conservative WHO estimates are that 3 million yearly deaths can be attributed to ambient air pollution in cities and towns worldwide) (Wiedinmyer, 2016 ${ }_{[60]}{ }^{16}$. The crisis has also seen a reduction in the number of people killed through crashes on the roads as a result of the large falls in traffic (ITF, 2020[61] $)$. However, the reduction in deaths has been less than proportionate to the reduction in traffic volume. In part this is accounted for by speeds that increased in decongested streets, underlining the importance of measures to manage speeds and enforce speed limits. Thus additional actions, including incorporating safe design standards when reconfiguring streets (see further discussion below), are needed.

\section{Mapping of selected recovery measures in surface transport}

To analyse transport recovery measures within the three stylised recovery pathways, this section employs the Avoid-Shift-Improve framework for mitigation actions in the transport sector, which is widely used (Bongardt Daniel and Swart Anthea, 2019[62]). Using these categories for each pathway, Figure 6 maps a selected number of recovery measures into Rebound, Decoupling and Wider well-being. The arrows in Figure 6 identify broad actions that can impact climate mitigation negatively or neutrally (dark/light orange) or positively (light/ dark green). The first arrow includes actions that are related to the "improve" objective, i.e. that have an effect on vehicle technologies (in the case of Rebound, measures would rather reinforce current technologies and hamper the shift to cleaner vehicle technologies - reflected by the dark orange in the arrow). The second to fourth arrows are related to "avoid" and "shift" effects, i.e. the shift from lowoccupancy private car to active modes, shared and high-occupancy trips and the avoidance of unnecessary trips and long distances. In the case of Rebound, measures would increase or reinforce barriers to modal shift and travel reduction, again reflected by the dark orange in the arrows).

The measures mapped here were selected after analysing measures announced by different countries (and cities). In some cases, additional ideas on how some of the measures could be implemented for Wider well-being are provided. For example, measures supporting the automotive sector with conditionality for improving vehicle technologies, but also adding requirements or incentives to increase shared, rather than private, mobility. ${ }^{17}$ In the same logic, support for charging infrastructure to foster the uptake of electrification as part of recovery measures would, if in line with a well-being approach, need to enable and be in line with the shift towards an increased role of active and shared (including public transport) mobility and the shift away from car dependency. Indeed, personal vehicle use reduction could require significantly less (Hsu, Slowik and Lutsey, 2020[63]) and different (Goetz, 2017[64]); (Transport \& Environment, 2020[65]) charging infrastructure than a future where private vehicle use remains along current trends; and so adapting investment accordingly will be important. Investing in a combination of slow and fast charging stations in optimal locations for sustaining shared fleets would be consistent with Wider well-being, although private home and work based charging points will still be necessary. (Transport \& Environment, 2020[65]) A charging masterplan to 2030 for Europe developed by Transport and Environment, uses this balanced approach. It sets as main priorities for charging plans to achieve full coverage of road networks, improve simplicity and transparency for consumers, implement smart charging to align charging with the

\footnotetext{
${ }^{16}$ Accounting only for PM2.5 and PM10 and not for Nitrous Oxides (NOx) or Ozone $\left(\mathrm{O}_{3}\right)$.

17 Sperling, Pike and Chase (2018[214]) establish that regulations and incentives to improve vehicle technologies (e.g. fuel efficiency standards) can be effectively linked to objectives for increasing shared and high-occupancy mobility. In the case of fuel efficiency standards, by awarding extra credit for the sale of vehicles used for passenger shared mobility services. The same logic could therefore be applied to measures envisaged for the recovery.
} 
generation of renewable electricity, and plan infrastructure "in the light of the need to reduce dependency on private cars" (Transport \& Environment, 2020[65])

Integrating land-use and transport planning is very relevant to the mitigation potential of the surface transport sector, particularly in the long-term but with significant implications for decisions taken in the short-term. As highlighted by (ITF, 2021 [66] $)$ road re-allocation and better urban planning are complementary. Measures that aim at better integrating transport and land-use are likely to take time to develop, however, as they may involve both national and local governments from multiple departments. Perhaps not surprisingly, recovery measures analysed have not in general shown a strong focus on explicitly improving integration between transport and land-use planning, though some do address road management improvement, namely through road re-allocation (see below). The way in which different plausible actions in this policy area could be categorised within the different pathways set out in this paper has also been included. A few examples of explicit measures to link transport and land-use planning that were found consistent with Wider Well-being, are provided. Other related examples, which attempt to avoid sprawl and undertake urban renovation (including social housing) in central areas are discussed in section 4. These will have relevant impact on the transport sector as well.

As pointed out in section 2 , a single country might use a mix of recovery measures within the transport sector that are not all aligned with the same pathway, potentially creating tensions and contradictions. Also, not all measures listed under a given pathway need to be implemented to achieve the aims of that pathway. Additionally, other measures not included in the figure could also be aligned with one or other of these pathways. Governments will need to adapt the framework and design measures in accordance with their specific context. The names of countries and cities that have implemented specific measures consistent with Wider well-being are shown in Figure 6, while Box 3 provides further detail on some of these cases. Where suggested or plausible, but not announced or implemented, measures are included and signalled by "*". The absence of this means that the measure described has been announced by one or more countries or cities. As shown in Figure 6, measures consistent with Wider well-being have so far been found mainly in OECD countries. Nonetheless, the approach is also relevant and could benefit developing countries, which in many cases are going through a phase of development that implies significant infrastructure investment Pressures to improve living standards might be even higher in developing, than developed, countries. So taking an approach that can enlarge synergies between climate and other goals (e.g. health, poverty alleviation, equity etc.) and better manage potential trade-offs between them can help ensure that meeting climate goals is not postponed or regarded as a second-order priority in these countries. Investment decisions could be greatly affected by the pathway chosen and they will have longlasting impacts on GHG emissions and the attainment of other well-being goals. 
Figure 6. Mapping of surface transport recovery measures according to the three pathways

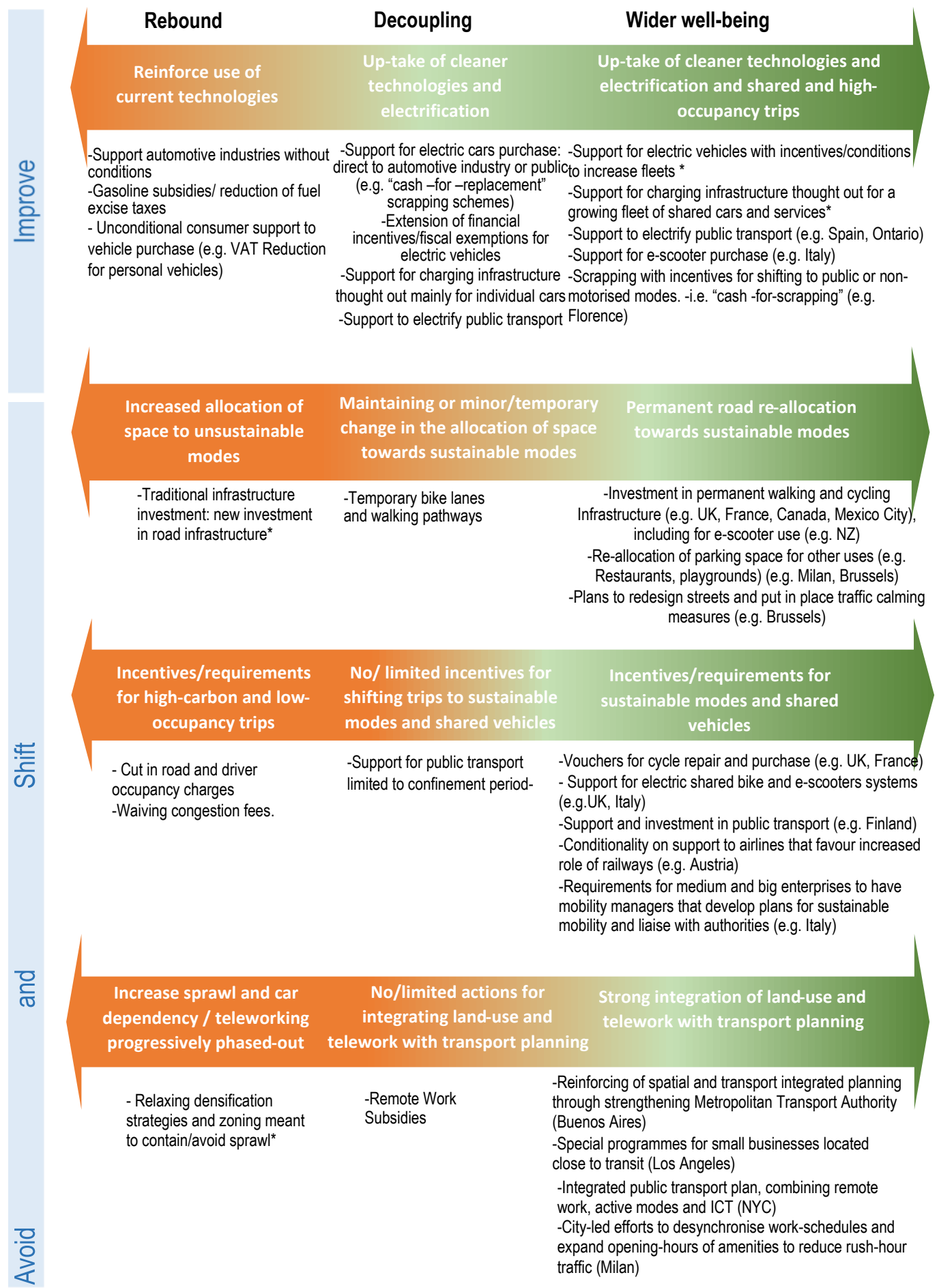

Note: Arrows indicate negative or neutral (dark/light orange) or positive (light/ dark green) impacts on climate mitigation. Suggested or plausible, but not announced or implemented, measures are denoted by "*”; all others examples reflect measures that have been announced or implemented by one or more countries. Analysis builds on measures announced by developed and developing countries from all world regions. The final balance in the Wider well-being example measures merely reflects the findings and is not based on any pre-selection or aim to focus on countries from a given region or level of development.

Source: Authors. 


\section{Rebound-type recovery measures: stimulating private car ownership and use}

Rebound will focus on boosting economic growth, jobs and disposable incomes by fostering the role for low-occupancy private vehicle ownership without introducing environmental conditionality (see some specific examples of measures below). The policy rationale behind a rebound approach is focused around physical movement (vehicle, passenger and ton-kilometres) and speed, as central performance indicators for the sector, and the belief that there is a positive correlation and virtuous circle between transport volumes and GDP (OECD, 2019[8]). Chapman $\left(2019_{[67]}\right)$ notes that policy directions for transport have historically been "expressed in terms of supporting mobility for economic growth, sometimes with social progress (including health) identified, but often with externalities such as climate change seen as a lower priority consideration". A focus on increasing transport volumes ignores the role of land-use and thus the trade-off between maintaining and or improving speeds of travel and creating a desirable spatial overlap of opportunities (jobs, education and consumption centres, etc.) and population (both of which need space).

Rebound has an overriding focus on cars - a fast ${ }^{18}$ but space-intensive mode - with a more limited role for public transport and a very limited or inexistent one for walking, cycling, or micro-mobility. These latter modes are overwhelmingly used for shorter but many times high-value trips that are not adequately reflected by metrics framed in terms of vehicle-kilometres and passenger-kilometres. As explained in (OECD, 2019 $\left.{ }_{[8]}\right)$, while transport volumes are necessary to understand emission drivers and demand trends, they are inadequate as measures of the ultimate performance of the sector. A Wider well-being approach (see below) would suggest instead the use of accessibility measures (e.g. number of opportunities that can be reached) to track performance and guide policy decisions (OECD, 2019[8]). Overall, Rebound will not have a focus on emissions reductions or reducing other social damage caused by the transport sector (e.g. air pollution, noise, social exclusion).

Indeed, Rebound-consistent measures analysed even include those that roll back policies and regulations to reduce emissions, or that support activities that actually increase $\mathrm{CO}_{2}$ emissions from transport (e.g. reducing fuel excise tax rates or introducing other fossil fuel subsidies ${ }^{19}$ ). Figure 6 also shows that planned recovery measures consistent with Rebound include incentives for the increased production or use of fossil fuel technologies as a way of boosting the economy, as well as tax reductions for vehicle purchase without any condition on emissions or fuel efficiency acquired. Increased incentives for car ownership (e.g. through VAT reduction- which is an example of a measure implemented in some places) can have some positive well-being benefits in terms of incomes for particular population and preserving jobs in the car manufacturing sector. However, especially if granted unconditionally, they may also jeopardise emissions reductions in line with agreed goals (contributing to an expansion of the car fleet, which in addition does not guarantee significant improvements in carbon intensity reductions). In addition these incentives tend to favour sectors of the population that are not the most vulnerable, while reducing the general tax base ${ }^{20}$.

\footnotetext{
${ }^{18}$ Despite high levels of congestion, cars continue to perform better than public transport in terms of the number of desired destinations that can be reached in a given time (ITF-OECD, 2019[227]). This is so even in European cities where public transport tends to be well developed relative to other regions, but the gap significantly grows if looking at the peripheries of cities, rather than the core (ITF-OECD, 2019[227]). In cities of developing countries the gap between cars and public transport tends to be even larger (ITF, 2019 [223]).

19 In many countries with fossil fuel subsidies, these already make up a significant share of government expenditures (OECD, 2018[218]) and in 2019, fossil fuel subsidies increased by $38 \%$ due to increasing oil prices (OECD-IEA, 2020[219]).

${ }^{20}$ Consumption subsidies are very costly and imply severe consequences for (already stressed) public budgets (OECD, 2018[218]).
} 
Rebound recovery measures may also increase the proportion of public space devoted to cars relative to more sustainable modes (public and active transport), for example by focusing infrastructure investments on road projects dedicated to car use. Other Rebound-type measures found support car ownership and use by (temporarily or permanently) waiving or reducing charges that reflect negative externalities of car use (e.g. congestion or driving charges). While not yet announced explicitly by any country, densification strategies and urban containment or zoning to avoid sprawl could theoretically be relaxed (Simard, 2020[68]).; (Gintrand, 2020[69]) Motivations might include boosting housing development projects in peripheral green field areas to meet potentially increased demand for open space due to experiences during lock-down.

Thus, from both a mitigation and well-being perspective, Rebound-type measures could put the sector into an even worse position than a pre-COVID Business-as-Usual (BAU) trajectory. For instance, by increasing the lock-in to carbon-intensive infrastructure that can further entrench inequalities (e.g. car dedicated infrastructure that contributes to induced demand ${ }^{21}$ ) and rolling back pricing frameworks for externalities (including but not limited to $\mathrm{CO}_{2}$ ). Under Rebound, even if emissions take some time to return to preCOVID levels due to economic slow-down, additional fuel subsidies and other measures discussed could contribute to a faster pace of increase in emissions; leading potentially to higher than BAU emissions as the economy recovers. This would have direct implications for local air pollution and related health impacts from increased demand for petrol, diesel, and other transport fuels, both by incentivising travel and reducing demand for energy efficient technologies (Health \& Environment Alliance, 2019[70]).

\section{Decoupling-type recovery measures: stimulating cleaner car ownership and use}

Decoupling for the transport sector also has a "supporting mobility for economic growth" mind-set. However, there would also be strong incentives for low-carbon mobility, with concomitant well-being benefits from a reduction in related environmental impacts (e.g. reduced air pollution and related improved health). By still focusing on mobility, Decoupling does not seek to transform transport systems with high (or rapidly growing) private, low-occupancy car use, disfavouring shared and active modes. Mitigation results, to a great extent, from improving the energy efficiency and reducing the carbon intensity of the vehicle (especially private) fleet, and of the fuels they use, fostering improvement of vehicle technologies, including electrification (plug-in and regular hybrids and Battery -BEV- and fuel cell -FCEV-). "Shift" and "avoid" type policies and measures have a smaller role than "improve", as significant travel reduction and modal shift will not be main drivers of mitigation in this pathway. The refocusing on low and zero carbon vehicles, in this pathway might still, however, bring significant job creation and expand the range of skills needed by the industry (Matchtech, 2016 $\left.{ }_{[71]}\right)$. It could, however, also pose risks to existing direct and indirect jobs linked to automobile manufacturing (IAO and Brandstätter, 2018[72]).

Measures consistent with Decoupling introduced so far include Improve-type measures like support for car ownership conditioned on a move towards cleaner technologies and fuels and for the improvement of vehicle and fuel technologies of public transport modes. Decoupling measures that do fall in the "Avoid" and "Shift" categories tend to be either: (i) temporary (e.g. temporary infrastructure for active and increased public transport services) rather than resulting in a permanent re-allocation of road-space; or (ii) of limited scope, e.g. incentives for teleworking without a direct link to increasing public transport capacity and planning.

Some measures consistent with Decoupling, such as scrapping schemes, based on a "cash-for replacement" model ${ }^{22}$ (first arrow in Figure 6) were also used to steer economic recovery after the 2009 financial crisis. Multiple ex-post evaluations of this specific measure highlight the need for careful

\footnotetext{
${ }^{21}$ Evidence exists that car-centred planning, based on a "predict-and-provide" approach (i.e. predicting traffic and providing road infrastructure accordingly) leads to additional car traffic (OECD, $2019_{[8]}$ ).

22 Where the old vehicle needs to be replaced by a newer one that has a cleaner technology.
} 
assessment of potential effects on multiple well-being objectives, e.g. allowing only replacement by the cleanest models of vehicles (electric) improves the mitigation outcome but may limit the "economic stimulus" objectives (e.g. jobs and value added for industry) because sales will not be as high (Oldenburger, 2009[73]). Overall, the cost-effectiveness of these schemes has been questioned (Miller,

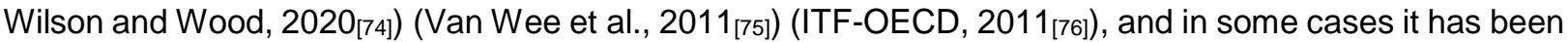
shown that these may have adverse consequences (IEA, 2020[77]). For instance, in some cases, these schemes have even prompted net increases in $\mathrm{CO}_{2}$ emissions (Klößner and Pfeifer, 2015 [78]) and regressive effects have also been found (Busse et al., 2012[79]). This should all be taken into account.

\section{Wider well-being type recovery measures: stimulating shared and active transport use along with cleaner vehicles and fuels}

Wider well-being shifts the focus from mobility to accessibility, the ease to reach opportunities and destinations. As described in (OECD, 2019 ${ }_{[8]}$ ) "in many cases, overall transport volumes (vehicle, passenger and tonne kilometres) can be high precisely because accessibility is limited, causing people and/or freight services to travel longer distances and incur higher expenditure on travel, while generating greater $\mathrm{CO}_{2}$ emissions and air pollution". ${ }^{23}$ For this reason, the shift from a mobility (and traffic) to an accessibility focus and its link to sustainable transport has been put forward in a number of studies and research in the field (ITF-OECD, 2019 $9_{[80]}$ ) (Silva and Larsson, 2017[81]) (OECD, 2019 $\left.{ }_{[8]}\right)$.

By combining proximity and mobility, an accessibility focus recognises that the creation of proximity between people and places is as important as the quality of transport connections. This assigns a high value to active, shared (including all modes of public transport), and micro-mobility transport modes that can contribute to an efficient use of space and that can contribute to reducing $\mathrm{CO}_{2}$ emissions and air pollution. Mixed use urban development and investment in mass transit to link centres of employment, commerce and housing are elements of the strategy. Designing proximity into urban development reduces travel distances, enlarging the scope for active transport and micro-mobility and contributing to lowering emissions.

An accessibility-based approach can also contribute to reducing emissions by better managing and designing space. For instance, a "complete streets" rationale brings a way of rethinking road space allocation and design; placing the emphasis on promoting safe access to all users, rather than on increasing vehicle travel speed (Perk, 2015[82]). It aims at safely balancing space between a diverse range of users and activities (Litman, 2015[83])ensuring the quality of the urban environment (including the provision of green and recreational space) while prioritising active and public transport modes as well as freight services relative to private car use. Although there is no one-size-fits- all design, main elements complete streets include prioritisation of space for pedestrian environment (i.e. sidewalks, crosswalks), implementing traffic calming measures, bicycle accommodation (i.e. protected or dedicated bicycle lanes) and dedicated space for public transport (i.e. Bus Rapid Transit (BRT), transit signal priority, bus shelters) (Litman, 2015[83]). Public transport can greatly improve opportunities for low-income populations and people with impaired mobility at the same time as improving the liveability of cities (Cervero, 2011[84]). Cycling is both an affordable mode of transport and contributes to health, both through reduced pollution and improved physical and mental health from increased physical exercise ${ }^{24}$ (ITF, 2013[85]), and increased life expectancy (Feder, 2020[86]).

Focusing directly on improving access to important destinations (rather than on transport volumes per se) can better secure well-being improvements. Focusing on enhancing accessibility also opens the door to

\footnotetext{
${ }^{23}$ The latter negative costs are of course not adequately reflected in GDP (and the health implications may even boost GDP through healthcare spending).

${ }^{24}$ Cycling, as a form of moderate exercise, can greatly reduce clinical health risks linked to cardiovascular disease, obesity, Type-2 diabetes, certain forms of cancer, osteoporosis and depression (ITF, 2013[85])
} 
large-scale emission reductions through reduced transport volumes, i.e. reducing travel and distances, and shifting trips to modes that provide access even when trips translate into lower overall transport volumes (e.g. active modes, micro-mobility). Consequently, a Wider well-being approach aims at transforming transport systems to make shared and active trips a high share of total trips and making "avoid' and "shift- type measures as central to climate mitigation action as "improve" type measures. While making use of pricing mechanisms, as mentioned in section 2, Wider well-being also recognises the limitations of pricing and also relies on actions such as the re-allocation and re-design of road space, results that would be difficult or even impossible to obtain if relying solely on road or carbon pricing. In addition, Wider well-being would place accessibility based analysis at the core of decision making and design of measures that would change relative prices of transport modes (e.g. using vulnerability indicators that combine income and levels of access through alternative modes of different population groups when assessing policy options) (OECD, 2019).

"Improve"-type measures in a Wider well-being approach remain an important and key component of climate mitigation strategies, but a balanced approach where these go hand-in-hand significant "avoid" and "shift" is argued for. Therefore, recovery measures consistent with Wider well-being (see Figure 6), would not only make support for the car industry subject to the adoption of cleaner technologies, like in Decoupling, but would also look to enhance accessibility and therefore support increased use of shared and high-occupancy modes of mobility. This would include for instance tailoring support for electric vehicle charging facilities to the shift away from car dependency and the higher role for shared mobility, through a balanced approach between private and public (both slow and fast) charging points. .

Measures consistent with Wider well-being also support electric vehicles others than cars, such as buses (e.g. Spain), e-shared bikes and scooters (UK). In the case of public transport, moves towards cleaner technologies or fuels beyond electrification would also be compatible with Decoupling. The difference being that, in Wider well-being, this might be done while also substantially expanding or improving services. In addition, if used (see discussion above on questions on their cost-effectiveness), scrapping schemes consistent with Wider well-being would be "cash-for-scrapping" schemes (as opposed to "cash-forreplacement" ones like in the Decoupling pathway). "Cash-for- scrapping" schemes provide support for other actions, such as using public transport or purchasing a bicycle, in exchange for the scrapping of an old vehicle, in addition to, or in place of, one-for-one replacement. . Schemes implemented in Canada (e.g. British Columbia) have shown this more flexible approach can yield much better mitigation, as well as health, safety and equity results (Antweiler, 2011 ${ }_{[87]}$ ) and cities like Florence have made this type of project part of its phase 2 package of measures for de-confinement (City of Florence, 2020[88]). Although again, cost-effectiveness of these schemes would need to be carefully assessed and compared with alternatives.

A number of measures consistent with Wider well-being also build on the re-allocation of road-space away from private vehicles that took place during the emergence from lock-down. In this period a number of cities introduced temporary infrastructure for active, public transport and shared sustainable modes (including micro-mobility) (ITF-OECD, 2020[48]). Some have now been made permanent and complemented by measures to re-design streets and calm traffic, leading to better conditions for both pedestrians and users of new sustainable modes (see for instance case study below on the "slow streets programme" in Brussels in Box 3). It is estimated that the shift of a 5-km trip from car to cycling or walking saves on average $747 \mathrm{~g} \mathrm{CO}_{2}$ (ITF, 2020[89]). In addition, redesigning streets and increasing pedestrian and cycling activity is associated with positive outcomes for local shops and businesses (Forbes, 2020[90]). There can be some concern that the re-allocation of road space in favour of active, public and micromobility transport modes can shift car traffic to other locations and increase car trip lengths and travel. However, conclusions from studies (for instance in a number of European cities) are that "traffic problems following the implementation of a scheme are usually far less serious than predicted; after an initial period of adjustment, some of the traffic that was previously found in the vicinity of the scheme 'disappears' or 'evaporates', due to drivers changing their travel behaviour; as a result the urban environment becomes 
more liveable in many respects" (EC, 2009 $\left.{ }_{[91]}\right)$. Nonetheless, communication and consultation efforts, as well as careful design, implementation and monitoring, are key to materialising benefits and avoiding unwanted negative effects (EC, 2009[91]).

The use of active, public and shared sustainable modes (e.g. a GBP 2bn package to expand cycling infrastructure in the UK and supplementary budgets for upgrade and expansion of public transport in Finland worth EUR 1.3bn) have also been identified as measures aligned with Wider well-being. In Italy, the national government has implemented new requirements for medium and big enterprises to introduce mobility managers, which need to develop plans for sustainable mobility and liaise with authorities (Gazzetta Ufficiale, 2020[92]). In Austria, conditions for airline support also favour an increased role for railways (Transport \& Environment, 2020[93]). In addition some measures to better integrate land-use and transport planning have also been identified. For example, special SME programmes have been introduced for businesses located close to mass transit (Los Angeles) and in some cases the strengthening of Metropolitan Transport Agencies has also been placed higher in the agenda (Buenos Aires - see Box 3). According to (ITF, 2020[89]) average household's transport demand (measured in vehicle-kilometres) could be reduced by between $5 \%$ and $12 \%$ due to a two-fold increase in the metropolitan residential density, and could even reach a $25 \%$ reduction if increased density is accompanied by other measures, e.g. mixed land-uses.

Finally, measures that seek to support teleworking, and build on this for optimising transport systems and ensure capacity and resilience have also been identified (Bloomberg City Lab, 2020[53]). Mitigation impacts from teleworking are not straightforward. Trade-offs between emission reductions from avoided commuting travel and activity at the work-place, and emission increases from energy use at the home can exist (IEA, 2020[94]), (Crow, 2020[95]). Impacts can be highly dependent on trip lengths and modes, with generally emissions dropping when car commuters telework, but increasing when public transport users do (IEA, $2020[94]$ ). Impacts can also depend on regions (as the potential share of jobs that can be done while working from home differ), and seasons (e.g. emissions from car users may be larger do that they use mobile air conditioning) (IEA, 2020[94]). In addition, non-commuting trips can off-set a large part the reduction in commuting trips (Hook, 2020[96]). For instance (Kim, Choo and Mokhtarian, 2015[97])finds that in the Metropolitan Region of Seoul, kilometres travelled by car, due to non-commuting trips, were significantly higher when the head of family commuting by car could telework, and when this was the only car in the household. Understanding all of these effects and planning public and other sustainable transport services to meet new travel demand trends would be necessary. . In addition, since public transport usage will be influenced by and perhaps even dependent on the ability to socially distance while travelling, public transport capacity will need to be more flexible to the changing patterns of demand (i.e. working with businesses within key areas of employment concentration to better understand changes in demand due to telework and deferred working schedules). In Milan, for instance, the city will engage in efforts to desynchronise work-schedules and expand opening-hours of amenities with the aim of reducing rush-hour traffic (Government of Milan, 2020[98]). Public bus services could provide such flexibility at the margin

\section{Comparing the pathways}

Overall as shown in Figure 6, measures in line with Decoupling will be better in terms of climate mitigation outcomes than those in Rebound. Nonetheless, Decoupling does not address the multiple strategies in a balanced way (i.e. having a much stronger focus on "improve", relative to "avoid" and "shift" type measures). It therefore misses a number of mitigation opportunities and can lock the system into a more emissions-intensive pathway, particularly in the first half of the century (where mitigation is particular important to avoid high risks from climate change). In other words, while Decoupling could achieve absolute decoupling through focusing on improving vehicle technologies, some modelling exercises (see below) suggest that the pace would be too slow to achieve international climate goals. This is because it is unlikely that very clean and electric vehicles and cleaner fuels, will be able to dominate the vehicle fleet in the first half of the century, even with increased efforts to promote technology change. Applying a Wider well-being 
approach speeds up emission reductions through "avoid" and "shift" effects, in parallel with promoting adoption of cleaner vehicles.

Looking at modelling exercises that reflect and contrast scenarios that mirror the principles established for the different approaches behind the recovery pathways for surface transport, as described in this paper is useful. Even when some of these exercises were developed before the COVID crisis, and they reflect longterm scenarios (for world urban transport and the UK respectively), rather than focusing on shorter-term actions and impacts, they provide insights into the type of future that might be associated with each of the three different stylised recovery pathways. For both exercises, Wider well-being shows greater chance of achieving Paris-compatible mitigation outcomes. These results can also be complemented by looking at more recent modelling exercises that take account for the COVID-19 crisis (see below), and that although not providing explicit scenarios that correspond to each pathway, they do provide insights on the role and need of improve, shift, and avoid strategies in reaching mitigation targets.

Table 1 compares the main results from two modelling exercises that reflect the main features of each of the three pathways. The first exercise, described in (Fulton et al., 2017[99]) and (Fulton, 2018[100]) develops alternative world urban transport scenarios to 2050. It assumes high automation in the transport sector and compares on the one hand, a scenario with accelerated electrification of private vehicles ${ }^{25}(\mathrm{EV})$, but business as usual trends in terms of transport and land-use planning, transport demand management, evolution towards shared vehicle use and public and non-motorised transport use. This scenario is called the 2 Revolutions scenario, and is comparable with Decoupling since it reflects an overriding focus of mitigation policy on improving technologies, while "shift" and "avoid" efforts remain second order strategies. An alternative scenario, the 3 Revolutions scenario, assumes that on top of accelerated automation and electrification there is also an accelerated transformation of the sector towards a higher use of shared ${ }^{26}$ and high-occupancy vehicles (including public transport), as well as walking and cycling (made possible due to urban space liberated by much lower car use). In this scenario, efforts to improve urban planning are also assumed to be significantly increased ${ }^{27}$. The balanced combination of improve, avoid and shift strategies would be consistent with Wider well-being. As seen in Table 1, a 3 Revolutions scenario brings deeper emissions cuts (76\% relative to 2015 ) compared to those in the 2 Revolutions scenarios (44\%), and thus increases the likelihood of being consistent with Paris Agreement goals.

In the IEA Energy Technology perspective scenarios, the 2 degree scenario (2DS) also includes detailed modelling on urban transport, incorporating a combination of policies that include higher fuel prices, and vehicle taxes, access restrictions to private vehicle use and low-emission corridors, as well as policies to incentivise compact development. These policies result in both significant shifts towards cleaner fuel sources (although hydrogen remains limited), in addition to a decrease $(-10 \%$ relative to 2015$)$ in car shares. The improvements in energy efficiency and the smaller car fleets are important drivers in total urban transport emission cuts, which are between $23 \%-31 \%$ by 2050 , compared to a scenario that would be consistent with a 6 degree temperature rise (6DS).

A further exercise, described in Brand et al. (2020[101]), was tailored for the UK. The modelling exercise tests multiple scenarios combining the banning by 2030 or 2040 of different type of vehicles, i.e. (i) combustion engine only; (ii) combustion engine and hybrid vehicles; and (iii) combustion engine, hybrid

\footnotetext{
${ }^{25} \mathrm{EVs}$ in this work include a range of vehicles, from electric minicars to plug-in hybrid sport-utility vehicles (Fulton et al., 2017[99]).

${ }^{26}$ Ride-hailing services, which are not used for ride-sharing are not included.

27 All three scenarios (BAU, 2R, and 3R) are modelled under the same population assumptions, taken from UN data and estimations indicating that the world urban population was 4 billion in 2015 and will reach 6.5 billion by 2050 .
} 
and plug-in hybrid vehicles. ${ }^{28}$ As expressed by the authors, banning policies "target improving the efficiency and carbon content of travel, not travel reduction or mode shift". Due to the dominance of improve-type strategies to increase mitigation potential, this scenario is compatible with Decoupling. A further Life-style scenario, reflecting shift and avoid effects as well, is also combined with different ban scenarios. The Lifestyle scenario shifts the focus from mobility to accessibility, with a resulting radical change in travel patterns, modal choice and occupancy levels. Due to this explicit change in focus and the balanced combination between avoid, shift and improve actions, scenarios combining bans and the Life-style scenario are in line with Wider Well-being. These scenarios, bring the largest emission cuts by 2050 (up to $86 \%$ relative to 2016 ) and place the sector within the carbon budget estimated by the authors for cars and vans (see Table 1).

In both the Fulton and Brand modelling exercises, the Business-as-usual (BAU) or reference scenarios can be considered in line with Rebound since they do not increase efforts to improve, avoid or shift. Although these scenarios (developed before the COVID-19 crisis) might in the short-run have higher emissions than is currently the case due to economic recession, they could plausibly be seen as a lower bound for a Rebound pathway. They simulate a continuation of pre-COVID trends and do not include any rollback of climate action or any measures that might further increase energy and carbon-intensity of transport.

A relevant point is that Wider well-being can also deliver better outcomes by having a much smaller vehicle car fleet in comparison to the other pathways (see car fleet comparisons in Table 1). For instance on air pollution and health outcomes, liberating important public space for other uses than car travel and parking, in addition to lower transport-related GHG emissions. As shown by different modelling exercises, penetration of low and zero-emission powertrain technologies such as electric vehicles-will take time, and smaller fleets and reduced car travel, regardless of the technology used, are significant contributors to lower GHG, pollution and health damage. In addition, electric vehicles have zero tailpipe emissions, but they are not completely neutral with regards to local pollutant emissions. Electric vehicles carry heavy batteries, and therefore can emit more particulate matter from non-exhaust sources, such as tyre wear, road surface wear and resuspension of road dust, than lighter vehicles (Timmers and Achten, 2016 ${ }_{[102]}$ ). These sources can account for relevant shares of PM2.5 and PM10 emissions. (Timmers and Achten, 2016[102])

In addition, smaller fleets also reduce the pressure on the demand for petroleum products and, in Wider well-being where motorised transport would be highly electrified, this can reduce the pressure on electricity demand as well as potential adverse effects of non-coordinated peak demand on electric grids. Moreover, shared mobility, which can lead to a reduced number of vehicles per capita on the road in the future ${ }^{29}$, has important synergies thanks to their high utilisation rates,-leading to better cost-effectiveness of technological change (Taiebat and Xu, 2019 $\left.9_{[103]}\right)$; (IEA, 2020 $\left.{ }_{[104]}\right)$ (Goetz, n.d.[105]). Fully materialising this potential will probably require overcoming some regulatory and infrastructure challenges, for example for optimised EV-grid integration (IEA, 2020[104]) and further innovations, for example in the fields of ultra-fast or even wireless charging, and smart charging (Taiebat and Xu, 2019[103]). Finally, although not modelled, analysis from both exercises reflected in Table 1, highlight that Wider well-being would significantly enlarge the scope and magnitude of other well-being benefits (e.g. mental and physical health, equity, system resilience, etc.) (Fulton et al., 2017[99]); (Fulton, 2018[100]); (Brand et al., 2020[101]).

New modelling from the IEA and the ITF, accounting for the COVID-19 crisis, also supports the need for shifting towards more balanced strategies, where demand management is significantly leveraged upon, along with vehicle technology and fuel improvements. The World Energy Outlook 2020 models a NZE

\footnotetext{
${ }^{28}$ Banning, especially of all vehicles other than fully electric or hydrogen - (iii) above, constituting a relatively strong "improve" type policy.

${ }^{29}$ As long as this is effectively incentivising shared trips and vehicles, and not low-occupancy ride-hailing services.
} 
2050 case that would reach net-zero $\mathrm{CO}_{2}$ emissions by 2050. It sets out additional measures that would be required to reach carbon neutrality by 2050 instead of 2070 (which the previous Sustainable Development Scenario-SDS- was in line with). The SDS incorporates ambitious shifts towards EV passenger car fleets (mostly fuel-cell but some hydrogen as well), and some shift in case of heavy-duty vehicles and trucks, and the extensive use of biofuels. Some behavioural changes (for instance, in the case of transport shifts towards public transport) are included in the SDS, but these are purposefully limited in both scale and scope, with the aim of showing what changes in the energy system solely could be consistent with the desired mitigation. The NZE 2050 attempts to illustrate a scenario in which, "behaviour changes are... essential to achieve the pace and scale of emissions reductions in the NZE2050, and they account for around 30\% of the difference in emissions between the SDS and NZE2050 in 2030" (IEA, $\left.2020_{[94]}\right)$ ). Among the behaviour changes assumed are those related to surface transport. Some of which are linked to shift and avoid effects: a) shift towards walking and cycling, b) working from home; while others result in fuel efficiency improvements due to better driving conditions or reduced use of appliances that increase fuel consumption: a) eco-driving, b) reduced speeds, c) increased temperature in cars. The need for these increased behavioural change is confirmed despite assumptions on increased progress towards better energy technologies and cleaner fuels (relative to those in the SDS). The NZE 2050 relies on higher shares of EVs and increased importance of hydrogen and advanced biofuel technologies. According to this analysis the latter two technology options (hydrogen fuel cell vehicles and biofuels) have degrees of maturity that vary, and are as of today only a small share of production and remain expensive.

The forthcoming ITF Transport Outlook 2021 models scenarios where ambitious climate policy would be undertaken through a comprehensive combination of avoid, shift and improve effects. The scenario that builds on the recovery to accelerate such process (Reshape + Scenario), as argued for in the Wider wellbeing pathway, brings the largest emission cuts by 2050 (-87\% relative to 2015 for urban passenger transport, $-73 \%$ for non-urban passenger transport -excluding aviation). The scenario assumes vehicle technology and fuel improvements in line with the IEA SDS scenario (see above), while also assuming low emission vehicles incentives and infrastructure investment in support of these vehicles. In addition, a number of policies to incentivise modal shift and higher occupancy are also modelled. These include car sharing, car-pooling and ride-sharing incentives, higher integration through Mobility-as-a-Service practices, urban vehicle restriction schemes and road and parking pricing, public transport priority measures (e.g. express lanes) and improvements, public and active transport infrastructure, and integrated ticketing. Urban development and design improvements are also central to the scenario, including through the assumption of densification strategies, Transit-oriented-development (TOD) (e.g. improvements in mixed-development). Thus while teleworking is also included, avoid effects are triggered through a comprehensive package of measures. In terms of non-urban passenger transport, some of the main measures included in the scenario are the significant development of ultra-high-speed rail and increase in rail service frequency and/or increase in operating speed. Ride-sharing and MaaS are relevant both to urban and non-urban passenger scenarios.

Results in term of accessibility are measured through estimating the time needed to go from the centre to the edge of a city by a given mode (for car and public transport). These results reveal that, while lowering the total travel demand growth (passenger-kms), the Reshape + scenario described above could improve accessibility by both car and public transport (as well as the relative competitiveness of public transport vis-à-vis the car ) compared to a scenario where only current and announced polices are implemented. This is a good illustration of the way in which strategies aiming at lower energy demand systems could indeed increase well-being at the same time as the likelihood for deep decarbonisation. 
Table 1. Scenarios mirroring the three different pathways and energy and carbon reduction potential

\section{Table 1.1. World urban scenarios}

\begin{tabular}{|c|c|c|c|c|c|c|}
\hline & \multicolumn{2}{|c|}{ Rebound } & \multicolumn{2}{|c|}{ Decoupling } & \multicolumn{2}{|c|}{ Wider Well-being } \\
\hline Corresponding scenario & \multicolumn{2}{|c|}{ BAU } & \multicolumn{2}{|c|}{$\begin{array}{c}2 \text {-Revolutions } \\
\text { (automation and } \\
\text { electrification with } \\
\text { dominance of private } \\
\text { vehicles) }\end{array}$} & \multicolumn{2}{|c|}{$\begin{array}{l}\text { 3-Revolutions } \\
\text { (automation, electrification shared-including } \\
\text { public transport, facilities for active transport and } \\
\text { integration of transport and land-use) }\end{array}$} \\
\hline Results & 2030 & 2050 & 2030 & 2050 & 2030 & 2050 \\
\hline $\begin{array}{l}\text { Energy demand (EJ) from } \\
\text { vehicle use } \\
\text { Relative to } 2015\end{array}$ & $+9 \%$ & $+49 \%$ & $-2 \%$ & $-9 \%$ & $-24 \%$ & $-58 \%$ \\
\hline $\begin{array}{l}\text { Vehicle use } \mathrm{CO}_{2} \text { emissions } \\
\text { (Mt) } \\
\text { Relative to } 2015(\mathrm{Mt})\end{array}$ & $+8 \%$ & $+50 \%$ & $-7 \%$ & $-44 \%$ & $-30 \%$ & $-76 \%$ \\
\hline Total vehicles on the road & - & 2.1 billion & - & $\begin{array}{r}2.1 \\
\text { billion }\end{array}$ & - & 0.5 billion \\
\hline $\begin{array}{l}\text { Alignment with Paris } \\
\text { Agreement } 1.5 \text { (according } \\
\text { to authors -assume } 50 \% \\
\text { emission reduction by } 2050 \\
\text { is consistent with } 1.5 \\
\text { degree target.) }\end{array}$ & \multicolumn{2}{|c|}{ No } & \multicolumn{2}{|l|}{ Maybe } & \multicolumn{2}{|l|}{ Yes } \\
\hline
\end{tabular}

Source: Authors, based on (Fulton et al., 2017[99]) (Fulton, 2018[100]

Table 1.2. UK scenarios

\begin{tabular}{l|r|r|r}
\hline & \multicolumn{1}{|c|}{ Rebound } & \multicolumn{1}{c|}{ Decoupling } & \multicolumn{1}{c}{ Wider Well-being } \\
\hline Corresponding scenario & Reference Scenario- & Car ban scenarios & "Life-style" (LS) combined with car \\
ban scenarios
\end{tabular}

Note: The difference in the ratio between car fleets in Decoupling and Wider well-being is much larger in the world scenario study. Many developing countries are still going through phases of rapid motorisation and population. Thus changes in the growth rate of vehicle ownership would translate in bigger differences than in the UK where in any case growth in vehicle fleet is relatively slow.

Source: Authors, based on (Brand et al., 2020[101])

The aims of Wider well-being entail more ambitious transformation than Decoupling. As such, some of the intermediate goals (e.g. enhanced urban planning, increased role and capacity of public transport, largescale road reconfiguration and re-design, etc.) take effect over long timeframes and need strong and continued action to bring their full benefits (the same is of course true of large scale electrification - as 
discussed above). Recovery measures consistent with Wider well-being can have a key role in paving the way for change. The case study of Brussels highlights how recovery measures were used to bring forward and accelerate the ambitious plan to shift Brussels out of car dependency (Bruxelles Mobilité, 2020[106]).

A challenge for Wider well-being is to address distributional and job/skills issues, e.g. those related to the car manufacturing sector, and to avoid to the greater extent possible any other potential trade-offs between climate and other well-being impact. Overall, an advantage of framing policy directly around well-being (as in Wider Well-being) is that analysis of the implications of measures (including compensatory measures) for different income and social groups becomes a core feature of the approach (Chapman, 2019[67]). Nonetheless, recognising these challenges (some of which are discussed next) is relevant. For instance, even if car manufacturing remains vibrant, the shift to low-carbon vehicles is likely to require different skills (IAO and Brandstätter, 2018[72]); a challenge shared by both Decoupling and Wider Well-being. ${ }^{30}$ Electrification can create job opportunities indeed, but this requires the manufacturing industry to diversify and adapt, e.g. battery manufacturing and charging infrastructure services. Both of which, have high employment multipliers (IEA, 2020[107]).

The extent to which the industry might need to adapt might be greater in Wider Well-being, since on the one hand jobs linked to vehicle manufacturing would still be needed, as systems would need less vehicles but vehicle turnover would be higher (off-setting some of the impact on sales) (Price Waterhouse Cooper, 2018[108]). But automotive manufacturers would potentially also engage in other type of economic activities, such as fleet operation or software development, which could also become a significant source for job creation but may also change the required skills of employees (Mc Kinsey, 2020[109]) (Mc Kinsey, 2017 [110]).

An approach based on accessibility can also create significant levels of employment, in other ways. Jobs in public transport, generated in $2013^{31}$ almost as many jobs as the car industry today - 13 versus 14 million globally (UITP, 2013[41]) (ILO, 2020[40]) and this number could grow significantly if the role of public transport is expanded and strengthened, particularly in contexts where it is currently limited. Evidence from the US during the 2009 recession indicates that investment in public transport infrastructure generates $31 \%$ more jobs for every dollar spent than the construction of roads and bridges. In Korea, $15 \%$ of jobs generated through the 2009 recovery package came from investment in public transport, cycling and railroads (Avellada, 2020[111]). Other jobs could come from bicycle manufacturing and repair, and infrastructure development for walking and cycling, which have high employment factors (IEA, 2020[107]), and jobs in companies providing shared mobility. Policies and plans to upgrade and expand active and public transport infrastructure can have important employment benefits that go beyond infrastructure construction. The development of complete streets (discussed above) for instance has demonstrated to bring positive impacts in terms of increased property values, tax collections, and increased business activity (e.g. creation of new businesses and jobs) ( (Perk, 2015[112]).

Wider well-being type measures can bring significant benefits, in addition to GHG mitigation, as they are framed around increasing accessibility and thus bring together a number of agendas (OECD, 2019 ${ }_{[8]}$ ). Nonetheless, this does not mean that benefits will come automatically and careful analysis and design is needed to avoid specific trade-offs that could arise. For instance, while safety improves with increased space allocation to walking and cycling, safe design (e.g. signalling at crossing, cycle boxes ${ }^{32}$ ) (Future

\footnotetext{
${ }^{30}$ Focused opposition to policy changes by a relatively small affected group may be able to stymie changes that bring much larger, but more widely distributed benefits (Vogt-Schilb and Hallegatte, 2017[220]) (Trebilcock, 2014[221]).

${ }^{31}$ No updated number was found.

32 Designated area at the head of a traffic lane at a signalized intersection that provides bicyclists with a safe and visible way to get ahead of queuing traffic during the red signal (Future Place Leadership, 2017[113])
} 
Place Leadership, 2017[113]), and an overall "safe system approach"33 (WRI, 2018[114]) needs to be at the core of space re-allocation to ensure safety benefits and avoid negative impacts. Ensuring safety when introducing micro-mobility options will need to be addressed. ${ }^{34} \mathrm{~A}$ number of principles for doing this have been drawn from experience in different contexts, e.g. in (ITF, 2020[115]).

While in principle the shared use of micro-mobility services has the potential to yield mitigation benefits, reduced emissions from the increased role of these transport modes can be off-set or even become negative if servicing is done with high polluting vehicles and involving long distances. Short vehicle life span and high shares of trips shifted from public transport can also jeopardise mitigation potential (de Bortoli and Christoforou, 2020[116]). Another important consideration is that social inclusion and equity are improved by increased accessibility through sustainable modes as a result of street reconfiguration or an expansion of public transport infrastructure that enhance social contact and employment access, etc. (Sauter and Huettenmoser, 2008 $\left.{ }_{[117]}\right)$. However, equity issues might arise if pilots and projects are concentrated in richer areas or do not anticipate potential gentrification from increase land-value prices. New standards for complete streets are increasingly including equity parameters to try to mitigate gentrification risks (Fast Company, 2017[118]).

Overall, the mapping of measures against recovery pathways highlights the range of options that governments have to adopt a Wider well-being recovery in transport. The example of street reconfiguration confirms that at least some Wider well-being measures do not have to imply high capital costs. The cost of adapting road infrastructure to provide improved walking and cycling infrastructure is estimated between USD 6,250-31,250 per km. At the same time studies in the UK have estimated that social benefits in terms of reduced adult mortality brought about by 1 GBP invested in such efforts are around 2.59 GBP (ITF, $2020[89])$. Indeed low-, medium- and high-cost measures could all be part of each of the recovery pathways.

For Wider well-being, the case for significant investment in public transport as part of the recovery is an important and a necessary complement to street reconfiguration. This investment will imply higher up-front costs, but also has high returns in terms of climate and well-being outcomes, including job creation (UITP, $\left.2013_{[41]}\right)\left(\mathrm{WRI}, 2^{2020_{[119]}}\right.$ ), In addition, when comparing the cost of different infrastructure per throughput (i.e. capacity) infrastructure for car use can have higher costs. For instance, a dual highway has a capital cost (USD/km) per capacity (persons/hour/direction carried) that ranges between USD 5,000 and USD10,000 and an urban street used solely for cars a cost between USD 5,000-USD 7,000. Metro rail and commuter rail (the two forms of public transport with the highest capital cost) has a capital cost per capacity of USD 2,000-USD 5,000 and USD 2000 respectively (IEA, 2020[120]). Other forms of public and active mode infrastructure have lower capital cost per capacity: Bus rapid transit costs between USD 200 and USD 250; bus lanes between USD 300 and USD 500; bicycle lanes USD 30, and pedestrian walkways USD 20 respectively (IEA, 2020[120]). Moreover, estimates of the cost of the three world scenarios shown in Table 1 indicate that the substantial investment in public transport and walking and cycling infrastructure needed in Wider well-being is likely to be more than compensated by savings from lower road construction, car ownership and energy costs (Fulton et al., 2017[99]).

\footnotetext{
${ }^{33}$ Safe System is based on the underlying principles that: human beings make frequent mistakes that lead to road collisions; the human body by nature has a limited ability to sustain collision forces with known tolerance to injury thresholds; and it is a shared responsibility between stakeholders (road users, road managers, vehicle manufacturers, etc.) to take appropriate actions to ensure that road collisions do not lead to serious or fatal injuries (PACTS, 2020[222])

${ }^{34}$ Such as for pedestrians vis-à-vis the e-scooters and e-scooter users vis-à-vis other modes like cars and buses.
} 


\section{Box 3. Case studies of selected Wider Well-being pathway compatible measures}

\section{National funds in support of walking, cycling and micro-mobility in the UK}

In facilitating for the transformation of urban transportation systems, the Department for Transport (DfT) has fast-tracked a pre-existing national agenda to overhaul bus and cycle links as well as to promote electrification. The £2bn package (part of £5bn in spending announced in February) is focused on stimulating the shift to active modes through providing additional incentives to individuals (e.g. £50 bikerepair voucher estimated at $€ 28 \mathrm{mn}$ ) and support for local authorities to make temporary pop-up infrastructure permanent (e.g. $240 \mathrm{~km}$ of protected bicycle tracks estimated at $€ 300 \mathrm{mn}$ or $€ 4,8$ per person). Well-being aspects are mainstreamed as GPs are mandated to prescribe biking as a healthimproving measure, a new national rental e-bike scheme will have discounted rates for those with preexisting conditions, and employers are encouraged to take on the "Cycle-to-work scheme". Mainstreaming allows to reduce emissions from the transports while attaining other objectives such as improving public health, work-life balance, crowding in public transports and congestion on the roads.

\section{Strengthening of Buenos Aires' Metropolitan Transport Agency - Argentina}

The metropolitan transport agency in the Buenos Aires Metropolitan Area (AMBA) aims at better managing transport services in the City's 43 municipalities (Ministerio de Transporte, 2020[121]). The crisis, has exposed the shortcomings of the agency in terms of planning, financial capacity and legal and institutional structure (Raffo, 2020[122]).Strengthening the institution has been identified as an important step for better integrating transport and land-use policy and solving a number of persistent challenges, such as rapidly increasing motorcycle and car ownership and travel, poor road safety, (Ministerio de Transporte, 2020[121]) and rebalancing road space allocation and design in favour of sustainable modes; all of which could importantly advance the equity and environmental agendas (Raffo, 2020[122]).

\section{Brussel's "Slow Streets" Programme and investment in additional bike-lanes - Belgium}

The Mobility Minister of the regional government of Brussels has endorsed a strategy of "tactical urbanism" to seize the opportunity presented by the crisis to implement measures to advance its longterm plan for sustainable urban transportation. Throughout confinement, the regional government has supported municipalities to create zones de rencontre, city-streets where the speed limit is set at 20 $\mathrm{km} / \mathrm{h}$. This is one of many complimentary measures such as biking infrastructure, and slow street instauration, which has contributed to reducing traffic by $20 \%$ below pre-confinement levels and reduced crowding on public transport. In a move to support population who will not be able to go on holiday and the development of neighbourhoods, the "Brussels en Vacances" programme provided small loans $(€ 2000-€ 15000)$ to reconfigure space in the city in an appealing way ahead of summer holidays. The regional governments hopes are that in rolling out these changes to improve well-being in the city, also serves to showcase its "Good Move" strategy and contributes to further strengthen long-term political support for continued action.

Source: Authors 


\section{Overview of recovery measures in the residential sector according to the three pathways}

This section maps recovery measures for the residential sector into the three stylised recovery pathways as done above in section 3 for surface transport. This sector was chosen since it is an important source of direct and indirect GHG emissions (see below), relates intimately to a range of well-being outcomes and governments have historically used investment in the construction and retrofitting of housing as a stimulus measure to recover from previous economic crises (e.g., the Great Depression in the 1930s and the financial crisis in 2007-2009). Public investment can directly stimulate demand and job creation, compensating for reduced private sector and household spending in this area.

The way buildings and the surrounding environment (e.g., density, presence of green and blue spaces, natural environment, physical location) are designed will determine the future trajectory of energy-related $\mathrm{CO}_{2}$ emissions needed for services inside the dwelling (e.g., lighting, cooling, heating). Buildings were responsible for approximately $26.4 \%$ of global $\mathrm{CO}_{2}$ emissions from fuel combustion in 2018 (with heat and electricity allocated to consuming sectors); the residential sector accounted for $16.6 \%$ of global $\mathrm{CO}_{2}$ (approximately $5.572 \mathrm{MtCO}_{2}$ ) whilst commercial made up the rest (IEA, 2020[42]). This, however, does not account for a building's lifecycle emissions, of which nearly 10 to $20 \%$ emerge from its construction, renovation and demolition (WorldGBC, 2019 $9_{[123]}$ ). Even though, there have been improvements in the energy efficiency of dwellings in the last decade, these improvements have been insufficient to offset the unrestrained growth in floor area globally (IEA, 2020[124]]). In addition, energy demand for heating and cooling has already tripled from 1990 to 2016, growing faster than other end use in buildings (OECD/IEA, $\left.2019_{[8]}\right)$. Current and announced policies will likely lead to a tripling of global energy demand for space heating and cooling by $2050,70 \%$ of which will be from the residential sector (OECD/IEA, 2019 ${ }_{[8]}$ ), especially since the climate will continue to warm for decades to come even if stringent mitigation goals are achieved later in the century.

The residential sector not only essential to the low-carbon transition, but to public health (e.g., indoor air quality, sufficient space), safety, security, comfort, affordability, jobs and equity. For example, around 9-30 jobs in manufacturing and construction would be created for every million dollars invested in retrofits or efficiency measures in new builds (IEA, 2020[124]). Construction jobs would benefit employment locally, whilst manufacturing jobs would be more global for the industrial sector, as a whole, because of increasing demands for building materials and equipment (e.g., insulation, heat pumps) (IEA, 2020[124]).

Urban density is as important as efficiency improvements in determining energy needs for a dwellings' heating and cooling requirements (Güneralp et al., 2017 $[125])$. Nevertheless, prior to the pandemic, housing was developing in unsustainable ways. Overly dense urban forms emerge without sufficient green spaces, sprawling suburban housing develops on the periphery, while other territories show a combination of the two (OECD, 2018[126]). Either way of developing the built environment can boost energy demand in dwellings for services; dense areas without green space from greater cooling needs due to urban heat 
island effects and sprawled development from lower densities (Güneralp et al., 2017[125]; Lee and Lee, 2014 $4_{[127]}$; Wamsler, Brink and Rivera, 2013[128]; Jones and Kammen, 2014 $\left.{ }_{[129]}\right)$. These urban forms, in turn, have enormous repercussions for transport emissions and the potential options for mitigation in the sector (OECD, 2019 $\left.{ }_{[8]}\right)$. The built environment (i.e., the neighbourhoods and cities in which a dwelling is embedded) is critical for well-being, since it enables people to live, work, and carry out daily activities in safety, security and comfort - or threatens these if degraded or has poor functionality. This aspect has been reinforced by cities' experience with COVID and green spaces will increasingly be needed to help regulate microclimates with increasing urban density as well as to provide safe breathing space for citizens.

The rest of this section examines a range of recovery measures related to surface transport and the residential sector against the three stylised recovery pathways set out in section 2 . The analysis in this section is qualitative and therefore indicative of what the implications for emissions and well-being could be (similar to section 3 on surface transport). More detailed quantitative analysis taking into account the specific context would be required for policy evaluation in specific contexts.

\section{Using the recovery to accelerate climate action in the residential sector}

During the "lockdown" in 69 developing and developed countries ${ }^{35}$ at the first peak of the COVID-19 pandemic, people spent vast amounts of times inside their homes and many are continuing to do so during the second wave. This led to higher energy usage in the residential sector during the first lockdowns (IEA, $2020[130])$. In the last week of March and first week of April, residential electricity demand was $40 \%$ higher across certain European economies than in the same weeks in 2019 (IEA, 2020[130]). This trend persisted well into the summer of 2020 (Liu et al., 2020[131]). Similar dynamics were observed outside Europe, for example, residential energy demand grew in Philippines, Malaysia, and Singapore substantially during lockdown (but this did not offset the decreased commercial demand during the lockdown period) (Lowder, Lee and Leisch, 2020[132] $)$. Millions continue to spend the majority of their time in their homes. Expert opinion suggests that $25-30 \%$ of the global workforce will continue to work from home multiple days of week until the end of 2021 (Global Workplace Analytics, 2020[133]). The ability to do this, however, depends on whether the work is manual, requires face-to-face interaction, the use of Internet Communication Technologies, and internet connectivity at-home (Hatayama, Viollaz and Winkler, 2020[134]). For example, the types of employment in Mexico, Peru, Ecuador, and Turkey have low amenability to work from home, compared to those with the highest like - Norway, Finland, Belgium, and Netherlands - according to a recent analysis at the World Bank (Hatayama, Viollaz and Winkler, 2020[134]).

This extra time spent at home heightens the need for quality dwellings in both developing and developed countries, especially given the second waves occurring globally. There are many aspects of an ideal high quality dwelling. These include sufficient living space (e.g., floor area, number of rooms); adequate services inside with temperature regulation, adequate light, high indoor air quality, satisfactory ventilation, and clean cooking fuels; along with proximity to quality neighbourhoods (e.g., green spaces, location efficient housing with access to services and opportunities). The quality of dwellings varies across the globe. In the developing world, 860 million still lack access to electricity (IEA, 2020[124]), 4.2 billion people lack safely managed sanitation services (United Nations, 2020[135]), and 2.6 billion have no access to clean cooking solutions (IEA, 2020[124]). Close to 1.02 billion people lack access to cooling and are unable to

${ }^{35}$ Countries with national lockdowns between March and June 2020 include: Albania, Argentina, Australia, Austria, Azerbaijan, Bangladesh, Barbados, Bermuda, Bolivia, Botswana, Colombia, Republic of Congo, Costa Rica, Croatia, Czech Republic, Ecuador, El Salvador, Eritrea, France, Georgia, Germany, Greece, Guernsey, Honduras, Hungary, India, Iran, Iraq, Ireland, Italy, Jordan, Kosovo, Kuwait, Lebanon, Libya, Lithuania, Malaysia, Mexico, Mongolia, Morocco, Namibia, Nepal, New Zealand, Pakistan, Panama, Papua New Guinea, Paraguay, Peru, Poland, Portugal, Romania, Russia, Rwanda, Samoa, San Marino, Serbia, Singapore, South Africa, Spain, Sri Lanka, Thailand, Trinidad and Tobago, Tunisia, Ukraine, United Arab Emirates, United Kingdom, Venezuela, Vietnam, and Zimbabwe. 
regulate their thermal comfort, either due lack of electricity in rural areas or insufficient incomes to buy or run a fan in urban areas (SEforALL, 2020[136]). Between 2000 and 2014, the proportion of the urban population living in slums declined from 28 to $23 \%$. However, this trend recently reversed course growing back up $23.5 \%$ in 2018 (UN, 2020 [137]).

These basic needs may be met in developed countries, but even in these countries, the pandemic has exposed latent disparities in society with respect to the quality of dwellings and their surroundings and how it is embedded in the fabric of the wider urban, social and natural environment. The lockdown illustrated how easy it is for low-income households even in developed countries to fall into energy poverty; more time at home led to higher energy bills, at times combined with temporary or permanent unemployment, which was further exacerbated by the fact that these households tend to live in lower quality and less efficient dwellings (Bouzarovski et al., 2020[138] $)$. For those whose movement was geographically restricted during the lockdowns, individuals who lived in quality neighbourhoods - with easy access to a diversity of services, like nature and green spaces, were less disadvantaged than those who did not have access to such opportunities (with respect to physical and mental health). Many more affluent city dwellers left urban environments during lockdown for better conditions (more space or gardens 1 ; this was not necessarily a possibility for those who were worse off.

The types of measures used in the housing sector could follow a Rebound, Decoupling, or Wider wellbeing (see section 2). The pathway chosen will have great implications for the future trajectory of GHG emissions from the residential sector and well-being in both the shorter and longer-term, as discussed below.

\section{Mapping of selected recovery measures in the residential sector}

Figure 7 maps examples of recovery measures in the residential sector to the three pathways (Rebound, Decoupling, and Wider well-being) drawing on real-world examples at both national and sub-national level. The recovery measures are grouped into three main categories (labelled in blue on the left-hand side), which reflect three major foci for potential mitigation action and well-being outcomes. These are:

- new builds (measures aimed at the construction of new homes),

- retrofits (measures modifying existing dwellings), and

- beyond the dwelling, which includes measures aimed at better spatial planning and the integration of housing with man-made and natural infrastructure.

Each of these three areas of focus is accompanied with an arrow in Figure 7. The labels within the arrow describe the types of measures that each pathway would include. The potential impact on mitigation is visualised by the colour gradient of the arrow from orange (negative or neutral impact on GHG mitigation) to green (positive effect on mitigation).

As in the transport sector (see section 3), the package of recovery measures for the residential sector in a given country could comprise a mix of measures that align with different pathways. Moreover, subnational governments may employ measures that follow different pathways than at the national level. In fact, several examples in Figure 7 draw on the subnational level. Governments will need to adapt the frameworks and design specific measures in accordance with their specific context, and not every government will need every single measure listed under a given pathway. The names of countries and cities that have implemented measures consistent with Wider well-being are shown in Figure 7, which provides further detail on some of these cases.

As shown below, measures consistent with Wider Well-being have so far been found mainly in OECD countries, which started developing recovery measures earlier than many developing countries, reflecting the spread of the pandemic. Nonetheless, the approach remains relevant and could benefit developing 
countries since many are going through phases of development that imply significant infrastructure investment. This is, in addition, to significant pressure to improve living standards. Therefore, taking such an approach to enlarge synergies between climate and other goals (e.g. health, poverty alleviation, equity etc.) and better manage potential trade-offs between them can help ensure that meeting climate goals is not postponed or regarded as a second-order priority.

Figure 7. Mapping of residential sector recovery measures according to the three pathways

\begin{tabular}{|c|c|c|c|c|}
\hline \multirow[b]{3}{*}{$\frac{\frac{\infty}{0}}{\frac{D}{3}}$} & 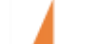 & Rebound & Decoupling & Wider well-being \\
\hline & & $\begin{array}{l}\text { mes without regard to energy } \\
\text { usage/embodied carbon }\end{array}$ & $\begin{array}{c}\text { Energy efficient homes (often } \\
\text { prescriptive rather } \\
\text { performance) }\end{array}$ & $\begin{array}{l}\text { State-of-the-art homes in line with } \\
\text { those of net-zero passivestandards } \\
\text { (performance-based) }\end{array}$ \\
\hline & $\begin{array}{l}-S \\
\text { sti } \\
\text { ne } \\
-A \\
\text { inf } \\
\text { ho } \\
- \text { - } \\
\text { on }\end{array}$ & $\begin{array}{l}\text { Support for home building: to } \\
\text { timulate the building market for } \\
\text { lew hom es Iow-value homes } \\
\text { Aoceleration of existing } \\
\text { nfrastructure projects for additional } \\
\text { lousing } \\
\text { Reimbursement of VAT of labour } \\
\text { in residential construction sites }\end{array}$ & $\begin{array}{l}\text { - Building municipal housing sites } \\
\text { with "energy efficient" apartments } \\
\text { - Call for proposals on energy } \\
\text { efficient housing that can be buit in } \\
\text { an emergency }\end{array}$ & $\begin{array}{l}\text { - Building affordable housing in } \\
\text { sustainable and liveable } \\
\text { neighbourhoods (e.g., Lis bon, } \\
\text { Portugal) } \\
\text { - Updating building codes to be in } \\
\text { line with state-of-the-art standards } \\
\text { (e.g., Seoul, Korea) }\end{array}$ \\
\hline & R & $\begin{array}{l}\text { Renovations to the design or } \\
\text { quality of building-energy } \\
\text { efficiency is not the focus }\end{array}$ & $\begin{array}{c}\text { Shallow retr ofits (piecemeal } \\
\text { improvements), only energy } \\
\text { usage }\end{array}$ & $\begin{array}{l}\text { Deep retrofits (holistically } \\
\text { improve the quality of the } \\
\text { dwelling) }\end{array}$ \\
\hline \multirow[t]{2}{*}{ 趈 } & & $\begin{array}{l}\text { - Infrastructure investments to } \\
\text { renovation schools, government } \\
\text { buildinas and schools } \\
\text {-One-vear investment incentives for } \\
\text { home renovation and construction }\end{array}$ & $\begin{array}{l}\text { - Tax reductions for more energ. } \\
\text { efficient heat pumps } \\
\text { - Grants to im prove dweling's } \\
\text { energy efficiency } \\
\text { - Subsidies for on-site solar PVs }\end{array}$ & $\begin{array}{l}\text { - Improve the energy efficiency of } \\
\text { buildings first to lower energy dem and } \\
\text { and then shift the energy source } \\
\text { towards renewables (e.g., Austria) } \\
\text { - Retroft housing for low-income } \\
\text { communities and provide training as } \\
\text { well as jobs to vulnerable groups (e.g., } \\
\text { Cape Town, South Africa) }\end{array}$ \\
\hline & & $\begin{array}{l}\text { Incentivising low-density } \\
\text { sprawling cities without } \\
\text { infrastructure upgrades } \\
\text { or impacts on ecosystems }\end{array}$ & $\begin{array}{l}\text { No incentives for creating } \\
\text { ompact cities or incorporating } \\
\text { natural solutions }\end{array}$ & $\begin{array}{l}\text { Guiding the growth of cities to be } \\
\text { compact and resilient with upgrades } \\
\text { infrastructure and maintaining/restoring } \\
\text { natural ecosystems }\end{array}$ \\
\hline 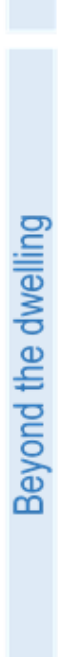 & 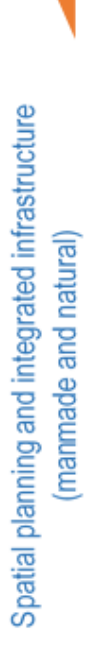 & $\begin{array}{l}\text { - Fast-tracking building permit proc } \\
\text { homes without any stipulations for t } \\
\text { energy usage or embodied carbon } \\
\text { dwellings } \\
\text { - Incentiving the purchase of hom } \\
\text { outside of urban cores } \\
\text { - Poorly integrated infrast ructure at } \\
\text { for buildings homes } \\
\text { - Incentivising the purchase of hom } \\
\text { outside of urban cores }\end{array}$ & $\begin{array}{l}\text { cess for } \\
\text { the } \\
\text { in } \\
\text { me } \\
\text { above } \\
\text { me }\end{array}$ & $\begin{array}{l}\text { - Increasing green spaces by } 50 \% \text { in } \\
\text { Freetown, with neighbourhoods and } \\
\text { providing jobs (e.g., Freetown, Sierra } \\
\text { Leone) } \\
\text { - Green New Deal includes transformation } \\
\text { of urban areas into smart green cities, } \\
\text { initiatives for landscape and watershed } \\
\text { management, ecosystem restoration, and } \\
\text { sustainable management of forests (e.g., } \\
\text { Korea) } \\
\text { - Offering em ployment by planting trees } \\
\text { (e.g., Pakistan) } \\
\text { - A tax credit of up to } 14 \% \text { for climate- } \\
\text { friendly investments, which includes natural } \\
\text { ecosystems (e.g., Austria) } \\
\text { - Rezoning to allow for mixed land use } \\
\text { developments - i.e., comm ercial, and } \\
\text { residential - and urban infill for housing in } \\
\text { dilapidated downtown core (e.g., Australia) } \\
\text { - Building greater capacityto recover and } \\
\text { recycle valuable resources from waste at } \\
\text { facilities that would otherwise have been } \\
\text { sent to landfill, } 130,000+\text { tonnes of } \\
\text { materials recovered from household waste } \\
\text { every year (e.g., Australia). }\end{array}$ \\
\hline
\end{tabular}

Note: Arrows indicate negative or neutral (dark/light orange) or positive (light/ dark green) impacts on climate mitigation. Analysis builds on measures announced by developed and developing countries from all world regions. The final balance in the wider well-being example measures merely reflects the findings and is not based on any pre-selection or aim to focus on countries from a given region or level of development. Source: Authors 


\section{Rebound-type recovery measures: Stimulate construction}

As seen in Figure 7, Rebound is primarily driven by stimulating short-term growth and employment opportunities in the labour-intensive construction sector, with no focus on early emissions reductions (as discussed in section 2). The guiding principle for housing under this pathway is "access to shelter" rather than the quality of the dwelling (e.g., space, thermal comfort, and indoor air) or its surrounding environment (e.g., access to green spaces and integration with existing infrastructure). In addition, a rebound-type logic does not incorporate efforts to shift towards a full-cost accounting rationale. This means that private and short-term costs are given higher priority than wider well-being costs and benefits, especially those that increase in the mid and longer-term (e.g. jobs, health, equitable opportunities, etc.). Measures in Rebound (the left-hand side of the arrows) rely on stimulus measures for residential construction in order to jumpstart the economy, e.g. via public procurement and grants and subsidies to homeowners, without embedding environmental considerations beyond meeting local building regulations in these measures. However, such measures could increase emissions over medium and longer-term, both from embodied carbon (e.g., from the materials used), by locking-in future energy usage from low quality building envelopes (e.g., walls, roof, insulation), and omit the density and quality of the neighbourhood beyond the dwelling that affect dwellings' energy usage - e.g., micro-climates and green spaces (as seen under Rebound and Beyond the Dwelling in Figure 7).

To decrease hurdles to construction, rebound-type measures also include fast-tracking building permit approvals often without any reported environmental conditionality, prolonging the length of existing permits, or even adjusting the conditions for building (e.g., extending the hours of the day in which construction sites can be open). In previous crises, construction companies have struggled to book projects throughout the crisis and in the post-crisis construction boom try to acquire as many projects as possible (Scalisi, 202 [139] . This is already happening in response to the COVID-19 crisis. In attempt to win contracts underbidding for government tenders is pervasive (i.e., governments are receiving tender bids below realistic estimates for cost) (RICS, 2020[140]). This could lower the quality of the dwellings constructed; meaning the quality of dwellings is only as high as the building code locally.

\section{Decoupling-type recovery measures: Stimulate construction in low-carbon and energy efficient housing}

Decoupling aims at fostering growth and providing "access to shelter" while also decreasing emissions from energy use, with the long-term aim of absolute decoupling. Measures that could fall under Decoupling are those that increase the supply of energy efficient dwellings (i.e., those that have the potential to lower energy usage when compared to conventional builds) and promote retrofits to either reduce the energy usage of dwelling (e.g., heat pumps) or to increase low-carbon energy usage by dwellings (e.g., rooftop solar PVs). Decoupling-type recovery measures may target dense development beyond the dwelling, but will lack a systemic vision that is intrinsic to compact development under wider well-being (e.g., dense, mixed land-uses, quality infrastructure to sustain densities including by public transport networks and green space).

Decoupling recovery measures are therefore largely constrained to energy efficient new builds and shallow retrofits, i.e. one-off measures instead of deep retrofits that reduce energy usage beyond $50 \%$. In the case of the latter, to become mainstream practice, important efforts would need to be made to adopt full-cost accounting would be necessary (Moreno et al., 2017[141]). In Decoupling, some isolated projects involving deep retrofits might exist but these do not become the norm. Moreover, since Decoupling does not look beyond the dwelling, options to reduce energy usage by modifying the surrounding environment, e.g., using green spaces to regulate the microclimate and reduce needs for cooling inside dwellings, are missed. Placing other well-being benefits (e.g. physical and mental health) at the centre of decisions along with emissions (like in the Wider well-being pathway) helps to further make the case for greenspace planning. It is possible that some of these measures may arise, but this is often piecemeal and does not reflect a 
mainstreamed view of that housing is a bundled good. For these reasons, as pointed out in section 2, Decoupling does not ensure that emission reductions from the residential sector are sufficient to reach climate goals consistent with the Paris Agreement. Nor does it take into account how the overall level of energy usage from the sector could hinder the ability of the energy sector to decarbonise in line with the Paris Agreement. High demand from the residential and other sectors for electricity may pressure grid operators to prioritise fossil fuels in order to provide reliable electricity access.

So far, many of the recovery measures related to energy efficient new builds do not specify the energy performance requirements. How emission-intensive these new builds are will depend on what these energy performance standards are. The easiest (and most convenient) time to intervene in a dwelling's future energy usage is during construction - so specifying ambitious performance levels for new dwellings well in advance is an opportunity to set the dwelling on a low emission trajectory. The impact of such measures will last a long time into the future because of the low turnover in housing stock. Therefore, the emissions of initiatives like the one in Figure 7 to build "energy efficient" dwellings for social housing in the near or long-term depends greatly on how this programme is defined.

Retrofit activities have potential for delivering both emission reductions and significant job creation. ${ }^{36}$ Costs tend to guide the types of energy efficient retrofits for public and private actors. However, these calculations omit costs and benefits that go beyond the dwelling; this pathway still views the primary role of housing as "access to low-carbon housing." Some (but not all) recovery packages established to date specify specific measures for the shallow retrofits - e.g., replacement and installation of heat pumps. The specific measures, and their potential, will of course vary by country and local circumstances. For example, climatic conditions determine what types of design features and energy use levels are needed to maintain thermal comfort inside dwellings. In addition, the age of the dwellings may influence the maximum level of "costefficient" retrofits.

\section{Wider well-being type recovery measures: Stimulate construction of low energy dwellings by design and by building compact resilient cities}

Wider well-being takes a systemic view of housing. This pathway views housing as a "bundled good" that provides a number of functions beyond access to shelter. "Good" housing would be a quality dwelling that meets minimum standards (e.g., health, safety), provide for occupants' comfort, offer equitable access to opportunities, goods and services and ensure a healthy as well as safe living environment, both, inside and beyond the dwelling (Howard et al., 2002[142]; Juaidi et al., 2019[143]; World Bank, 2016[144]; United Nations, $\left.2015_{[145]}\right)$. Housing built cheaply and quickly is often insufficient to bring about all of these bundled services (as explained above), leading to the disparities highlighted in the present crisis. Viewing housing as a bundle good leads to the prioritisation of recovery measures that not only reduce emissions in the residential sector, but facilitate the decarbonisation of other sectors and improve the broader well-being of occupants in new builds and retrofits. It would also include the broadening the scope for emission reductions from dwellings by linking them to the surrounding environment, e.g., by regulating microclimates with green spaces thus helping to reduce the urban heat island effect, and therefore reducing demand for cooling or creating compact cities with integrated planning.

Wider well-being takes into account the linkages between residential and other sectors, leading to a greater emphasis on lowering energy demand not just from dwellings themselves, but also from beyond the dwelling. This combined effect would lead to greater emission reductions than focusing solely on the dwellings themselves. This reduces strain on the electricity sector and facilitates its decarbonisation (as

\footnotetext{
${ }^{36}$ Recent research by the European Union has shown that for every $€ 1$ million invested in energy renovation of buildings, an average of 18 local and long-term jobs are created that will stimulate economic activity (Build Up Platform: The European Portal for EE in Buildings, 2020).
} 
discussed above). Therefore, Wider well-being prioritises new builds and retrofits that substantially lower energy demand (such as those reached under Passive Houses ${ }^{37}$ ). These new builds could potentially be accompanied with low-carbon energy, like rooftop solar. Lowering energy demand in conjunction with increasing the supply of low-carbon energy increases the probability of achieving net-zero energy dwellings. There are often several months where renewables will be insufficient to meet demand for electricity and thermal needs in many households globally (Petrichenko, Ürge-Vorsatz and Cabeza, $\left.2019_{[146]}\right)$. For this reason, it is still important to lower energy demand when installing rooftop solar in order to meet climate goals in the sector. Table 2 provides different projections of future energy usage until 2050 globally from state-of-the-art and suboptimal designs in new builds and retrofits.

This approach of lowering energy demand to the greatest extent possible can offer a longer-term solution to energy poverty (Ürge-Vorsatz and Tirado Herrero, 2012[147]). This solution minimises the energy needed for thermal comfort, so that the energy bills significantly decrease - which could in turn help those in vulnerable households who may have been furloughed or have lost their jobs in the pandemic. Typical policy solutions either supplement households' income or subsidise energy prices - neither of which is very stable in the long-term as these measures are often poorly targeted and a burden on public budgets (Ürge-Vorsatz and Tirado Herrero, 2012[147]). Adjusting energy prices, via subsidies or social tariff policies, sends a misaligned economic signal with climate goals (i.e., lower energy prices regardless of carbon content) and leads to capital stock whose efficiency is often lower than similar dwelling without subsidies. Moreover, such measures may inadvertently exacerbate energy poverty in the long run, since once this subsidy is reduced or removed, it leaves households with very inefficient buildings and equipment, potentially causing higher energy costs (Ürge-Vorsatz and Tirado Herrero, 2012[147]). This is not to say that supplementing household budgets or subsidising prices have no place, but in the longer-term lower energy demand that still meets users' needs offers a more viable solution.

In addition, private and public actors employ full-cost accounting under a Wider well-being approach, which means project appraisals take into account factors such as health that are related to the quality of the dwelling and its surrounding environment when evaluating projects for new builds or retrofits. For example, decreased health expenditure from higher quality state-of-the-art designs of dwellings are often omitted from calculations, e.g., worked-hours savings, number of premature deaths or coronary diseases avoided. For example, poor quality housing costs in France are nearly EUR 930 million annually because of ill health and could be costing the French economy as much as EUR 20 billion because of absenteeism and lower productivity, (BUILD UP, 2020[148]). The World Bank estimates the costs of indoor air pollution - from inefficient or poorly ventilated stoves burning biomass fuels - amount to 3.1\% of GDP in East Asia Pacific, 4.9\% of GDP in South Asia, and 2.5\% in sub-Saharan Africa (World Bank and Institute for Health Metrics, 2016[149]); since approximately three billion are exposed to such pollutants. Incorporating these costs into decision-making helps to tip the balance in favour of deeper retrofits as in the case of France or better quality designs for new builds in developing countries.

\footnotetext{
37 Total primary energy demand should not exceed $120 \mathrm{kWh}$ per $\mathrm{m}^{2}$ annually for all services in Passive Houses.
} 


\section{Box 4. Lowering energy demand from the residential sector}

Table 2 summarises modelling of projected energy demand in different climatic environments from suboptimal and state-of-the-designs for dwellings (because of retrofits and new builds). Suboptimal designs (that can arise from shallow retrofits) run the risk of locking in substantially higher energy demand into the future (Ürge-Vorsatz and Tirado Herrero, 2012[147]). The differences in energy demand could be far greater than what is seen below, as this modelling exercise does not incorporate aspects beyond the dwelling, associated with its urban from - e.g., density and presence of green spaces. If state-of-the-art designs were used in conjunction with compact cities, the reductions would likely be far greater than the $46.4 \%$ decrease by 2050 compared to 2005 found below. Some of these reductions captured by the transport scenarios above in section 3 , which models more integrated urban planning.

\section{Table 2. Scenarios for energy usage in buildings mirroring the three different pathways}

\begin{tabular}{|c|c|c|c|c|}
\hline & & Rebound & Decoupling & Wider well-being \\
\hline \multirow{4}{*}{$\begin{array}{l}\text { IIASA Global } \\
\text { Energy } \\
\text { Assessment - } \\
\text { Alternative } \\
\text { building retrofit } \\
\text { scenarios } \\
\text { (Ürge-Vorsatz et } \\
\text { al., 2012[10]) }\end{array}$} & Corresponding scenarios & BAU & $\begin{array}{r}\text { Suboptimal designs in } \\
\text { new builds and shallow } \\
\text { retrofits }\end{array}$ & $\begin{array}{r}\text { State-of-the-art standards } \\
\text { (equivalent to passive } \\
\text { houses) }\end{array}$ \\
\hline & Year & 2050 & 2050 & 2050 \\
\hline & $\begin{array}{r}\text { Annual global energy demand for space } \\
\text { heating and cooling relative to } 2005 \\
\text { (15 PWh per year) }\end{array}$ & $\begin{array}{r}26.85 \text { PWh per } \\
\text { year } \\
(79 \% \text { increase })\end{array}$ & $\begin{array}{l}21 \text { PWh per year } \\
\text { (32.5\% increase) }\end{array}$ & $\begin{array}{r}9 \text { PWh per year } \\
\text { (46.4\% decrease) }\end{array}$ \\
\hline & Alignment with Paris Agreement & Unlikely & Unlikely & Likely \\
\hline
\end{tabular}

Source: Authors, based on (Ürge-Vorsatz and Tirado Herrero, 2012[147])

Recovery measures for new builds in Figure 7 still stimulate construction by offering financial support (as seen in the Rebound and Decoupling) but these programmes aim to lower energy demand substantially compared to conventional builds. In addition, such programmes may also use on-site renewables to switch existing consumption to low-carbon sources as seen in Lisbon (Portugal) (C40, 2020[150]). Lisbon plans to build 3000 affordable housing units with the aim of creating zero-energy buildings that maximise thermal efficiency (i.e., lowering the energy demand of the dwelling) and increase installation of on-site renewables. Dwellings with lower energy demand would require more capital investment (e.g., insulation), but would also be more labour intensive than conventional builds (IEA, 2020[151]).

Likewise, recovery measures targeting retrofits still exist in Wider well-being, but focusing on deep retrofits that lower the energy performance of the building as a whole (e.g. Austria in Figure 7). This means the addition of top-rated insulation for ceilings, floors and walls; the installation of triple or double glazing; and the integration of passive heating and cooling solutions wherever possible (IEA, 2020[152]). Such deep retrofits can lead to reductions of energy usage greater than 50\% Deep retrofits also help to advance netzero goals by 2050. In the IEA's Net-Zero Emissions Scenario, all retrofits by 2022 are assumed to be deep in order to reach net-zero by 2050 (IEA, 2020[152]).

Traditionally, deep retrofits have faced major barriers to widespread uptake - such as costs and high fragmentation of the business model. For example, upfront costs of deep retrofits for property owners in the United States have been estimated at USD 50,000 to 100,000 on average per single family home in 2014 (Cluett and Amann, 2014[153]). The high costs currently associated with deep retrofits can be partially explained by the high overhead costs associated with deep retrofits today, e.g., architect, engineer, and site manager. The COVID-19 recovery is an opportunity to overcome these (which is the approach taken by France). Unlike new builds, deep retrofits have yet to be "industrialised", meaning that the same 
overhead costs are repeated across each retrofit. Rolling out deep retrofits with the recovery - en masse - could reduce these costs. For example, Energiesprong in the Netherlands, industrialised deep retrofits for Dutch dwellings. Energiesprong's first pilot in 2010 delivered 2,000 deep retrofits in existing and new home and the programme has now been extended to retrofit 110,000 more dwellings. In 2010, the cost of a deep retrofit was approximately EUR 130,000 (per unit for a terraced house), and by 2013, the cost decreased to EUR 60,000, and their goal is to bring it down to EUR 40,000 per unit (European Construction Sector Observatory, 2017[154] $)$. Countries could use their recovery packages as an opportunity to industrialise deep retrofits and bring down costs. In addition, the traditional retrofit business model, whilst suitable for the delivery of single measures fails to deliver an effective supply chain for deep retrofits for property owners. Traditionally, a separate contractor provides each retrofit measure and anyone undertaking a deep retrofit must pursue multiple points of contact in a highly fragmented renovation market. Energiesprong also helped to overcome this barrier by creating an integrated supply chain for property owners (Cicmanova, Esiermann and Maraquin, 2020[155]).

France is undertaking the above approach in their recovery ("France Relance"). Much of the social housing stock is now dilapidated or unsuited to current needs, with very low thermal performance that is leading to losses of well-being (Government of France, 2020[156]). France recognises the high costs inherent in deep retrofits and that these types of retrofits will not materialise without additional subsidies (Government of France, $2020_{[156]}$ ). Therefore, France will use the recovery as an opportunity to industrialise deep retrofit solutions of comprehensive and high-performance energy renovation of the "Energiesprong" type (Government of France, 2020[156]). Since 2018, France has been trying to replicate the Dutch Energiesprong model in lle-de-France and funding to this already existing programme will be increased as part of the recovery (Government of France, 2020[156]). As noted in the recovery strategy, deep retrofits will also help fight against urban sprawl in France by helping to reduce vacancy levels in social housing (Government of France, 2020[156]).

The recovery measures in Wider well-being aim to lower energy usage from individual dwellings by fully utilising opportunities for emission reductions beyond the dwelling which would promote compact liveable cities. For example, the programme mentioned above in Lisbon, plans for the neighbourhood surrounding these 3000 homes to be built for "collective use"- i.e., with green spaces and public spaces as well as being accessible via public transport, cycling and walking. In addition, certain localities in Australia are rezoning for mixed land-uses that allows for commercial, residential and industrial properties to be colocated. This helps to prevent sprawling communities and supports public transport, walking, and cycling, in addition to higher densities, which has been shown to lower dwellings' energy usage (because of smaller dwellings and shared walls) In parallel, other cities and countries are adding green spaces (such as restoring ecosystems or planting trees) in to avoid urban heat island effects (lowering the energy usage in the dwelling required for thermal comfort) and improve physical as well as mental health (and provide safe spaces for recreation during any future waves or pandemics). Box 5 explores two cases from Beyond the Dwelling in more in detail. 


\section{Box 5. Case studies of measures compatible with Wider well-being}

Creating jobs via retrofits in Cape Town (South Africa): Cape Town is simultaneously providing jobs and helping vulnerable communities by investing in retrofits of poor quality housing in low-income neighbourhoods. The city is training and employing marginalised communities on how to retrofit upgrading their skills. The city already conducted a pilot, which created 2300 jobs amongst a diverse workforce (e.g., women, young people), improved living conditions for more than 2000 households, an d reduced $7.4 \mathrm{ktCO} 2 \mathrm{e}$.

Green spaces in Free Town (Sierra Leone): Free Town is planting 1 million trees in 2020 and 2021 as part of its stimulus package, with the objective of increasing the city's green space by $50 \%$. The city is working with communities and neighbourhoods around the city on where to plant trees to understand their needs and desires for green spaces. This is a promising step to provide services around the dwelling; since green spaces can help improve physical and mental health as well as regulate microclimates to help decrease energy usage in dwellings (as discussed above). Moreover, the project will create jobs for tree planters, landscapers, and other greening businesses. Similar measures are appearing in the recovery packages of Montreal (Canada) and in Melbourne (Australia).

Source: C40 (2020), "C40 MAYORS' AGENDA FOR A GREEN AND JUST RECOVERY”, https://c40-productionimages.s3;amazonaws.com/other_uploads/images/2093_C40_Cities_\%282020\%29_Mayors_Agenda_for_a_Green_and_Just_Recovery. original.pdf?1594824518 (accessed on 7 August 2020)

\section{Comparing the Pathways}

The pursuit of compact cities (and within this relatively high-density development) can still allow cities to deliver a variety of housing options for different population groups. A challenge is of course that compactcity development entails smaller average living space areas for residents compared to more sprawled development (Kotulla et al., $\left.2019_{[157]}\right)$. Nevertheless, a compact city does not entail high-rise development only. In addition to the type of dwelling, characteristics such as the configuration and design of streets, and the block and lot size, all have an incidence on density.

Examples like the city of Curitiba in Brazil show that planning for compact cities can be designed with different density areas (within the same city) and different mixes of dwelling types providing choice for different population groups. In this case, the city is organised around transport corridors surrounded by neighbourhoods with the highest density and mixed land-uses. Density and mixed land use decrease as one moves towards corridors further away from the transport axis, with single-dwelling housing increasing its share when moving from central to outer corridors (ICLEI, 2016 $[158]$ ). The case of Curitiba has at its heart transit-oriented development, which has allowed the city to enhance access to public transport, and create proximity to local services. Proximity to green spaces as well as easy access to public transport and local services is key to ensure the liveability of compact city type development (Taylor, $2008_{[159]}$ ). 


\section{Links between COVID-19 recovery and NDCs}

As well as their economic impacts, governments' COVID-19 recovery measures will affect (positively or negatively) current and future GHG emissions levels, as well as other aspects of people's well-being. Establishing COVID-19 recovery measures is therefore an opportunity for countries to review a broad set of domestic policy goals, and ensure that they are aligned with one another, and along different time frames. This will help improve the effectiveness of policy implementation. Several governments have in fact introduced some measures to "green" their COVID-19recovery (see e.g. (OECD, 2020[160])).

Thus, the impact of COVID-19 recovery measures can affect the ability of a country to meet its current NDC, the ambition of the current and future NDCs, as well as the feasibility of achieving longer-term lowemissions development. The schedule agreed in the Paris Agreement for countries to communicate or update their NDCs also means that countries are doing so at the same time as developing their recovery measures. The pandemic and steps to recover from it can impact NDCs in multiple ways. These are discussed below and include:

- Ambition of current NDCs: the mitigation ambition of current NDCs can be affected by the form of the NDC, the depth and length of the economic downturn as well as the speed and pace of recovery in activities and emissions in the short term.

- Resources available to implement and update NDCs: the pandemic will affect the level of public and private funding available, including to implement climate responses, as well as domestic processes to update NDCs, e.g. collect and process data and information and undertake coordination with stakeholders.

- Recovery measures can hinder domestic policy alignment, e.g. between climate and other policy priorities. This may affect a country's policy coherence overall and longer-term climate ambition, e.g. as outlined in future NDCs.

\section{COVID-19 containment and recovery measures can impact the ambition of current NDCs}

The impact of the containment measures put in place as a result of the COVID-19 pandemic can impact the stringency of some current NDC targets (particularly for those countries with multi-year targets running to 2025). In the absence of a full and rapid bounce back of activities, the drop in GHG emissions during the crisis may mean that some current NDCs are now less challenging than originally anticipated. This is particularly so if the NDC runs only to 2025, was developed on a "deviation from BAU" basis where the BAU level is static (rather than dynamic), or are for countries where key emission sources are in sectors that have been particularly badly hit by the response measures to the pandemic. In such cases, the impact of the climate response actions taken by governments will be conflated with the reduction in emission and activity levels caused by containment or recovery measures. 
External effects, such as the COVID-19 pandemic and consequent sharp drops in activities and emissions, have highlighted the potential impact of such events on the ambition of NDCs, as well as a country's likelihood of meeting its NDC. The extent of such an impact depends on many factors. These include the speed and nature of a country's economic recovery from the pandemic, as well as on the NDC target date/period and type. For example, the impact of the pandemic on a country's GHG emission levels and GDP is likely to be larger for a country where a large proportion of GHG emissions and GDP are associated with sectors that have been most affected by responses to the pandemic, e.g. tourism. Further, the impact of e.g. an absolute decline in GHG emission levels e.g. from 2020-2023 on achieving an NDC will be higher for a country whose NDC is framed in terms of a multi-year emissions budget between 2021-2025 than for a country whose NDC is framed in terms of a single-year target in 2030. For example, Palau's first NDC runs to 2025 and has a target of reducing absolute GHG emissions in the energy sector by $22 \%$ compared to 2005. This target (developed in 2015) assumes a growth in GDP of 3.7\% p.a. whereas GDP declined in $2019(1.9 \%$ ) and is expected to drop sharply in both 2020 and 2021 (by 9.5 and $12.8 \%$ respectively) (Asian Development Bank, 2020[161]). This unexpected and large change in GDP trends is likely to make Palau's mitigation target much easier to reach than originally anticipated.

Whether achieving an emissions target (e.g. as outlined in an NDC) is representative of a country flattening and then lowering its emissions curve will also be influenced by several factors. These include the form of emissions target (e.g. whether the target is in absolute or relative terms), whether the target is static (i.e. not adjusted between being set and the end of the NDC implementation period), and the target's stringency. In terms of the form of emissions target, the Paris Agreement encourages all countries to take on to economy-wide absolute emission reductions over time. ${ }^{38}$ Indeed, absolute emission reductions are needed in order for countries to collectively meet the mitigation goal of the Paris Agreement. Nevertheless, the form of an emissions target does not necessarily correlate with its stringency. For example, some absolute emission reduction targets agreed to under the Kyoto Protocol were not ambitious, as these targets were above the level of BAU emissions.

Emissions targets in the form of deviation from BAU levels (the most common form of first NDC for developing countries) can become more or less stringent than originally anticipated. Targets can become less stringent if they were translated into $\mathrm{t}-\mathrm{CO}_{2}$ eq before the NDC implementation period but activities and emissions are limited or reduced over the implementation period because of COVID. In contrast, emissions targets in the form of deviation from BAU levels could become more stringent, if they were initially framed in terms of a fixed level of emission reductions from a BAU trajectory whose level is updated to take changes in key drivers into account.

A near-term reduction in activity and GHG emission levels caused by containment measures introduced because of the COVID-19 pandemic could therefore weaken the stringency of some current NDCs, e.g. if the target is expressed in terms of absolute emission reductions relative to a pre-crisis baseline. In turn, this could reduce the short-term pressure for countries to undertake or enhance their emission reduction efforts and could also impede efforts for the longer-term transition of economies. In the longer-term, the impact of this sudden fall in emissions could allow countries to proceed with plans for emissions-intensive infrastructure that would not otherwise have been built, as highlighted by some of the examples of Rebound-type measures in the previous sections. Countries might also be tempted to delay introducing policies and measures that integrate supply and demand considerations, and therefore improve the efficiency of a system as a whole (e.g. integrated land-use and transport planning) rather than on incremental improvements on individual aspects of that system (e.g. fuel efficiency of vehicles). There

\footnotetext{
38 The Paris Agreement provides guidance as to the "end goal" for the type and coverage of NDCs in its Article 4.4 of the Paris Agreement which states that that developed countries should undertake "economy-wide absolute emissions reductions targets" and that developing countries are encouraged to move towards such type of targets over time.
} 
could also be potential delays to GHG-mitigation projects if the crisis leads to disruption of supply chains (e.g. for renewable energy components).

\section{The pandemic may affect resources available to governments for the purposes of implementing and achieving their NDCs}

The COVID-19 pandemic has affected the availability of public finance in the short-term in many countries $^{39}$, and may also have diverted human resources to focus on issues related to containment and recovery. These effects may also continue in the longer-term. This can therefore affect the resources available to governments to focus on actions needed to implement and achieve their current NDC, as well as the processes and resources available to update it. Indeed, several countries have indicated subsequent to the start of the pandemic - that they expect a $15-30 \%$ cut in funding for climate spending in 2020 (Viera, 2020[162] $)^{40}$

This pressure on resource availability is likely to influence the attractiveness of recovery measures, favouring those with lower capital cost, short lead-times (e.g. those that are "shovel-ready"), or with large and immediate employment or trade benefits. Indeed, several countries have developed Rebound-type recovery measures. Such measures provide incentives to boost or secure employment - but for activities that will increase GHG emissions in the short and - in some cases, such as facilitating permitting of coalfired power plants - also in the long-term. The impact of such measures may therefore be in direct contradiction to the stated climate-related goals of individual countries, and could therefore result in misaligned policies at a national level. Rebound, if replicated widely across countries, would clearly be at odds with achieving a well-below $2^{\circ} \mathrm{C}$ or more stringent goal except with risky assumptions about the availability and acceptability of large scale CDR technologies later in the century. A policy mix that is misaligned with a country's short, medium or long-term emissions target is unlikely to be the most costefficient and would be a gamble on a particular set of still immature and in some cases controversial technological options.

It may however be more cost-efficient to use available finances in a manner that meets multiple goals. However, what different governments assess as "efficient" will be significantly influenced by their metric(s) of measurement and their way of assessing benefits. For example, if governments use monetary metrics only (e.g. cost-effectiveness, benefits per USD etc.), this would only reflect the sub-set of benefits that are monetised. Such a metric would therefore routinely include issues such as employment and those GHG emissions that are priced. However, cost-benefit analysis or a monetary metric would not reflect a policy's impact on currently under- or unpriced GHG emissions (the large majority of GHG emissions, see (OECD, $\left.2019_{[163]}\right)^{41}$ ) or on any other often-unpriced impacts, e.g. those related to SDG targets and well-being measures such as health, hunger, access to services. Such analyses could therefore be biased against policies which have multiple benefits (such as mobility management), particularly if any benefits are unpriced, difficult to quantify or perceived as difficult to model (Litman, 2017[164]). Nevertheless, these measures can contribute highly to well-being (as measured by life satisfaction, see e.g. (Frijters et al., $\left.2019_{[165]}\right)$. Thus, focusing "efficiency" arguments solely on currently-monetised impacts of a policy would skew policy decisions towards those which have benefits which are monetised, and away from those which

\footnotetext{
39 Indeed, the pandemic has led to the sharpest peacetime decline in GDP in many countries seen from the first quarter 2020. For example, the ADB has forecast the GDP of Pacific Islands to drop by an average of $10 \%$ in 2020 (Asian Development Bank, 2020[161]).

40 Such a cut could also lead to setbacks in countries achieving their objectives relating to the Sustainable Development Goals.

41 A recent survey (OECD, 2019 $\left.{ }_{[163]}\right)$ highlighted that $70 \%$ of energy-related $\mathrm{CO}_{2}$ emissions in OECD and G20 countries in 2018 were unpriced.
} 
do not - even if such policies have significant well-being benefits. An alternative could be to use multicriteria analysis that is designed to weigh different, possibly incommensurable benefits, to generate a more rounded assessment of the impact of a specific measure - for further discussion see e.g. (Atkinson et al., $2018[166])$.

Thus, activities assessed under the current framework as cost-effective or low-cost in the short-term are not necessarily those leading to the greatest benefits in the longer-term, because many benefits (or avoided costs) may not be assessed. Nevertheless, as outlined in box 3.3 and table 3.1, activities undertaken in the short term may have very significant impacts for decades in the future, i.e. including during future NDC implementation periods, on GHG emission levels, as well as on health and other wellbeing effects. For example, as discussed in section 3, (Fulton et al., 2017 ${ }_{[167]}$ ) highlights that the increased investment in public and non-motorised transport infrastructure under a well-being type pathway is likely to be more than off-set by savings due to lower expenditure in road infrastructure, car ownership and fuel..

When benefits such as e.g. improvements to health and mortality rates, or reduction in commuting time are taken into account, policies that encourage increased well-being become much more favourable. For example, transport sector analysis of the most cost-effective set of policies of meeting an $80 \%$ GHG reduction target in Finland's transport sector by 2050 is to encourage increased shared mobility - once wider benefits such as benefits to health are taken into account (Liimatainen, Pöllänen and Viri, 2018 ${ }_{[168]}$ ). The same study also indicated that this would be $11 \%$ more capital-intensive than a technology-focused scenario. Increased uptake of active transport is also to have many potential benefits in New Zealand, with NZD 630m infrastructure investment leading to NZD 13bn in co-benefits (the vast majority of which are associated with reduced mortality in road accidents) (Ministry for the Environment, 2018[169]). Incorporating benefits related to saving commuting time in transportation projects in Colombo (Sri Lanka) and Balikpapan (Indonesia) also changes the financial valuation of these projects from negative to positive (Rashidi, Stadelmann and Patt, 2017[170]).

Nature-based solutions (NBS) are increasingly considered as an alternative to traditional "grey" or "hard" infrastructure solutions in cities (Kabisch et al., 2016 $6_{[171]}$ ), and policies to include these solutions could generate many benefits but face challenges to be scaled up (Danielson and Gamper, 2020[172]). For example, urban "green roofs" have many environmental and well-being benefits including significantly reducing cooling and heating needs (He et al., 2020[173]), mitigate the urban heat island effect and helping stormwater management (Keeler et al., 2019 [174]; Manso et al., 2021 [175]; Rasul and Arutla, 2020[176]). However, high estimated installation (up to EUR $362 / \mathrm{m}^{2}$ ) and operating costs EUR4.3-7,8/ $\mathrm{m}^{2} /$ year) (Manso et al., 2021 [175] $)$ or - in some countries - a lack of knowledge and skilled workforce, are a barrier to the further uptake of green roofs (e.g. (Teotónio et al., 2020[177]; Sangkakool et al., 2018[178])), particularly when the ecosystem and other benefits of green roofs are not monetised (GSA, 2011 $[179])$.

\section{The pandemic can also exacerbate the challenges of updating NDCs in line with the Paris Agreement}

Both COVID-19 containment and recovery measures can exacerbate the challenges inherent in developing an ambitious NDC under Article 4 of the Paris Agreement. Developing such an NDC will require technical and institutional inputs, as well as human and financial resources. These inputs are likely to be greater for NDCs with a broader scope (e.g. covering a country's climate response, economic recovery and progress to well-being goals) than with a narrower scope (e.g. focused solely on climate). Further, many countries - particularly developing countries - already faced significant challenges relating to these three sets of inputs pre-pandemic, with two-thirds of the developing countries consulted in a study indicating that they had difficulties assessing the economic impact and co-benefits of mitigation actions (Kurdiziel, Day and Frauke Roeser, 2016[180]). These challenges are in some cases highlighted by specific national reporting of constraints, needs and gaps in National Communications, Biennial Update Reports and/or initial NDCs. 
In other cases, challenges are implicit, e.g. as can be implied in the case of widespread non-reporting, late reporting, or incomplete reporting under the UNFCCC.

\section{Technical and data barriers, including in assessing BAU, have been exacerbated}

At a technical level, the collection and collating of timely data and information needed to develop or update an NDC has been hampered in several developing countries by the restrictions on movement introduced as a response to the COVID-19 pandemic (NDC Partnership, 2020[181]). Such data could include those relating to GHG emissions, emissions drivers, mitigation potential and costs, monitoring and enforcement of current policies, as well as the infrastructure and equipment necessary to take up low-GHG solutions. If countries aim to develop integrated policies that meet multiple aims (such as economic recovery, climate mitigation, well-being benefits) further datasets and information would be needed, e.g. on impacts, synergies and trade-offs between different possible measures that could be undertaken, as well as their relative cost. In contrast, some governments (particularly local governments in both developed and developing countries) have, or are looking for ways to strengthen their data collection processes as a means of gathering data needed to develop an integrated recovery from COVID. In Barcelona, for instance, the Metropolitan Transport Authority for the Metropolitan Region (ATM) created an Emergency Committee that meets virtually every day. In parallel, a technical group was created to support the Emergency Committee. Among other things, the two bodies have dedicated important efforts to gather and analyse (on a daily basis) key indicators related to the transport system, transport demand trends and related environmental impacts. The data collection and analysis has been key to develop a mobility plan for the lock-down exit phase, as well as a number of potential future scenarios. Among the most important aims is avoiding the expansion of private mobility and its related increase in pollution and $\mathrm{CO}_{2}$ emissions (Alegre, $2020_{[182]}$ In Buenos Aires, the Metropolitan Transport Agency, is planned to be significantly strengthen as an institution. In great part this is due to the important role the institution has played during the COVID-19 crisis and the aim of better integrating land-use and transport planning to advance equity and environmental goals (see Box 3 in section 3). Among the most important actions planned for this body is for it to become the lead institution for mobility data; including through the development by the Agency of a data bank that integrates open data sources (Ministry of Transport of Argentina, 2020[183]).

Lack of data, co-ordination and consultation can hinder the development of ambitious targets and effective policies. For example, an assessment of the transport sector in selected countries' first NDCs indicated that "estimates of mitigation potential are usually more conservative without adequate data" (Löhr et al., $\left.2017_{[184]}\right)$. Delays in estimating GHG emissions are likely to be particularly significant for any GHG emission sources where there is no automated collection of underlying activity data, or where estimates need to be manually aggregated. Movement restrictions introduced for the purposes of containing the spread of COVID-19 can also impede monitoring and enforcement of policies, which could lead to reduced levels of compliance as well as reduced information about the effectiveness of different actions. The importance of such restrictions will vary by sector and country, but can hinder the calculation of current emissions trends, projected emissions trends, and the effectiveness of current emission mitigation policies. However, such information would be crucial input to any "business as usual" projection of GHG emissions.

The COVID-19 pandemic has also made the direction and magnitude of future BAU developments, e.g. in terms of GDP and GHG emission trends, more uncertain (see text box). This uncertainty will make it more difficult for countries to accurately assess their "BAU", as well as possible deviations from this BAU - both in the short and long-term. "Deviation from BAU" was the most common form of NDC type for the initial NDC of developing countries. The text box highlights that projections for $\mathrm{CO}_{2}$ emissions in Mexico in 2020 as made in 2009 were approximately $20 \%$ lower than the equivalent projections for the same country and year, made by the same organisation, two years earlier. This variation is of the same order of magnitude as many "deviation from BAU" targets in current NDCs. 
There is thus a risk that developing or updating NDCs of a "deviation from BAU" type during a time of severe economic shocks will lead to BAU emission levels being significantly under or over-estimated. This is because there is large uncertainty in GDP and GHG emission trends caused by multiple factors. For example, countries whose economies and emissions levels are heavily influenced by the levels of tourism will be influenced by the GDP and any COVID-related travel restrictions in the home countries of the tourists. Similarly, availability of public and private finance will impact the extent of finance for clean energy infrastructure or other climate responses. Such uncertainty could also impact the willingness of governments to focus on integrated policy responses and/or policy responses with significant long-term benefits to the extent that such approaches are more capital intensive, and instead lead countries to focus on short-term issues, even if this could compromise their ability to meet longer-term goals.

Such uncertainty can in turn impact the ambition of NDCs, if associated BAU levels, and the deviation from them, are fixed up front (rather than being dynamic, to respond to significant changes in relevant drivers and assumptions such as GDP levels) (Vaidyula and Hood, 2018[185]). It is not always clear from Parties' first NDCs how BAU has been defined, and if it is static or dynamic. This will change in future, as Parties agreed at COP24 that second NDCs "shall" provide an agreed set of information necessary for clarity, transparency and understanding of NDCs, and that updated NDCs "may include" information to facilitate clarity, transparency and understanding (UNFCCC, 2019 [186]). In particular, countries' second NDCs shall include "[i]nformation on the circumstances under which the Party may update the values of the reference indicators". This means that second NDCs are likely to contain a greater level of detailed information on quantifiable information, including on assumptions and methodologies, than initial NDCs. Updated NDCs may also contain this detailed information. Countries could apply the COP24 decision by including information in their NDC of thresholds of specific indicators (e.g. total primary energy supply, GDP, oil prices) at which BAU emission levels will be recalculated. This could help to ensure that a target agreed in 2020 for 2025 or 2030 continues to represent the mitigation effort implied by the initial target.

Article 4.3 of the Paris Agreement indicates that NDCs are to be of the "highest possible ambition". Thus, the current uncertainty could also lead to countries erring on the side of caution when estimating what level of mitigation represents "its highest possible ambition". 


\section{Box 6. Increased uncertainty of developing BAU scenarios during an economic downturn}

Many developing countries' first NDC were established on a "deviation from BAU" basis. Developing BAU projections is inherently uncertain, as there can be many plausible development paths for a country, as well as many plausible options for key assumptions (Vaidyula and Hood, 2018[185]). Nevertheless, developing BAU projections during severe economic downturns is likely to lead to greater forecasting errors (IMF, 2018 $\left.{ }_{[187]}\right)$. Further, there is particular uncertainty as to the extent and speed of economic recovery, given the possibility of future spikes of the pandemic, and lack of clarity on the timing for development of any vaccine (OECD, 2020[188]).

Nevertheless, if countries are to meet the UNFCCC-set deadlines for developing NDCs, these NDCs will need to be developed in 2020 , i.e. during a particularly unstable and uncertain period. The economic uncertainties can be illustrated by the variation in GDP growth projections for 2020 and 2021 for selected countries, as estimated in different points in 2020 by the IMF and by the OECD (IMF, 2020[189]). There was a more than 10 percentage point difference in the GDP projections for 2020, made at different points in 2020, for selected countries. The US Energy Information Administration (EIA) notes in their July 92020 Sort Term Energy Outlook that their "forecast is highly dependent on assumptions regarding the economic impact and subsequent recovery from COVID-19 mitigation efforts." (US Energy Information Administration, 2020[190]).

\section{Figure 8. Variations in GDP projections for 2021 for selected countries}

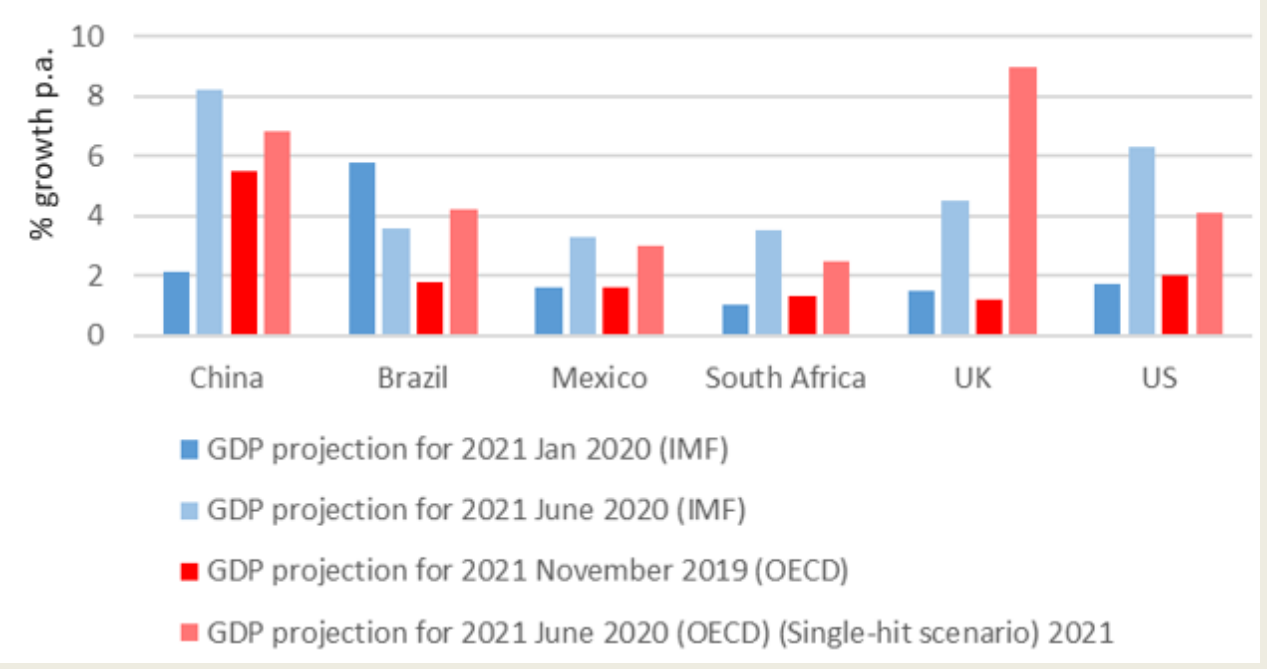

Source: (OECD, 2020[188]; IMF, 2020[189])

The impact of economic crises on projected levels of GHG emission levels can also be significant, e.g. of the same order of magnitude as NDC targets.

This is illustrated below, which compares projections of $\mathrm{CO}_{2}$ emissions for the years 2015 and 2020 made before, during and after the global financial crisis for selected countries. (The projection for the country and year made in the 2006 edition of the International Energy Outlook (IEO) is given an index of 1 , and projections in subsequent IEO editions are compared to this 2006 projection). Figure 9 highlights that the impact of the crisis on GHG projections can be significant, and can vary widely (up to $20 \%$ difference over 2-3 years) depending on the country. 
Figure 9. Variation in $\mathrm{CO}_{2}$ emissions levels projected for selected countries and time periods, as estimated over 2006-2010

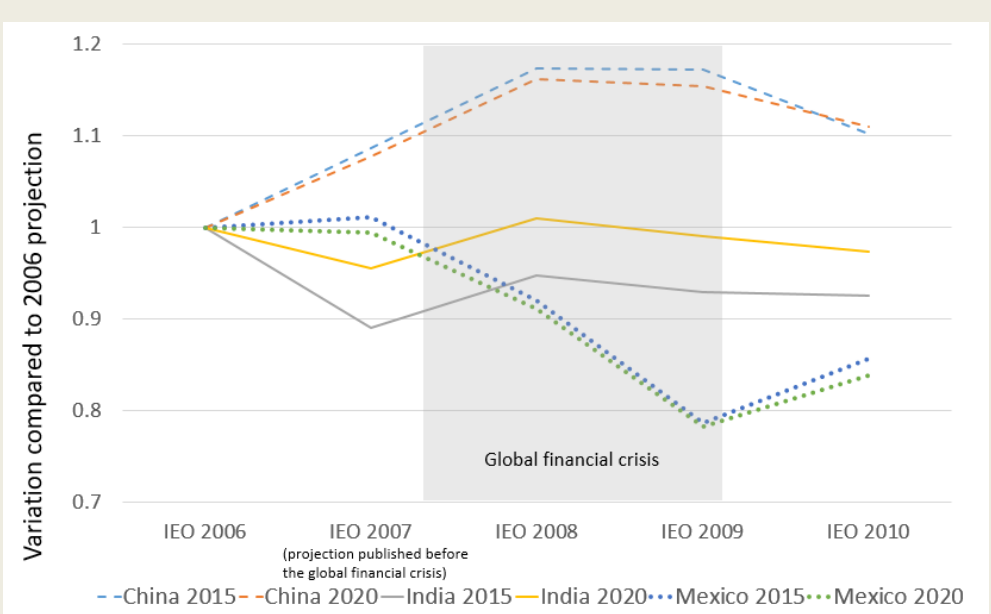

Source: Authors calculations, based on EIA International Energy Outlooks, 2006-2010

\section{Institutional processes can also face further barriers}

A country's COVID-19containment and response measures may have hindered its ability to undertake the institutional processes needed in order to develop a NDC (NDC Partnership, 2020[181] $)$. However, in order to develop an ambitious NDC and an effective strategy to achieve the targets in the NDC, effective coordination and decision making is needed. However, consultation with relevant stakeholders and effective co-ordination amongst decision-makers can be impeded during lockdown or remote working, e.g. due to poor information technology infrastructure $\left(\right.$ Gore, $\left.2020_{[191]}\right)$. Whether this is an important barrier, resulting in significant delays or not to preparing the NDC will vary by country.

\section{COVID-19 responses can help or hinder the domestic policy alignment and coherence needed in order to efficiently achieve NDC targets}

Many national governments are taking steps to improve policy coherence There is a growing recognition by governments of the interlinkages between their objectives in different areas (e.g. across the SDGs, which are closely linked to countries' well-being). Many governments have therefore taken steps in their domestic policy process to improve policy coherence and alignment between the measures implemented in different sectors to ensure that they are aligned with one another and/or with internationally-agreed goals. For example, Mexico has established a Senate Working Group and an online platform to monitor implementation of the SDGs (OECD, 2020[9]), and Germany requires all new laws and regulations to undergo a sustainability impact assessment (OECD, 2019 [192]). The use of carbon pricing is also increasing (World Bank, 2018[193]). Like $90 \%$ of African governments, Rwanda has mainstreamed progress on SDGs in its national development plan, accessing synergies across sustainable development, disaster risk reduction and climate change (Hachileka, 2017[194]) (Begashaw, 2020[195]). Nevertheless, section 3 has highlighted several examples of recovery measures introduced that run counter to stated domestic aims, e.g. as related to climate mitigation.

This drive to improve policy coherence is reflected in some countries' first NDCs, which sometimes reference wider well-being aspects as important considerations. For example, the co-benefits mentioned in some first NDCs include food security (e.g. South Sudan), rural and regional development (e.g. Indonesia), resilience to natural disasters (e.g. Bangladesh) and employment (e.g. Niger). While by 24 
November 2020 only 15 countries have currently updated their first NDC, and two have submitted a second NDC, a significant proportion of those who have highlighted the importance of addressing multiple goals in both environmental and non-environmental areas. For example, Chile's recently-revised NDC requires each goal in the NDC to also contribute to fulfilling one or more sustainable development goal (Government of Chile, $\left.2020_{[196]}\right)$ Jamaica is drawing on integrated approaches across energy and land-use sectors, yielding co-benefits such as health and strengthening of ecosystems. Rwanda is mainstreaming gender equality and nature-based solutions in actionable items within the agriculture sector.

Some countries' recovery packages place a prominent role on meeting multiple other goals, including climate mitigation and wider well-being. For example, the government of New Zealand has developed its second "Wellbeing Budget: Rebuild Together" (Government of New Zealand, 2020[197]), based on the NZ Treasury's Living Standard Framework. This budget is set to "embrace any opportunity, albeit uninvited and unwelcome, offered to us by the disruption to business-as-usual that COVID-19 caused" to put people, jobs, health, and the environment at the heart of its recovery ${ }^{42}$. The government of Iceland has adopted a framework of 39 well-being indicators, across social, ecological and environmental aspects, with the potential to shift policy priorities (of the recovery) from favouring economic growth to fostering wider wellbeing (Government of Iceland, 2019 ${ }_{[198]}$ ). The government of Jamaica has indicated that it is including climate perspectives into its recovery plan (Gordon, 2020[199]).

An integrated framing for specific policy documents or NDCs highlights that measures developed under a Wider well-being rationale can have large potential synergies between economic, environmental and social outcomes - both in the short and long-term. Such measures are therefore often consistent with multiple policy aims of governments, who could therefore usefully assess what role the potential domestic use of such measures could play in their national COVID-19recovery efforts. Examples of such measures (highlighted in section 3 above) include those that guide urban growth to foster compact and resilient cities, or that encourage modal shift away from cars and towards sustainable modes, through re-allocation of road-space.

However, the explicit linking of climate mitigation targets and other targets (e.g. as related to wider wellbeing) was not widespread in the first round of NDCs. For example, the focus of transport actions mentioned in countries' first NDCs was predominantly (>60\%) on "improve"-type actions (which re consistent with Decoupling). In contrast, "Avoid"-type measures (which in Wider well-being have a role as significant as "Improve"-type actions) accounted for less than $10 \%$ of actions mentioned (Gota et al., $\left.2016_{[200]}\right)$. Similarly, policies mentioned in countries' first NDCs for the building sector largely focused on developing or extending existing building codes (the focus of more than half of the actions in the building sector that were included in countries' first NDCs). Such a strong focus on this type of action also reflects a Decoupling-type approach. As for the transport sector, policies for the residential sector that in Wider well-being would also have a prominent role, such as integrating decision-making on building location and design with sustainable urban planning, were the focus of less than $10 \%$ of policies mentioned in countries' first NDCs (Graham, 2018[201]).

As highlighted in sections 3 and 4, a large number of national-level COVID-19 recovery measures introduced to date are misaligned with governments' stated national goals. This is particularly true for goals in environmental and social areas, as well as with internationally-agreed goals such as the SDGs. Thus, several COVID-19 recovery measures being planned or introduced roll back existing climate efforts by specifically encouraging increased use of fossil fuels, e.g. such as waiving congestion fees. This can have a significant impact on the feasibility of meeting long-term goals, such as climate neutrality or long-term low-emissions development. Such measures are more consistent with Rebound. However, it is not clear whether such measures reflect a change in priorities of governments, or whether they are a consequence of rapid policy development at a time when co-ordination is more challenging than usual. These measures

\footnotetext{
${ }^{42}$ https://treasury.govt.nz/publications/wellbeing-budget/wellbeing-budget-2020-html
} 
can therefore also hinder a country's achievement of its current NDC, potentially encouraging the country to set a less ambitious NDC in the future, and can also impede achievement of broader development and well-being goals. For example, although the exact level of expenditure is uncertain, the majority of expected COVID-19 recovery expenditure for some G20 countries is focused on measures that support for increased use of fossil fuels without introducing any environmental conditionality (energypolicytracker.org, 2020[202]). In addition, the misalignment between COVID-19 recovery measures and climate goals include that $65 \%$ of the 29.9 billion EUR bailout agreed or under discussion for European airlines does not have any climate conditions attached. ${ }^{43}$ (Transport \& Environment, 2020[203]) Similarly, there are no climate conditions on the 1 billion EUR (925 million GBP) loan to two UK-based car manufacturers (Honda and Toyota) from the COVID Corporate Financing Facility of the UK's Bank of England (Bank of England, 2020[204]). This misalignment between recovery measures and stated policy goals may be in part due to urgent government actions to counteract sharp drops in sub-sectoral activity (e.g. airlines), domestic prioritisation of measures to maintain employment (e.g. car manufacturers) or the rapidity with which recovery packages have been developed.

A misalignment in countries between some COVID-19 recovery measures and climate or well-being targets will ultimately make it more difficult for those countries to meet their stated goals in the short to medium term. This misalignment may also make reaching long-term goals such as net-zero GHG more difficult (as delaying emission reductions now will lead to requiring faster emission reductions after a later, as highlighted in section 2), and/or more expensive (if following recovery pathways that lock in high levels of emissions leads to large volumes of stranded assets).

Nevertheless, reporting changes being introduced by the enhanced transparency framework under the Paris Agreement, which is to be applied by countries by 2024 at the latest, will require countries to report on the policies and measures that will be implemented in order to fulfil the goals of the NDC. Having such a roadmap to achieving medium-term as well as long-term objectives can help countries decide on the most appropriate and cost-effective technologies and systems to meet such targets (Falduto and Rocha, $\left.2020_{[205]}\right)$. A roadmap could also encourage governments to identify measures that can meet multiple goals (e.g. relating to economic recovery from the COVID-19 pandemic, GHG mitigation, well-being benefits, as highlighted for selected measures in road transport and buildings above).

Making a clear link in updated or second NDCs between recovery measures and climate and well-being benefits could help to increase public acceptability of measures that have multiple benefits, such as those outlined in section 3 above. Indeed, research on communicating carbon pricing has highlighted that focusing on the non-climate benefits could increase public acceptability of such policies (Partnership for Market Readiness (PMR), 2018[206]) (WB 2018). Analysis of support for different climate mitigation policies in the transport sector has also highlighted that there is higher public support for policies perceived as being fair and less intrusive - as well as effective - than for just highly-effective policies (Partnership for Market Readiness (PMR), 2018[206]).

\section{COVID-19 recovery measures have highlighted the misalignment in national and sub- national policy priorities in some countries}

Misalignment between stated SDG/climate/well-being objectives and the recovery measures being put in place also arise from different priorities between national and sub-national governments, as well as the varying mandates of sub-national governments. Some countries have benefitted from a strong top-down indication that COVID-19 recovery measures should also take climate and/or well-being considerations into account. For example, France and Germany have explicitly agreed to put climate at the heart of their COVID-19 recovery plans (Government of France, 2020[207]).

\footnotetext{
43 The remaining $35 \%$ have some or weak (non-binding) climate conditions.
} 


\section{4 | COM/ENV/EPOC/IEA/SLT(2020)4/REV2}

COVID-19 recovery measures have also highlighted the differences in priorities of local and national governments in relation to climate mitigation and/or well-being in some countries. In some cases, particularly for countries that have pledged to become carbon neutral, the national government is more ambitious in terms of climate mitigation than sub-national governments. For example, there has been a marked acceleration in provincial permitting of coal-fired power plants in China with the aim of stimulating local economies after the initial impacts of the COVID-19 crisis (energypolicytracker.org, 2020[208]). This is despite the current significant over-capacity in coal-fired power in China, the statement by six national ministries including the NDRC that coal plants should only be built as needed (Centre for Research on Energy and Clean Air, 2020[209]) and the subsequent indication that China will aim for carbon neutrality by 2060 (Climate Home News, 2020[210]). Of course, building coal-fired power plants is likely to lock in high levels of associated GHG emissions - as well as local air pollution that could damage health or other wellbeing aspects - for decades to come. In other cases, sub-national governments are more ambitious, e.g. with several cities developing policies on surface transport that mitigate GHG emissions and increase wellbeing - as outlined in sections 3 and 4 above. 


\section{Conclusions}

Government focus of COVID-19 response measures in many countries has shifted from emergency support to economic recovery from the COVID-19 crisis. The nature, focus and design of COVID-19 recovery measures and overall packages will have profound implications for multiple domestic economic, social and environmental policy areas and will affect the well-being of populations for many decades to come. Financial and other capacity constraints due to the crisis also mean that countries cannot afford to tackle these multiple challenges sequentially or in isolation - even if there was time to do so, which limited carbon budgets associated with stringent mitigation goals do not allow. A useful focus would therefore be to identify recovery pathways that achieve multiple benefits in an integrated and cohesive way, in order to cost-effectively generate both near-term well-being benefits and longer-term reductions in climate risk.

The coming decade is also critical in addressing a number of global challenges. In particular, the Paris Agreement goals, the envisaged post-2020 framework for biodiversity as well as the 2030 Sustainable Development Goals (SDGs). The aggregate effect of countries' recovery pathways will likely determine our collective ability to limit warming to well-below $2^{\circ} \mathrm{C}$. Even before the COVID-19 crisis, it was clear that current NDCs under the UNFCCC, even if fully implemented, would not put emissions on a credible path to keep warming to well-below $2^{\circ} \mathrm{C}$. Yet by 25 November 2020, G20 countries have provided significantly more support to fossil fuel energy than clean energy according Energy Policy Tracker. ${ }^{44}$ Despite the sharp fall in $\mathrm{CO}_{2}$ emissions during the initial phase of the COVID-19 pandemic, seasonally-adjusted atmospheric $\mathrm{CO}_{2}$ concentrations (and thus climate risks) have continued to increase through this period at broadly the same (rapid) rate through the previous two decades. ${ }^{45}$ Sustained and rapid annual global reductions in carbon dioxide $\left(\mathrm{CO}_{2}\right)$ emissions will be necessary to achieve a well-below $2^{\circ} \mathrm{C}$ or more stringent target.

Yet many of the recovery measures and associated expenditures announced to date provide support for fossil fuels, much of which is unconditional. This paper developed three stylised recovery pathways designed to capture very distinct approaches to economic recovery, climate mitigation and the securing broader well-being outcomes. Rebound would prioritise a rapid re-establishment of economic growth and macroeconomic stability, but would not explicitly prioritise $\mathrm{CO}_{2}$ emission reductions nor wider social or environmental objectives. At best, it would result in a relative decoupling of GHG emissions and economic growth. Wider well-being improvements would only be prioritised to the extent they correlate with GDP growth, which they may not - for example, even before the crisis, inequality was at its highest level across OECD countries for the past half century despite sustained GDP growth over this period. ${ }^{46}$ Rebound might even be incompatible with existing NDCs, particularly if economic activity rebounds quickly since several COVID-19 recovery measures are likely to increase GHG emissions intensity in some countries. To be consistent with a well-below $2^{\circ} \mathrm{C}$ or more stringent goal, Rebound at a global scale would likely have to

${ }^{44}$ See https://www.energypolicytracker.org/region/g20/ for data on public spending by G20 countries and EU institutions since the beginning of the pandemic. The institutions producing this tracker can be found https://www.energypolicytracker.org/about/.

${ }^{45}$ Atmospheric concentrations of $\mathrm{CO}_{2}$ have been increasing at around or above $2 \mathrm{ppm}$ p.a. according to measurements
by NOAA - see https://www.esrl.noaa.gov/gmd/ccgg/trends/gr.html .

${ }^{46}$ See http://www.oecd.org/fr/social/inequality.htm. 
rely on large-scale implementation of Carbon Dioxide Removal (CDR) technologies to remove $\mathrm{CO}_{2}$ from the atmosphere in the second half of the century. Relying on CDR to offset any overshoot in $\mathrm{CO}_{2}$ emissions is at best a risky strategy, as these technologies are currently not commercially available at scale, may involve difficult trade-offs with other goals and may not be publicly acceptable. ${ }^{47}$

Decoupling would seek both to restore economic growth and to achieve absolute decoupling of emissions from growth through improvements in energy efficiency and a rapid scaling up of low-carbon energy. This pathway might or might not be consistent with a well-below $2^{\circ} \mathrm{C}$ target. To achieve this target, the rate of $\mathrm{CO}_{2}$ emission reductions would need to be far higher rate than seen historically or CDR technologies would be required to remove "excess" $\mathrm{CO}_{2}$ from the atmosphere to compensate for overshooting carbon budgets. A limited range of environmental benefits would be inherent to this pathway, e.g. reductions in local air pollution associated with lower levels of fuel combustion. Some social dimensions of well-being could be addressed to facilitate the implementation of core aspects of this approach. So Decoupling might include compensation to low-income households for higher energy prices due to carbon pricing. There could also be well-being benefits from reduced climate risks to humans and ecosystems over the medium to longterm. Green growth strategies such as the OECD's, go well beyond a focus on absolute decoupling to also cover natural capital and aspects of environmental quality beyond climate, though retaining a central focus on growth.

Wider well-being would seek to integrate economic recovery, early $\mathrm{CO}_{2}$ emissions reductions and sustained improvements in well-being or, broadly equivalently, progress towards the SDGs. The relationships between these diverse goals are complex and context dependent, requiring decision makers to identify and quantify their synergies and trade-offs, exploiting the former and managing the latter based on country priorities. Wider well-being would recognise some limitations to the effectiveness of carbon pricing (e.g. political acceptability, constraints on responses to price signals) in driving transformations. It would use complementary non-price measures that alter the supply and demand of key services, to open up wider mitigation options, e.g. by focusing on accessibility and re-allocating road space in surface transport and by focusing on lowering the energy demand from dwellings. By explicitly aiming to limit growth in energy and material demand, Wider well-being would make it easier to achieve stringent mitigation goals without large-scale CDR and would enhance synergies between climate change mitigation and the SDGs. The capacity, co-ordination and investment requirements could be higher than for other pathways but the potential to achieve both the near-term benefits of improvements in e.g. health, reduced inequality and accessibility as well as reductions in climate risks might make this pathway attractive in both the short and longer-term. This depends on having robust accounting and decision-making frameworks that reflect external costs and adequately capture benefits that may not currently be monetised or which may not lend themselves to monetisation.

These stylised pathways were used to analyse selected real-world recovery measures that have been proposed or implemented in a variety of countries for two specific sectors: surface transport and residential (sections 3 and 4). There is a wide divergence in the environmental and social impacts of COVID-19 recovery measures developed to date. Many recovery packages (and their component measures) were necessarily developed in a short timeframe and predominantly focus on restoring economic output. However, a single-minded focus on economic growth risks impeding national progress towards other policy goals, including climate change mitigation and the SDGs. In contrast, other measures that have been introduced under national and sub-national recovery packages are structured in an integrated way that can help jurisdictions progress towards multiple goals, both in the shorter and longer-term. For some recovery measures, their impact on broader policy goals is unclear, and will depend on how exactly the measures are implemented (which may not yet be fixed).

\footnotetext{
47 These technologies are unproven at commercial scale and likely to be controversial.
} 
Recovery measures introduced in the surface transport sector have been most consistent with Rebound and Decoupling, with few national-level measures introduced to date that focus on Wider well-being. Nonetheless, a number of sub-national actions reflect this approach, with important co-ordination between national and sub-national authorities playing an important role in some cases. The types of recovery measures consistent with Rebound focus on economic growth, jobs and disposable incomes by supporting mobility. This strongly favours low-occupancy private vehicle ownership with little or no environmental conditionality. Examples include fossil fuel subsidies, VAT reductions for car purchase (irrespective of emissions or fuel efficiency) and waiving or reducing charges that reflect the negative externalities of car use (e.g. congestion or driving charges). Decoupling in surface transport seeks to reduce GHG emissions within a growth paradigm that depends on high levels of private and low-occupancy car use. It therefore mainly relies on improving energy efficiency and carbon intensity through improved technologies but only marginally on measures to limit journeys and distances travelled and to encourage modal shift. Examples include "cash-for-scrapping" schemes with conditionality (e.g. only new vehicles that are fuel efficient or electric), support for electric vehicle charging stations but with a focus on vehicle fleets that continue to be mostly privately owned and used, and electrification of public transport without necessarily any service expansion or quality upgrade. Wider Well-being seeks to change the focus of surface transport from mobility to accessibility - the combination of proximity and mobility. To achieve significant modal shift from private vehicles to active and shared modes and to reduce journeys and distances, measures might include support for electric vehicle charging stations in the light of the need to reduce dependency on private cars, i.e. through a balanced approach between private and public charging points; "cash-for-scrapping" schemes that provide incentives for public transport and bicycle use; investment in permanent infrastructure for walking, cycling and micro-mobility; and support for businesses locating near public transport. This opens the door to large-scale emission reductions, more efficient use of urban space, better air quality and other well-being benefits (e.g. health).

Recovery measures introduced to date by national governments in the residential sector also include examples consistent with all three pathways. The GHG and well-being impacts of different recovery measures will occur over different time periods, resulting in potential trade-offs between short-term and long-term emission reductions, as well as emission reduction potentials. Rebound focuses on individual dwellings and aims to stimulate short-term growth and employment opportunities in the labour-intensive construction sector. Measures consistent with this pathway include e.g. encouraging renovations (without an energy efficiency focus); incentivising purchase of dwellings outside urban cores; and fast-tracking building permits, without sustainable planning considerations. Rebound can jeopardise the sector's progress towards specific climate change mitigation, SDG or well-being goals either due to a short-term focus or to the rollback of existing regulations that may impact the infrastructure and technologies in use for decades to come. Decoupling also fosters growth and focuses on individual dwellings and measures to incentivise energy efficiency or reduced emissions, e.g. through roof insulation or installation of rooftop solar. Decoupling measures may not use best available technology and design for retrofits and new builds due to inadequate assessment and failure to apply full-cost accounting in project appraisals. In addition, these measures typically do not address the broader issues beyond the dwelling itself, which can contribute to urban sprawl and increased emissions from transport. Wider well-being measures would also aim at energy-efficient, low or zero-emissions buildings but that also address the broader neighbourhood and urban systems. Examples include rezoning to allow for mixed land use and the colocation of commercial, residential and industrial buildings; creation of green spaces; infrastructure and housing planning that promotes accessibility to opportunities (e.g. jobs, services).

Measures aligned with Wider well-being in both of these sectors tend to be embedded in ambitious transformation programmes (e.g. enhanced urban planning, large-scale road reconfiguration and redesign, etc.). These measures have long timeframes and require strong and continued action at national, and often sub-national level to realise their full benefits. To date, measures consistent with Wider Wellbeing have so far been found mainly in OECD countries or sub-national jurisdictions. Immediate pressures to re-establish growth or financial constraints in emerging and developing economies may be a factor in 
this. Nevertheless, an integrated approach to economic, social and environmental goals is important for all countries, at any stage of their development. If potential synergies and trade-offs are not identified, recovery pathways are likely to be suboptimal with many undesirable side-effects. A challenge for Decoupling and, perhaps to a greater extent, Wider well-being is to address the distributional, jobs and skills issues related to transforming economic and social systems e.g. from shifting to low-carbon vehicles. At the same time, both Decoupling and Wider well-being could also generate significant new job opportunities; with a Wider well-being pathway bringing potentially greater changes in the relative importance of different activities (e.g. increasing public, shared and active transport related jobs). Overall, an advantage of framing policy directly around well-being is that analysis of policy implications to diverse income and social groups (and adjustment for the most affected) becomes a core feature of the approach (Chapman, 2019[67]).

Examining selected countries' COVID-19 recovery measures reveals that the individual measures being planned or implemented within a given country do not always fit into the same stylised recovery pathway. A given country and/or its sub-national jurisdictions may have introduced measures consistent with all three pathways, even within a given sector. The type of recovery measures can vary even within a sector of a given country, as well as across national and sub-national jurisdictions. However, countries which have been given a high-level directive (e.g. by their president or prime minister) to ensure that the COVID19 recovery packages include environmental and/or well-being priorities have a greater proportion of finance or initiatives focused on climate or well-being type elements, as well as on economic recovery. Such countries are therefore more likely to have more measures in line with Decoupling or Wider wellbeing, in line with a previous analysis of the policy coherence of long-term low-emissions development strategies (Aguilar Jaber et al., 2020[211])(OECD, 2020). For example, the government of New Zealand's recovery budget "considers the needs of New Zealand's people and environment alongside [the] economy". Jamaica has also indicated that it is aligning its recovery package with its NDC.

The nature and pace of economic recovery in different countries and in aggregate will clearly have important implications for existing, updated and new NDCs under the Paris Agreement. Given the significant uncertainties around the timing of economic recovery and emissions pathways, countries may face challenges during this period in formulating updated or new NDCs that accurately represent the strength of intended mitigation action and that are robust to this uncertainty. This uncertainty could have significant implications for the level of ambition of NDCs, particularly for targets based on a "deviation from BAU" emissions trajectory, which was the most common type of first NDC for developing countries.

If there is, as anticipated, a sharp rebound in economic growth across all country groupings in 2021 and the emissions intensity of economic activity does not radically change from previous trends, emissions are also likely to rebound towards (or perhaps even beyond) the pre-crisis Business as Usual (BAU) trajectory. In this case, the implications of the crisis for 2030 NDC targets of any type may be quite limited. For NDCs running to 2025, the implications of the speed and extent of rebound may be larger - particularly for countries with multi-year NDC targets, which may be more easily achieved than anticipated. This may offer opportunities for some countries to over-achieve their initial target, or to revise it. ${ }^{48}$ For 2030, however, the type of recovery pursued is likely to result in significant changes to the GDP and emissions pathways envisaged pre-crisis. Rebound will likely make existing mitigation targets more challenging to achieve, and - by encouraging increased emissions - may limit future mitigation ambition. Decoupling and Wider wellbeing on the other hand may offer new opportunities for simultaneously achieving recovery and emission reductions that may allow countries to adopt more stretching mitigation targets or still deliver already ambitious targets in far more difficult economic and social circumstances than originally envisaged. The Wider well-being pathway will further increase the likelihood of achieving the Paris Agreement targets,

\footnotetext{
48 Targets formulated in terms of the emissions intensity of GDP may be less affected, depending on the precise sectors affected by the crisis in each country since the fall in emissions will be correlated with the fall in GDP.
} 
while also delivering significant progress on well-being goals (which can in turn make implementing climate action more feasible).

The scale and nature of future infrastructure and other investments could vary significantly depending on the chosen recovery pathway. Measures to achieve stringent mitigation action are likely to be more capital intensive than Rebound, though capable of yielding significant savings in terms of fuel costs and without materially affecting growth rates. Wider well-being may, however, lead to reductions in aggregate capital demand, e.g. by reducing the need for new electricity generation capacity or overall vehicle numbers relative to other scenarios. It also has the potential to deliver both longer-term climate benefits and important near-term improvements in well-being (e.g. health, environmental health and reduced inequalities) that tend to have high social returns. These features may be attractive in a post-crisis situation where inequalities within and between generations have been amplified and where there have been sharp increases in public debt due to economic support measures. Adopting a Wider well-being approach might seem less feasible for many countries under current financial constraints. Nevertheless, such concerns could be alleviated through the strategic use of public funds to mobilise private finance and through the use of investment decision-making frameworks that make visible the potential benefits from improved wellbeing and mitigation, as well as the aggregate economic benefits.

When rolling out COVID-19 recovery measures, it will therefore be important to understand the impact of policy choices across multiple dimensions (economic, social, environmental) and different time periods (short and long-term). Several countries are developing recovery measures that are misaligned with their broader stated policy aims, including those relating to national and international social and environmental goals (e.g. NDCs and SDGs). Taking a well-being approach to mitigation would encourage a focus on outcomes and not outputs and help quantify and make more visible the synergies and trade-offs between different goals. This could in turn encourage greater co-ordination and policy coherence, which is key to delivering on the multiple challenges that governments are currently facing.

The COVID-19 containment measures that were introduced, and that remain in many places, can also exacerbate the challenges associated with developing and implementing NDCs. For example, the collection and collating of relevant data may have been delayed and/or hampered, making it difficult to assess current climate mitigation measures and whether they need to be strengthened in order to meet targets laid out in the NDC. Lack of recent data, combined with the large swings in current activity and emission levels in different sectors, and changed sectoral contexts brought about by the recentlyintroduced recovery measures, also makes it more difficult to develop a robust "business as usual" (BAU) GHG emissions scenario. Deviation from BAU was the most common form of NDC for developing countries' first NDC. Difficulties in developing a robust BAU could make it more difficult for countries to assess what the "highest possible ambition" would be of an updated NDC that is framed in such a manner. Evidence suggests that such challenges have increased in many developing countries. However, in other, often sub-national contexts, the crisis has motivated efforts to collect data and develop innovative solutions, e.g. in the transport sector. Such initiatives at the local level will be important to take into account in developing national-level recovery pathways and updated or new NDCs that are coherent across jurisdictional levels.

Finally, this analysis underlines the complex inter-relationships between domestic recovery pathways, international climate and sustainable development commitments, and the challenges of developing, updating and implementing countries' NDCs. It will be important for governments to improve their understanding of the impact of their recovery measures across multiple policy dimensions (economic, social, environmental) as well as across different time periods (short and long-term) and spatial scales. Governments may find it helpful to assess their options for achieving economic recovery, climate mitigation and wider well-being in an integrated manner, evaluating the cost-effectiveness of policies on the basis of how helpful they are in achieving multiple climate and well-being outcomes, rather than just on their effect on single aggregate indicator such as GDP. 


\section{References}

(n.a.) (2020), Metropolitan Governance and Resilient Mobility in AMBA in an Unprecedented Global Crisis Verónica Raffo Senior Infrastructure Specialist.

(n.a.) (n.d.), La bicicleta nos puede llevar hacia un futuro más sostenible e inclusivo tras la pandemia - Sostenibilidad, https://blogs.iadb.org/sostenibilidad/es/la-bicicleta-nos-puedellevar-hacia-un-futuro-mas-sostenible-e-inclusivo-tras-la-pandemia/ (accessed on 25 November 2020).

(n.a.) (n.d.), Making the green recovery work for jobs, income and growth, https://www.oecd.org/coronavirus/policy-responses/making-the-green-recovery-work-for-jobsincome-and-growth-a505f3e7/ (accessed on 24 November 2020).

(n.a.) (n.d.), POLICY BRIEF: MAKING THE GREEN RECOVERY WORK FOR JOBS, INCOME AND GROWTH - OECD, https://read.oecd-ilibrary.org/view/?ref=136 136201ctwt8p7qs5\&title=Making-the-Green-Recovery-Work-for-Jobs-Income-and-Growth (accessed on 24 November 2020).

Aguilar Jaber, A. et al. (2020), "Long-term low emissions development strategies: Cross-country experience", OECD Environment Working Papers, No. 160, OECD Publishing, Paris, https://dx.doi.org/10.1787/1c1d8005-en.

Alegre, L. (2020), Alineamiento de las administraciones para descarbonizar el transporte y responder a la crisis del Covid-19, https://www.itfoecd.org/sites/default/files/docs/alineamiento-administraciones-descarbonizar-transporteresponder-crisis-covid-19.pdf (accessed on 24 August 2020).

Antweiler, W. (2011), An Analysis of British Columbia's SCRAP-IT Program: Emissions Savings, Participation, and Transportation Choice, http://www.aircare.ca/ (accessed on 10 July 2020).

Asian Development Bank (2020), "Pacific Economic Monitor", http://dx.doi.org/10.22617/SPR200213-2.

Atkinson, G. et al. (2018), Cost-Benefit Analysis and the Environment FurthEr DEvElopmEnts AnD poliCy usE.

Avellada, S. (2020), Safer, More Sustainable Transport in a Post-COVID-19 World, https://www.wri.org/blog/2020/04/coronavirus-public-transport-stimulus-packages (accessed on 1 August 2020).

Bank of England, U. (2020), Covid Corporate Financing Facility (CCFF): information for those seeking to participate in the scheme / Bank of England, https://www.bankofengland.co.uk/markets/covid-corporate-financing-facility (accessed on 6 August 2020). 
BBC (2020), Coronavirus: How pandemic sparked European cycling revolution - BBC News, https://www.bbc.com/news/world-europe-54353914 (accessed on 25 November 2020).

Begashaw, B. (2020), Strategies to deliver on the Sustainable Development Goals in Africa In: FORESIGHT AFRICA, https://www.brookings.edu/wpcontent/uploads/2020/01/ForesightAfrica2020 20200110.pdf (accessed on 17 August 2020).

Bergh, J. (2009), "The GDP paradox", Journal of Economic Psychology, Vol. 30/2, pp. 117-135, http://dx.doi.org/10.1016/j.joep.2008.12.001.

Bloomberg City Lab (2020), 4 Steps to Saving NYC's Mass Transit System - Bloomberg, https://www.bloomberg.com/news/articles/2020-05-12/4-steps-to-saving-nyc-s-mass-transitsystem (accessed on 10 July 2020).

Boarini, R. and M. D'Ercole (2013), "Going beyond GDP: An OECD Perspective*”, Fiscal Studies, Vol. 34/3, pp. 289-314, http://dx.doi.org/10.1111/j.1475-5890.2013.12007.x.

Bongardt Daniel, S. and W. Swart Anthea (2019), Sustainable Urban Transport: Avoid-ShiftImprove (A-S-I), https://www.transformativemobility.org/assets/publications/ASI TUMI SUTP iNUA No-9 April-2019.pdf (accessed on 28 July 2020).

Bouzarovski, S. et al. (2020), Towards an inclusive energy transition in the European Union: Confronting energy poverty amidst a global crisis, EU Energy Poverty Observatory, http://dx.doi.org/10.2833/103649.

Brand, C. et al. (2020), "Road to zero or road to nowhere? Disrupting transport and energy in a zero carbon world", Energy Policy, Vol. 139, p. 111334, http://dx.doi.org/10.1016/i.enpol.2020.111334.

Bruxelles Mobilité (2020), Plan régional de mobilité 2020-2030 Plan stratégique et opérationnel, http://www.mobilite-mobiliteit.brussels (accessed on 19 August 2020).

BUILD UP (2020), Why national building renovation plans are key for the recovery, BUILD UP: The European Portal for Energy Efficient Buildings, http://www.buildup.eu/es/node/59844? gid=56582.

Busse, M. et al. (2012), Did "Cash for Clunkers" Deliver? The Consumer Effects of the Car Allowance Rebate System.

C40 (2020), C40 MAYORS' AGENDA FOR A GREEN AND JUST RECOVERY, C40, https://c40productionimages.s3.amazonaws.com/other uploads/images/2093 C40 Cities \%282020\%29 Mayors Agenda for a Green and Just Recovery.original.pdf?1594824518 (accessed on 7 August 2020).

Centre for Research on Energy and Clean Air (2020), A New Coal Boom in China NEW COAL PLANT PERMITTING AND PROPOSALS ACCELERATE.

Cervero, R. (2011), State Roles in Providing Affordable Mass Transport Services for Low-Income Residents, http://www.internationaltransportforum.org (accessed on 31 July 2020). 
Chapman, R. (2019), Managing environmental and energy transitions for regions and cities Managing the Transition to a Climate-Neutral Economy in Cities and Regions Background information Managing environmental and energy transitions for regions and cities.

Cicmanova, J., M. Esiermann and T. Maraquin (2020), HOW TO SET UP A ONE-STOP-SHOP FOR INTEGRATED HOME ENERGY RENOVATION?, EU Energy Cities, https://energycities.eu/wp-content/uploads/2020/07/INNOVATE guide FINAL.pdf (accessed on 13 November 2020).

City of Florence (2020), Piano della mobilità / Città di Firenze, https://www.comune.fi.it/dalleredazioni/piano-della-mobilita?language content entity=it (accessed on 27 August 2020).

Climate Home News (2020), Xi Jinping: China will aim for carbon neutrality by 2060, https://www.climatechangenews.com/2020/09/22/xi-jinping-china-will-achieve-carbonneutrality-2060/ (accessed on 7 December 2020).

Cluett, R. and J. Amann (2014), Residential Deep Energy Retrofits, American Council for an Energy-Efficient Economy, http://www.aceee.orgaceee.org/sites/default/files/publications/researchreports/a1401.pdf (accessed on 11 November 2020).

Crow, D. (2020), Working from home can save energy and reduce emissions. But how much? Analysis - IEA, https://www.iea.org/commentaries/working-from-home-can-save-energy-andreduce-emissions-but-how-much (accessed on 29 July 2020).

Danielson, L. and C. Gamper (2020), Nature-based solutions for adapting to water-related climate risks, https://www.oecd-ilibrary.org/docserver/2257873den.pdf?expires $=1598212720 \& i d=i d \& a c c n a m e=0 c i d 84004878 \&$ checksum $=6058$ A695CF9E60 844A995EC9F6DC112F (accessed on 23 August 2020).

de Bortoli, A. and Z. Christoforou (2020), "Consequential LCA for territorial and multimodal transportation policies: method and application to the free-floating e-scooter disruption in Paris", Journal of Cleaner Production, Vol. 273, p. 122898, http://dx.doi.org/10.1016/i.jclepro.2020.122898.

Earth Observatory (2020), Airborne Nitrogen Dioxide Plummets Over China, https://earthobservatory.nasa.gov/images/146362/airborne-nitrogen-dioxide-plummets-overchina (accessed on 20 August 2020).

EC (2009), Directorate-General for the Environment Reclaiming city streets for people Chaos or quality of life?.

EEB (2020), Air pollution returns to China - EEB - The European Environmental Bureau, https://eeb.org/air-pollution-returns-to-china/ (accessed on 20 August 2020).

Energy Agency, I. (n.d.), Recovery Sustainable World Energy Outlook Special Report in collaboration with the International Monetary Fund, http://www.iea.org/t\&c/ (accessed on 18 June 2020).

energypolicytracker.org (2020), G20 - Energy Policy Tracker, https://www.energypolicytracker.org/region/g20/ (accessed on 23 August 2020).

energypolicytracker.org (2020), G20 - Energy Policy Tracker, https://www.energypolicytracker.org/region/g20/ (accessed on 17 August 2020). 
European Construction Sector Observatory (2017), Energiesprong, European Commission.

Falduto, C. and M. Rocha (2020), Aligning short-term climate action with long-term climate goals Opportunities and options for enhancing alignment between NDCs and long-term strategies, http://www.oecd.org/environment/cc/ccxg.htm (accessed on 21 August 2020).

Falduto, C. and M. Rocha (2020), "Aligning short-term climate action with long-term climate goals: Opportunities and options for enhancing alignment between NDCs and long-term strategies", OECD/IEA Climate Change Expert Group Papers, No. 2020/02, OECD Publishing, Paris, https://dx.doi.org/10.1787/7c980fce-en.

Fast Company (2017), No Street Is "Complete" Without Taking Equity Into Account, https://www.fastcompany.com/40502981/no-street-is-complete-without-taking-equity-intoaccount (accessed on 10 July 2020).

Feder, S. (2020), "People who bike to work may live longer, according to new research".

Fleurbaey, M. (2009), "Beyond GDP: The Quest for a Measure of Social Welfare", Journal of Economic Literature, Vol. 47/4, pp. 1029-1075, http://dx.doi.org/10.1257/jel.47.4.1029.

Forbes (2020), Cyclists Spend 40\% More In London's Shops Than Motorists, https://www.forbes.com/sites/carltonreid/2018/11/16/cyclists-spend-40-more-in-londonsshops-than-motorists/\#38482bf0641e (accessed on 24 August 2020).

Fricko, O. et al. (2017), "The marker quantification of the Shared Socioeconomic Pathway 2: A middle-of-the-road scenario for the 21st century", Global Environmental Change, Vol. 42, pp. 251-267, http://dx.doi.org/10.1016/..gloenvcha.2016.06.004.

Frijters, P. et al. (2019), A Happy Choice: Wellbeing as the Goal of Government, Centre for Economic Performance, http://cep.Ise.ac.uk/pubs/download/dp1658.pdf (accessed on 6 August 2020).

Fujimori, S. et al. (2017), "SSP3: AIM implementation of Shared Socioeconomic Pathways", Global Environmental Change, Vol. 42, pp. 268-283, http://dx.doi.org/10.1016/i.gloenvcha.2016.06.009.

Fulton, L. (2018), Three Revolutions in Urban Passenger Travel, Cell Press, http://dx.doi.org/10.1016/j.joule.2018.03.005.

Fulton, L. et al. (2017), TRANSPORTATION Three Revolutions in Urban, https://itdpdotorg.wpengine.com/wp-content/uploads/2017/04/UCD-ITDP-3R-ReportFINAL.pdf (accessed on 30 June 2019).

Fulton, L. et al. (2017), TRANSPORTATION Three Revolutions in Urban, https://steps.ucdavis.edu/wp-content/uploads/2017/05/STEPS ITDP-3R-Report-5-10-20172.pdf (accessed on 24 June 2020).

Future Place Leadership (2017), The effect of pedestrianisation and bicycles on local business, http://www.FuturePlaceLeadership.com (accessed on 10 July 2020).

Gambhir, A. et al. (2019), "Energy system changes in $1.5^{\circ} \mathrm{C}$, well below $2^{\circ} \mathrm{C}$ and $2{ }^{\circ} \mathrm{C}$ scenarios", Energy Strategy Reviews, Vol. 23, pp. 69-80, https://doi.org/10.1016/i.esr.2018.12.006. 
Gazzetta Ufficiale (2020), Gazzetta Ufficiale, https://www.gazzettaufficiale.it/eli/id/2020/05/19/20G00052/sg (accessed on 27 August 2020).

Gintrand, F. (2020), Opinion / Coronavirus : tous à la campagne ? / Les Echos, https://www.lesechos.fr/idees-debats/cercle/opinion-coronavirus-tous-a-la-campagne1193182 (accessed on 25 November 2020).

Global Workplace Analytics (2020), Work-At-Home After Covid-19-Our Forecast, https://globalworkplaceanalytics.com/work-at-home-after-covid-19-our-forecast (accessed on 7 August 2020).

Goetz, M. (2017), Policy Brief Electric Vehicle Charging Considerations for Shared, Automated Fleets Introduction and Background.

Goetz, M. (n.d.), Policy Brief Electric Vehicle Charging Considerations for Shared, Automated Fleets Introduction and Background.

Gordon, U. (2020), A New Development Reality: NDCs at the Heart of COVID-19 Responses /, https://ndcpartnership.org/news/new-development-reality-ndcs-heart-covid-19-responses (accessed on 21 August 2020).

Gore, J. (2020), Insights from project developers \& other stakeholders How is COVID-19 impacting Green Climate Fund projects?.

Gota, S. et al. (2016), Nationally-Determined Contributions (NDCs) Offer Opportunities for Ambitious Action on Transport and Climate Change Partnership on Sustainable Low Carbon Transport October 2016 (Updated), http://unfccc.int/resource/docs/2015/cop21/eng/l09r01.pdf (accessed on 10 August 2020).

Gota, S. et al. (2019), "Decarbonising transport to achieve Paris Agreement targets", Energy Efficiency, Vol. 12/2, pp. 363-386, http://dx.doi.org/10.1007/s12053-018-9671-3.

Government of Canada (2020), Government of Canada takes action on COVID-19 - Canada.ca, https://www.canada.ca/en/public-health/services/diseases/2019-novel-coronavirusinfection/canadas-reponse/government-canada-takes-action-covid-19.html (accessed on 16 August 2020).

Government of Chile (2020), Chile's Nationally Determined Contribution - update 2020, https://www4.unfccc.int/sites/ndcstaging/PublishedDocuments/Chile\%20First/Chile\%27s ND C 2020 english.pdf (accessed on 6 August 2020).

Government of France (2020), France Relance, https://www.economie.gouv.fr/files/files/directions services/plan-de-relance/annexe-fichemesures.pdf (accessed on 23 November 2020).

Government of France, M. (2020), La France et l'Allemagne placent la protection climatique au cœur de (...) - RPUE - Représentation Permanente de la France auprès de l'Union européenne, https://ue.delegfrance.org/la-france-et-l-allemagne-placent\#Groupe-de-travailde-Meseberg-La-France-et-I-Allemagne-placent-la-nbsp (accessed on 11 August 2020).

Government of Iceland, P. (2019), Indicators for Measuring Well-being Government of Iceland Prime Minister's Office.

Government of Milan (2020), Milan 2020 Adaptation strategy. 
Government of New Zealand (2020), REBUILDING TOGETHER.

Government of the Philippines (2020), The Duterte administration's Philippine Program for Recovery with Equity and Solidarity (PH-PROGRESO).

Graham, P. (2018), A guide for incorporating buildings actions in NDCs, http://www.globalabc.org. (accessed on 11 August 2020).

Grubler, A. et al. (2018), "A low energy demand scenario for meeting the $1.5^{\circ} \mathrm{C}$ target and sustainable development goals without negative emission technologies", Nature Energy, Vol. 3/6, pp. 515-527, http://dx.doi.org/10.1038/s41560-018-0172-6.

GSA (2011), The Benefits and Challenges of Green Roofs on Public and Commercial Buildings A Report of the United States General Services Administration, https://www.gsa.gov/cdnstatic/The Benefits and Challenges of Green Roofs on Public a nd Commercial Buildings.pdf (accessed on 28 August 2020).

Güneralp, B. et al. (2017), "Global scenarios of urban density and its impacts on building energy use through 2050", PNAS, Vol. 114/34, pp. 8945-8950, http://dx.doi.org/10.1073/pnas.1606035114.

Haberl, H. et al. (2020), "A systematic review of the evidence on decoupling of GDP, resource use and GHG emissions, part II: synthesizing the insights", Environmental Research Letters, Vol. 15/6, p. 065003, http://dx.doi.org/10.1088/1748-9326/ab842a.

Hachileka, E. (2017), National Development Plans / UNDP in Africa, https://www.africa.undp.org/content/rba/en/home/blog/2017/national-development-plans.html (accessed on 17 August 2020).

Hatayama, M., M. Viollaz and H. Winkler (2020), “Jobs' Amenability to Working from Home: Evidence from Skills Surveys for 53 Countries”, Policy Research Working Paper, No. 9241, World Bank, http://documents1.worldbank.org/curated/en/673341589224762491/pdf/JobsAmenability-to-Working-from-Home-Evidence-from-Skills-Surveys-for-53-Countries.pdf (accessed on 7 August 2020).

Hawkins, A. (2020), How the novel coronavirus is speeding the scooter apocalypse - The Verge, https://www.theverge.com/2020/5/13/21257307/electric-scooter-bikeshare-covid-19-bird-limeuber-subsidies (accessed on 29 July 2020).

Health \& Environment Alliance (2019), Hidden Price Tags: How ending fossil fuels would benefit our health, http://raymond.com.ar (accessed on 24 August 2020).

$\mathrm{He}, \mathrm{C}$. et al. (2020), "Potential impacts of cool and green roofs on temperature-related mortality in the Greater Boston region", Environmental Research Letters, Vol. 15/9, p. 094042, http://dx.doi.org/10.1088/1748-9326/aba4c9.

Hook, A. (2020), "Environmental Research Letters ACCEPTED MANUSCRIPT • OPEN ACCESS A systematic review of the energy and climate impacts of teleworking", http://dx.doi.org/10.1088/1748-9326/ab8a84.

Howard, G. et al. (2002), Healthy Villages: A guide for communities and community health workers, World Health Organization. 
Hsu, C., P. Slowik and N. Lutsey (2020), City charging infrastructure needs to reach $100 \%$ electric vehicles: The case of San Francisco / International Council on Clean Transportation, https://theicct.org/publications/sf-ev-charging-infra-oct2020 (accessed on 2 December 2020).

IAO, F. and M. Brandstätter (2018), The Effects of Electromobility on Employment in the German Automotive Sector, https://www.spotlightmetal.com/the-effects-of-electromobility-onemployment-in-the-german-automotive-sector-a-724298/ (accessed on 21 August 2020).

ICLEI (2016), The importance of Transit Oriented Development.

IEA (2020), A sustainable recovery plan for the energy sector - Sustainable Recovery - Analysis - IEA, https://www.iea.org/reports/sustainable-recovery/a-sustainable-recovery-plan-for-theenergy-sector (accessed on 4 December 2020).

IEA (2020), CO2 Emissions from Fuel Combustion: Overview - Analysis - IEA, https://www.iea.org/reports/co2-emissions-from-fuel-combustion-overview (accessed on 24 August 2020).

IEA (2020), Employment multipliers for investment in the transport sector - Charts - Data \& Statistics - IEA, https://www.iea.org/data-and-statistics/charts/employment-multipliers-forinvestment-in-the-transport-sector (accessed on 9 July 2020).

IEA (2020), Global energy and CO2 emissions in 2020 - Global Energy Review 2020 - Analysis - IEA, https://www.iea.org/reports/global-energy-review-2020/global-energy-and-co2emissions-in-2020 (accessed on 24 August 2020).

IEA (2020), Global Energy Review 2020: The impacts of the Covid-19 crisis on global energy demand and CO2 emissions, OECD/IEA, https://webstore.iea.org/download/direct/2995 (accessed on 4 August 2020).

IEA (2020), Global EV Outlook 2020 - Analysis - IEA, https://www.iea.org/reports/global-evoutlook-2020 (accessed on 2 December 2020).

IEA (2020), Rail - Analysis - IEA, https://www.iea.org/reports/rail (accessed on 25 November 2020).

IEA (2020), Recovery Sustainable World Energy Outlook Special Report in collaboration with the International Monetary Fund, OECD/IEA, Paris, https://webstore.iea.org/download/direct/3008 (accessed on 23 November 2020).

IEA (2020), Sustainable Recovery: World Energy Outlook Special Report, IEA, https://www.iea.org/reports/sustainable-recovery/buildings\#abstract (accessed on 8 July 2020).

IEA (2020), Transport - The Covid-19 Crisis and Clean Energy Progress - Analysis - IEA, https://www.iea.org/reports/the-covid-19-crisis-and-clean-energy-progress/transport\#abstract (accessed on 25 November 2020).

IEA (2020), World Energy Outlook 2020, OECD/IEA, https://www.oecdilibrary.org/docserver/557a761ben.pdf?expires $=1606138754 \&$ id=id\&accname $=0$ cid84004878\&checksum=AAD2BBD38DE4F 82EC41DF903DC93BBBF (accessed on 23 November 2020). 
IEA (2020), World Energy Outlook 2020 - Analysis - IEA, https://www.iea.org/reports/worldenergy-outlook-2020 (accessed on 25 November 2020).

ILO (2020), COVID-19 and the automotive industry, https://www.ilo.org/wcmsp5/groups/public/--ed dialogue/---sector/documents/briefingnote/wcms 741343.pdf (accessed on 30 July 2020).

ILO (2020), ILO Monitor: COVID-19 and the world of work. Sixth edition., https://www.ilo.org/wcmsp5/groups/public/---dgreports/--dcomm/documents/briefingnote/wcms 755910.pdf (accessed on 4 December 2020).

IMF (2020), World Economic Outlook Update, June 2020: A Crisis Like No Other, An Uncertain Recovery, https://www.imf.org/en/Publications/WEO/Issues/2020/06/24/WEOUpdateJune2020 (accessed on 7 August 2020).

IMF (2018), World Economic Outlook, October 2018: Challenges to Steady Growth, https://www.imf.org/en/Publications/WEO/Issues/2018/09/24/world-economic-outlookoctober-2018 (accessed on 10 August 2020).

IPCC (2018), Global warming of $1.5^{\circ} \mathrm{C}$. An IPCC Special Report on the impacts of global warming of $1.5^{\circ} \mathrm{C}$ above pre-industrial levels and related global greenhouse gas emission pathways, in the context of strengthening the global response to the threat of climate change, sustainable development, and efforts to eradicate poverty, IPCC, Geneva, https://www.ipcc.ch/sr15/.

IPCC (2014), Summary for policymakers. . In: Climate Change 2014: Impacts,Adaptation, and Vulnerability. Part A: Global and Sectoral Aspects. Contribution of Working Group II to the Fifth Assessment Report of the Intergovernmental Panel on Climate Change [Field, C.B., V.R. Barros, D.J. Dokken, K.J. Mach, M.D. Mastrandrea, T.E. Bilir, M. Chatterjee, K.L. Ebi, Y.O. Estrada, R.C. Genova, B. Girma, E.S. Kissel, A.N. Levy, S. MacCracken, P.R. Mastrandrea, and L.L.White (eds.)]., Cambridge University Press, Cambridge, United Kingdom and New York, NY, USA pp.1-132.

IPCC (2014), Summary for Policymakers. In: Climate Change 2014: Mitigation of Climate Change. Contribution of Working Group III to the Fifth Assessment Report of the Intergovernmental Panel on Climate Change [Edenhofer, O., R. Pichs-Madruga, Y. Sokona, E. Farahani, S. Kadner, K. Seyboth, A. Adler, I. Baum, S. Brunner, P. Eickemeier, B. Kriemann, J. Savolainen, S. Schlömer, C. von Stechow, T. Zwickel and J.C. Minx (eds.)], https://www.ipcc.ch/site/assets/uploads/2018/02/ipcc wg3 ar5 summary-forpolicymakers.pdf (accessed on 31 May 2019).

ITF (2021), Avoiding Car Dependency.

ITF (2021), ITF Transport Outlook 2021.

ITF (2020), Road Safety Annual Report 2020 / ITF, https://www.itf-oecd.org/road-safety-annualreport-2020 (accessed on 25 November 2020).

ITF (2020), Safe Micromobility, https://www.itf-oecd.org/sites/default/files/docs/safemicromobility 1.pdf (accessed on 10 July 2020).

ITF (2020), Transport Climate Action Directory - measures / ITF, https://www.itf-oecd.org/tcadmeasures (accessed on 31 July 2020). 
ITF (2019), ITF Transport Outlook 2019, OECD Publishing, Paris, https://dx.doi.org/10.1787/transp outlook-en-2019-en.

ITF (2019), ITF Transport Outlook 2019, OECD Publishing, Paris.

ITF (2013), Cycling, Health and Safety, ITF Research Reports, OECD Publishing, Paris, https://dx.doi.org/10.1787/9789282105955-en.

ITF-OECD (2020), Re-spacing Our Cities For Resilience.

ITF-OECD (2019), Benchmarking Accessibility in Cities, https://www.itf-oecd.org/benchmarkingaccessibility-cities (accessed on 3 July 2019).

ITF-OECD (2019), Improving Transport Planning and Investment Through the Use of Accessibility Indicators Case-Specific Policy Analysis, http://www.itf-oecd.org (accessed on 28 June 2019).

ITF-OECD (2011), Do car scrapping schemes help the environment and increase safety?.

Jones, C. and D. Kammen (2014), "Spatial Distribution of U.S. Household Carbon Footprints Reveals Suburbanization Undermines Greenhouse Gas Benefits of Urban Population Density", Environ. Sci. Technol, Vol. 48, p. 23, http://dx.doi.org/10.1021/es4034364.

Juaidi, A. et al. (2019), "Urban design to achieving the sustainable energy of residential neighbourhoods in arid climate", Journal of Cleaner Production, Vol. 228, pp. 135-152, http://dx.doi.org/10.1016/i.jclepro.2019.04.269.

Julien Bert, D. (2020), How COVID-19 Will Shape Urban Mobility / BCG, https://www.bcg.com/publications/2020/how-covid-19-will-shape-urban-mobility (accessed on 29 July 2020).

Kabisch, N. et al. (2016), "Nature-based solutions to climate change mitigation and adaptation in urban areas: perspectives on indicators, knowledge gaps, barriers, and opportunities for action", Ecology and Society, Vol. 21/2, http://dx.doi.org/10.5751/es-08373-210239.

Keeler, B. et al. (2019), "Social-ecological and technological factors moderate the value of urban nature", Nature Sustainability, Vol. 2/1, pp. 29-38, http://dx.doi.org/10.1038/s41893-018-0202$\underline{1 .}$

Kim, H. et al. (2013), Moving towards a Common Approach on Green Growth Indicators.

Kim, S., S. Choo and P. Mokhtarian (2015), "Home-based telecommuting and intra-household interactions in work and non-work travel: A seemingly unrelated censored regression approach", Transportation Research Part A: Policy and Practice, Vol. 80, pp. 197-214, http://dx.doi.org/10.1016/j.tra.2015.07.018.

Klößner, S. and G. Pfeifer (2015), A Service of zbw Leibniz-Informationszentrum Wirtschaft Leibniz Information Centre for Economics, http://hdl.handle.net/10419/113207 (accessed on 25 November 2020).

Kotulla, T. et al. (2019), "What does it take to make the compact city liveable for wider groups? Identifying key neighbourhood and dwelling features", Sustainability (Switzerland), Vol. 11/12, http://dx.doi.org/10.3390/SU11123480. 
Kriegler, E. et al. (2017), "Fossil-fueled development (SSP5): An energy and resource intensive scenario for the 21st century", Global Environmental Change, Vol. 42, pp. 297-315, http://dx.doi.org/10.1016/i.gloenvcha.2016.05.015.

Kurdiziel, M., T. Day and Frauke Roeser (2016), Challenges and lessons learned in the preparation of Intended Nationally Determined Contributions (INDCs), http://mitigationpartnership.net/indcs-after-paris (accessed on 21 August 2020).

Le Quéré, C. et al. (2020), "Temporary reduction in daily global CO2 emissions during the COVID-19 forced confinement", http://dx.doi.org/10.1038/s41558-020-0797-x.

Le Quéré, C. et al. (2020), "Temporary reduction in daily global CO2 emissions during the COVID-19 forced confinement", Nature Climate Change, Vol. 10/7, pp. 647-653, http://dx.doi.org/10.1038/s41558-020-0797-x.

Lee, S. and B. Lee (2014), "The influence of urban form on GHG emissions in the U.S. household sector”, Energy Policy, Vol. 68, pp. 534-549, http://dx.doi.org/10.1016/i.enpol.2014.01.024.

Liimatainen, H., M. Pöllänen and R. Viri (2018), "CO2 reduction costs and benefits in transport: socio-technical scenarios", European Journal of Futures Research, Vol. 6/1, pp. 1-12, http://dx.doi.org/10.1186/s40309-018-0151-y.

Litman, T. (2017), Smart Transportation Emission Reduction Strategies - identifying truly optimal ways to conserve energy and reduce emissions, https://www.vtpi.org/ster.pdf (accessed on 10 August 2020).

Litman, T. (2015), Evaluating Complete Streets The Value of Designing Roads For Diverse Modes, Users and Activities Evaluating Complete Streets: The Value of Designing Roads For Diverse Modes, Users and Activities Evaluating Complete Streets: The Value of Designing Roads For Diverse Modes, Users and Activities, http://www.vtpi.orglnfo@vtpi.org (accessed on 19 August 2019).

Liu, L. and L. Meng (2020), "Patterns of Urban Sprawl from a Global Perspective", Journal of Urban Planning and Development, Vol. 146/2, p. 04020004, http://dx.doi.org/10.1061/(ASCE)UP.1943-5444.0000558.

Liu, Z. et al. (2020), "Near-real-time monitoring of global CO2 emissions reveals the effects of the COVID-19 pandemic.", Nature communications, Vol. 11/1, p. 5172 , http://dx.doi.org/10.1038/s41467-020-18922-7.

Löhr, E. et al. (2017), Transport in Nationally Determined Contributions (NDCs) Lessons learnt from case studies of rapidly motorising countries Synthesis Report.

Lowder, T., N. Lee and J. Leisch (2020), COVID-19 AND THE POWER SECTOR IN SOUTHEAST ASIA: IMPACTS AND OPPORTUNITIES, National Renewable Energy Laboratory and Two Degrees Group, https://www.nrel.gov/docs/fy20osti/76963.pdf (accessed on 7 August 2020).

Mahato, S., S. Pal and K. Ghosh (2020), "Effect of lockdown amid COVID-19 pandemic on air quality of the megacity Delhi, India", Science of the Total Environment, Vol. 730, http://dx.doi.org/10.1016/i.scitotenv.2020.139086. 
Manso, M. et al. (2021), "Green roof and green wall benefits and costs: A review of the quantitative evidence", Renewable and Sustainable Energy Reviews, Vol. 135, p. 110111, http://dx.doi.org/10.1016/i.rser.2020.110111.

Matchtech (2016), Expanding skillsets: the electric vehicle and the automotive engineer, https://www.matchtech.com/expanding-skillsets-the-electric-vehicle-and-the-automotiveengineer (accessed on 21 August 2020).

Mc Kinsey (2020), The case for an automotive software platform / McKinsey, https://www.mckinsey.com/industries/automotive-and-assembly/our-insights/the-case-for-anend-to-end-automotive-software-platform (accessed on 31 July 2020).

Mc Kinsey (2017), How shared mobility will change the automotive industry / McKinsey, https://www.mckinsey.com/industries/automotive-and-assembly/our-insights/how-sharedmobility-will-change-the-automotive-industry (accessed on 31 July 2020).

Miller, K., W. Wilson and N. Wood (2020), "ENVIRONMENTALISM, STIMULUS, AND INEQUALITY REDUCTION THROUGH INDUSTRIAL POLICY: DID CASH FOR CLUNKERS ACHIEVE THE TRIFECTA?", Economic Inquiry, Vol. 58/3, pp. 1109-1128, http://dx.doi.org/10.1111/ecin.12889.

Ministerio de Transporte (2020), "Movilidad Metropolitana y gobernanza multi-nivel".

Ministry for the Environment, N. (2018), The co-benefits of emissions reduction An analysis, http://www.mfe.govt.nz. (accessed on 15 August 2020).

Ministry of Transport of Argentina (2020), Movilidad Metropolitana y gobernanza multi-nivel.

Moreno, A. et al. (2017), "Housing Polices", Habitat III Policy Units and Paper, No. 10, UN Habitat, http://habitat3.org/wp-content/uploads/Habitat\%201I\%20Policy\%20Paper\%2010.pdf (accessed on 25 August 2020).

Narloch, U., T. Kozluk and A. Lloyd (2016), Measuring Inclusive Green Growth at the Country Level, Taking Stock of Measurement Approaches and Indicators, Green Growth Knowledge Platform Working Paper 02 2016, GGKP Research Committee on Measurement \& Indicators, http://www.greengrowthknowledge.org/sites/default/files/downloads/resource/Measuring Incl usive Green Growth at the Country Level.pdf (accessed on 25 August 2020).

NDC Partnership (2020), The NDC Partnership's Economic Advisory Support | NDC Partnership, https://ndcpartnership.org/economic-advisory-support (accessed on 24 August 2020).

New York Times (2020), Pandemic Lockdowns Lead to Less Traffic and Better Air - The New York Times, https://www.nytimes.com/2020/06/04/climate/coronavirus-traffic-air-quality.html (accessed on 10 July 2020).

O'Neill, B. et al. (2017), "The roads ahead: Narratives for shared socioeconomic pathways describing world futures in the 21st century", Global Environmental Change, Vol. 42, pp. 169180, http://dx.doi.org/10.1016/i.gloenvcha.2015.01.004.

OECD (2020), Beyond Growth: Towards a New Economic Approach, New Approaches to Economic Challenges, OECD Publishing, Paris, https://dx.doi.org/10.1787/33a25ba3-en. 
OECD (2020), Building Back Better: A Sustainable, Resilient Recovery after Covid-19 - OECD, https://read.oecd-ilibrary.org/view/?ref=133 133639-s08q2ridhf\&title=Building-back-better- Asustainable-resilient-recovery-after-Covid-19 (accessed on 29 July 2020).

OECD (2020), How's Life? 2020: Measuring Well-being, OECD Publishing, Paris, https://dx.doi.org/10.1787/9870c393-en.

OECD (2020), OECD Economic Outlook, Volume 2020 Issue 1, OECD Publishing, Paris, https://dx.doi.org/10.1787/0d1d1e2e-en.

OECD (2020), OECD Economic Outlook, Volume 2020 Issue 2: Preliminary version, OECD Publishing, Paris, https://dx.doi.org/10.1787/39a88ab1-en.

OECD (2020), POLICY BRIEF: MAKING THE GREEN RECOVERY WORK FOR JOBS, INCOME AND GROWTH - OECD, https://read.oecd-ilibrary.org/view/?ref=136 136201ctwt8p7qs5\&title=Making-the-Green-Recovery-Work-for-Jobs-Income-and-Growth (accessed on 3 December 2020).

OECD (2020), Towards Sustainable Land Use: Aligning Biodiversity, Climate and Food Policies, OECD Publishing, Paris, https://dx.doi.org/10.1787/3809b6a1-en.

OECD (2019), Accelerating Climate Action: Refocusing Policies through a Well-being Lens, OECD Publishing, Paris, https://dx.doi.org/10.1787/2f4c8c9a-en.

OECD (2019), Policy Coherence for Sustainable Development 2019: Empowering People and Ensuring Inclusiveness and Equality, OECD Publishing, Paris, https://dx.doi.org/10.1787/a90f851f-en.

OECD (2019), Taxing Energy Use 2019: Using Taxes for Climate Action, OECD Publishing, Paris, https://dx.doi.org/10.1787/058ca239-en.

OECD (2018), OECD Companion to the Inventory of Support Measures for Fossil Fuels 2018, OECD Publishing, Paris, https://dx.doi.org/10.1787/9789264286061-en.

OECD (2018), Rethinking Urban Sprawl: Moving towards sustainable cities, http://dx.doi.org/10.1787/9789264189881-en (accessed on 17 September 2020).

OECD (2017), Green Growth Indicators 2017, OECD Green Growth Studies, OECD Publishing, Paris, https://dx.doi.org/10.1787/9789264268586-en.

OECD (2013), How's Life? 2013: Measuring Well-being, OECD Publishing, Paris, https://dx.doi.org/10.1787/9789264201392-en.

OECD (2011), How's Life?: Measuring Well-being, OECD Publishing, Paris, https://dx.doi.org/10.1787/9789264121164-en.

OECD (2011), Towards Green Growth: Monitoring Progress: OECD Indicators, OECD Green Growth Studies, OECD Publishing, Paris, https://dx.doi.org/10.1787/9789264111356-en.

OECD (2006), Decoupling the Environmental Impacts of Transport from Economic Growth, https://www.oecd-ilibrary.org/docserver/9789264027138en.pdf?expires $=1596792416 \&$ id=id\&accname $=0$ cid84004878\&checksum $=66$ AE4DAB779356 0522C26A4053383C12 (accessed on 7 August 2020). 
OECD (2002), Indicators to Measure Decoupling of Environmental Pressure from Economic Growth.

OECD-IEA (2020), Governments should use Covid-19 recovery efforts as an opportunity to phase out support for fossil fuels,, https://www.oecd.org/newsroom/governments-should-usecovid-19-recovery-efforts-as-an-opportunity-to-phase-out-support-for-fossil-fuels-say-oecdand-iea.htm (accessed on 27 August 2020).

Oldenburger, J. (2009), "Essay: Scrapping allowance for old private cars to stimulate sale of modern green vehicles......fact or fiction to reduce $\mathrm{CO} 2$ emissions from Dutch car fleet".

PACTS (2020), Safe systems - PACTS, https://www.pacts.org.uk/safe-system/ (accessed on 28 August 2020).

Paris Agreement (2015), 15 December 2015, United Nations Treaty Collection Certified True Copies (CTCs) of Multilateral Treaties Deposited with the Secretary-General Chapter XXVII.7.d, https://treaties.un.org/pages/ViewDetails.aspx?src=TREATY\&mtdsg no=XXVII-7d\&chapter=27 (accessed on 28 April 2020).

Partnership for Market Readiness (PMR), C. (2018), GUIDE TO COMMUNICATING CARBON PRICING.

Perk, V. (2015), Capturing the Benefits of Complete Streets.

Perk, V. (2015), Final Report Capturing the Benefits of Complete Streets PREPARED FOR Florida Department of Transportation.

Petrichenko, K., D. Ürge-Vorsatz and L. Cabeza (2019), "Modeling global and regional potentials for building-integrated solar energy generation", Energy and Buildings, Vol. 198, pp. 329-339, http://dx.doi.org/10.1016/j.enbuild.2019.06.024.

Price Waterhouse Cooper (2018), Five trends transforming the Automotive Industry, http://www.pwc.com/auto (accessed on 29 July 2020).

Raffo, V. (2020), Metropolitan Governance and Resilient Mobility in AMBA in an Unprecedented Global Crisis.

Rashidi, K., M. Stadelmann and A. Patt (2017), "Valuing co-benefits to make low-carbon investments in cities bankable: the case of waste and transportation projects", Sustainable Cities and Society, Vol. 34, pp. 69-78, http://dx.doi.org/10.1016/i.scs.2017.06.003.

Rasul, M. and L. Arutla (2020), "Environmental impact assessment of green roofs using life cycle assessment”, Energy Reports, Vol. 6, pp. 503-508, http://dx.doi.org/10.1016/j.egyr.2019.09.015.

Riahi, K. et al. (2017), "The Shared Socioeconomic Pathways and their energy, land use, and greenhouse gas emissions implications: An overview", Global Environmental Change, Vol. 42, pp. 153-168, https://doi.org/10.1016/.gloenvcha.2016.05.009.

RICS (2020), How has global construction activity fared in the face of COVID-19?, RICS, https://www.rics.org/fr/news-insight/latest-news/news-opinion/how-has-global-constructionactivity-fared-in-the-face-of-covid-19/ (accessed on 6 November 2020). 
Sangkakool, T. et al. (2018), "Prospects of green roofs in urban Thailand - A multi-criteria decision analysis", Journal of Cleaner Production, Vol. 196, pp. 400-410, http://dx.doi.org/10.1016/i.jclepro.2018.06.060.

Sauter, D. and M. Huettenmoser (2008), "Liveable streets and social inclusion", Urban Design International, Vol. 13/2, pp. 67-79, http://dx.doi.org/10.1057/udi.2008.15.

Scalisi, T. (2020), Not So Fast: Starting slow is best construction strategy after recession, https://www.levelset.com/blog/starting-slow-best-construction-strategy-after-recession/ (accessed on 7 August 2020).

Schwedhelm, A. (2020), Cycling During COVID-19 / World Resources Institute, https://www.wri.org/blog/2020/04/coronavirus-biking-critical-in-cities (accessed on 29 July 2020).

SEforALL (2020), CHILLING PROSPECTS TRACKING SUSTAINABLE COOLING FOR ALL 2020, Sustainable Energy for All, https://www.seforall.org/system/files/2020-07/CP-2020SEforALL.pdf (accessed on 6 August 2020).

Silva, C. and A. Larsson (2017), Challenges for Accessibility Planning and Research in the Context of Sustainable Mobility Discussion Paper, http://www.itf-oecd.org (accessed on 26 June 2020).

Simard, M. (2020), "La pandémie de COVID-19 et le débat sur l'étalement urbain : tournant majeur ou accident de parcours?", Revue Organisations \& territoires, Vol. 29/2, pp. 175-183, http://dx.doi.org/10.1522/revueot.v29n2.1160.

Sperling, D., S. Pike and R. Chase (2018), "Will the Transportation Revolutions Improve Our Lives-or Make Them Worse?", in Three Revolutions, Island Press/Center for Resource Economics, http://dx.doi.org/10.5822/978-1-61091-906-7 1.

Stiglitz, J., J. Fitoussi and M. Durand (2018), Beyond GDP: Measuring What Counts for Economic and Social Performance, OECD Publishing, Paris, https://doi.org/10.1787/9789264307292-en (accessed on 7 August 2020).

Stoknes, P. and J. Rockström (2018), "Redefining green growth within planetary boundaries", Energy Research and Social Science, Vol. 44, pp. 41-49, http://dx.doi.org/10.1016/j.erss.2018.04.030.

Taiebat, M. and M. Xu (2019), "Synergies of four emerging technologies for accelerated adoption of electric vehicles: Shared mobility, wireless charging, vehicle-to-grid, and vehicle automation", Journal of Cleaner Production, Vol. 230, pp. 794-797, http://dx.doi.org/10.1016/j.jclepro.2019.05.142.

Taylor, Z. (2008), Shaping the toronto region, past, present, and future, http://www.neptis.org (accessed on 24 August 2020).

Teotónio, I. et al. (2020), "Decision support system for green roofs investments in residential buildings", Journal of Cleaner Production, Vol. 249, p. 119365, http://dx.doi.org/10.1016/j.jclepro.2019.119365.

Timmers, V. and P. Achten (2016), "Non-exhaust PM emissions from electric vehicles", Atmospheric Environment, Vol. 134, pp. 10-17, http://dx.doi.org/10.1016/i.atmosenv.2016.03.017. 
Transport \& Environment (2020), Austrian Airlines' bailout 'climate conditions' explained, https://www.transportenvironment.org/publications/austrian-airlines-bailout-climate-conditionsexplained (accessed on 27 August 2020).

Transport \& Environment (2020), Bailout tracker / Transport \& Environment, https://www.transportenvironment.org/what-we-do/flying-and-climate-change/bailout-tracker (accessed on 23 August 2020).

Transport \& Environment (2020), Recharge EU, http://www.transportenvironment.org (accessed on 2 December 2020).

Trebilcock, M. (2014), Dealing with Losers, Oxford University Press, http://dx.doi.org/10.1093/acprof:oso/9780199370658.001.0001.

UITP (2020), Critical for COVID-19 recovery: CEOs and city representatives call for public transport to be key sector in European plan / UITP, https://www.uitp.org/news/critical-covid19-recovery-ceos-and-city-representatives-call-public-transport-be-key-sector (accessed on 18 August 2020).

UITP (2013), "(No Title)Public transport: creating green jobs and stimulating inclusive growth", https://www.uitp.org/sites/default/files/cck-focus-papers-files/fp green jobs-EN.pdf (accessed on 9 July 2020).

UN (2020), SDG Indicators: Make cities and human settlements inclusive, safe, resilient and sustainable, https://unstats.un.org/sdgs/report/2019/Goal-11/ (accessed on 25 August 2020).

UNEP (2011), Towards a Green Economy: Pathways to Sustainable Development and Poverty Eradication - A Synthesis for Policy Makers, http://www.unep.org/greeneconomy (accessed on 7 August 2020).

UNFCCC (2019), Decisions adopted by the Conference of the Parties serving as the meeting of the Parties to the Paris Agreement, https://unfccc.int/sites/default/files/resource/cma2018 03a01E.pdf (accessed on 27 August 2020).

United Nations (2020), Policy Brief: COVID-19 in an Urban World, United Nations, https://www.ohchr.org/Documents/lssues/Housing/SR housing COVID-19 Guidance (accessed on 7 August 2020).

United Nations (2015), The Geneva UN Charter on Sustainable Housing Chapter 1. Challenges to sustainable housing, United Nations, http://sustainabledevelopment.un.org/content/documents/4518outcomedocument.pdf (accessed on 7 August 2020).

University of Melbourne (2020), COVID-19 drop in pollution to be short-lived / Pursuit by The University of Melbourne, https://pursuit.unimelb.edu.au/articles/covid-19-drop-in-pollution-tobe-short-lived (accessed on 20 August 2020).

Ürge-Vorsatz, D. and S. Tirado Herrero (2012), "Building synergies between climate change mitigation and energy poverty alleviation", Energy Policy, Vol. 49, pp. 83-90, http://dx.doi.org/10.1016/j.enpol.2011.11.093. 
US Energy Information Administration (2020), Short-Term Energy Outlook - U.S. Energy Information Administration (EIA), https://www.eia.gov/outlooks/steo/?src=email (accessed on 27 August 2020).

Vaidyula, M. and C. Hood (2018), "Accounting for baseline targets in NDCs: Issues and options for guidance", OECD/IEA Climate Change Expert Group Papers, No. 2018/02, OECD Publishing, Paris, http://www.oecd.org/environment/cc/Accounting for baselines targets in NDCS.pdf (accessed on 13 August 2018).

Van den Bergh, J. (2011), "Environment versus growth - A criticism of "degrowth" and a plea for "a-growth"”, Ecological Economics, Vol. 70/5, pp. 881-890, http://dx.doi.org/10.1016/i.ecolecon.2010.09.035.

Van Wee, B. et al. (2011), "Transport Reviews A Transnational Transdisciplinary Journal Accelerating Car Scrappage: A Review of Research into the Environmental Impacts Accelerating Car Scrappage: A Review of Research into the Environmental Impacts", http://dx.doi.org/10.1080/01441647.2011.564331.

Viera, P. (2020), Aligning COVID-19 Response Plans with NDCs, https://www.slideshare.net/OECD ENV/ccxg-forum-june-2020-pablo-vieira (accessed on 21 August 2020).

Vincendon, S. (2020), Un mois après le déconfinement, la pollution de l'air a fait son retour, https://www.bfmtv.com/environnement/deconfinement-la-pollution-de-l-air-revient-peu-apeu AN-202006090099.html (accessed on 20 August 2020).

Vivid Economics (2020), Green Stimulus Index.

Vogt-Schilb, A. and S. Hallegatte (2017), Climate Policies and Nationally Determined Contributions: Reconciling the Needed Ambition with the Political Economy, Inter-American Development Bank, http://dx.doi.org/10.18235/0000714.

Wamsler, C., E. Brink and C. Rivera (2013), "Planning for climate change in urban areas: From theory to practice", Journal of Cleaner Production, Vol. 50, pp. 68-81, http://dx.doi.org/10.1016/i.jclepro.2012.12.008.

Weitzman, M. (1976), On the Welfare Significance of National Product in a Dynamic Economy.

Wiedinmyer, C. (2016), "Research Briefs", Clean Air Journal, Vol. 26/2, pp. 6-6, http://dx.doi.org/10.17159/2410-972x/2016/v26n2a4.

World Bank (2020), GDP, PPP (current international \$) / Data, https://data.worldbank.org/indicator/NY.GDP.MKTP.PP.CD (accessed on 24 August 2020).

World Bank (2018), Carbon Pricing Dashboard / Up-to-date overview of carbon pricing initiatives, https://carbonpricingdashboard.worldbank.org/map data (accessed on 16 September 2018).

World Bank (2016), Housing is at the center of the sustainable development agenda, World Bank Blogs, https://blogs.worldbank.org/psd/housing-center-sustainable-development-agenda (accessed on 7 August 2020). 
World Bank (2012), Inclusive Green Growth : The Pathway to Sustainable Development., https://openknowledge.worldbank.org/handle/10986/6058 License: CC BY 3.0 IGO. (accessed on 7 August 2020).

World Bank and Institute for Health Metrics (2016), The Cost of Air Pollution Strengthening the Economic Case for Action, World Bank, Washington DC, http://documents1.worldbank.org/curated/en/781521473177013155/pdf/108141-REVISEDCost-of-PollutionWebCORRECTEDfile.pdf (accessed on 7 August 2020).

WorldGBC (2019), Bringing embodied carbon upfront, World Green Building Council, London, https://www.worldgbc.org/bringing-embodied-carbon-upfront-report-webform.

WRI (2020), Public Transit and Transportation Infrastructure: Creating Jobs and Supporting Transit Across the.

WRI (2018), Cities Safer By Design, https://publications.wri.org/citiessafer/ (accessed on 10 July 2020). 
www.oecd.org/environment/cc/ccxg.htm

www.iea.org

With the financial assistance

of the European Union 